Portland State University

PDXScholar

$1-1-2011$

\title{
Gendering the Body: Exploring the Construction of the Sexually Dimorphic Body
}

Sarah Kaye Lewis

Portland State University

Follow this and additional works at: https://pdxscholar.library.pdx.edu/open_access_etds Let us know how access to this document benefits you.

\section{Recommended Citation}

Lewis, Sarah Kaye, "Gendering the Body: Exploring the Construction of the Sexually Dimorphic Body" (2011). Dissertations and Theses. Paper 152.

https://doi.org/10.15760/etd.152

This Thesis is brought to you for free and open access. It has been accepted for inclusion in Dissertations and Theses by an authorized administrator of PDXScholar. Please contact us if we can make this document more accessible: pdxscholar@pdx.edu. 
Gendering the Body: Exploring the Construction of the Sexually Dimorphic Body

by

Sarah Kaye Lewis

A thesis submitted in partial fulfillment of the requirements for the degree of

Master of Science

in Sociology

Thesis Committee:

Grant Farr, Chair

Ann Mussey

Martha Balshem

Portland State University

(C)2011 


\begin{abstract}
Gender is a pervasive and regulating social institution that is operationalized in mainstream Western culture as a natural extension of the ontological difference perceived to exist between the binarily sexed bodies of male and female. Feminist theory has widely established, however, that gender is done - i.e., gender is not a naturally occurring phenomenon, but is an ongoing construction engaged and replicated by individual actors and which, while compulsory, is nevertheless optional. Within this canon is a small number of feminist theorists, notably Judith Lorber, Judith Bulter, and Nancy Tuana, who argue that the constructive manifestations of gender performativity (that is, doing of gender) are not limited to the social sphere. They argue the role of gender in the production of the material body, asserting that doing gender has a constructive role in physical embodiment: what we do influences, and in fact creates, what our bodies are.
\end{abstract}

This study engages the feminist theory on the production of the body through a qualitative exploration of the lived experience of gendered bodily change, as described in the first-hand narratives of trans-identified individuals. I predict that the analysis of the narratives in the sample will show that in comparison to cisgender individuals, trans individuals possess a heightened awareness of the performative nature of gender, and that trans individuals consciously engage performativity in order to conform to the normative expectations associated with the desired gender role. I further predict that trans 
individuals experience sexually dimorphic bodily change to be a direct result of changes to their gender identity.

The interview analysis findings provide mixed support for the first hypothesis, demonstrating that while trans individuals in the sample do demonstrate a heightened awareness of the ways in which gender is performed, the respondents' insights came largely from their experiences in their compulsorily cisgender, pre-transition lives, rather than their current gender embodiments. The concept of performativity and its perceived implication of artificiality clashed with the respondents' sense of their gendered actions as an expression of an authentic self, and my analysis thus addresses performativity as a necessarily polemic concept located between the subjectivity of the individual narratives and the theoretical position that gender is done. The findings provide a substantial level of support for the second hypothesis that trans individuals understand experienced bodily change to be a direct result of changes in gender identity.

This study's exploration of trans experiences of lived bodily change contributes a narrative perspective to the ongoing discussion in feminist theory which surrounds the role of gender in the production of the material body. 
for Max

S. K. Lewis - Gendering the Body / Dedication 


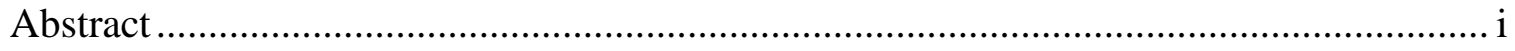

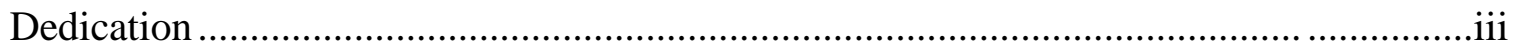

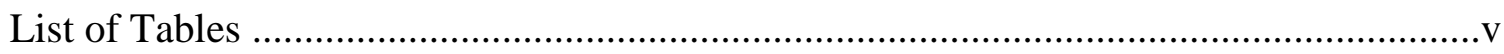

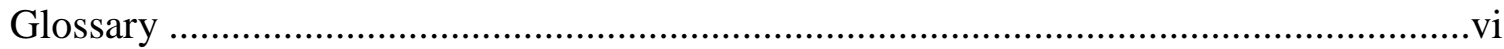

Chapter One

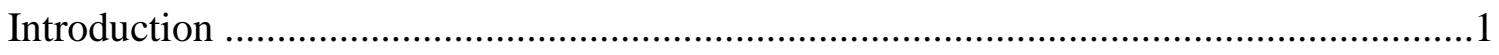

Chapter Two

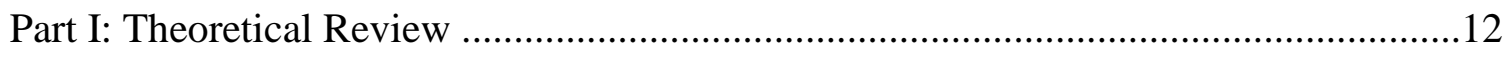

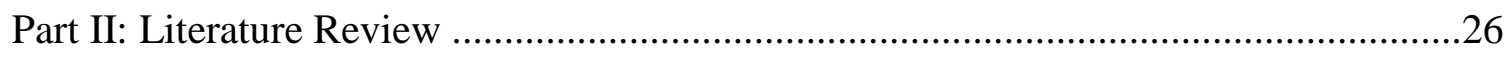

Chapter Three

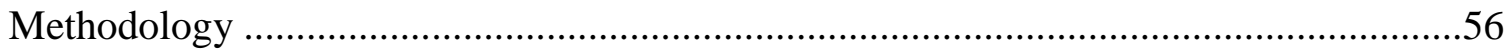

Chapter Four

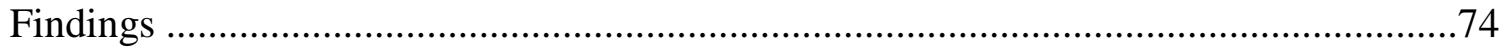

Chapter Five

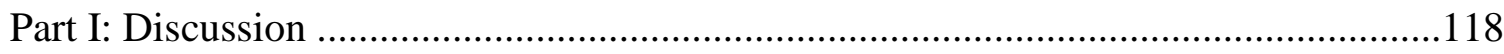

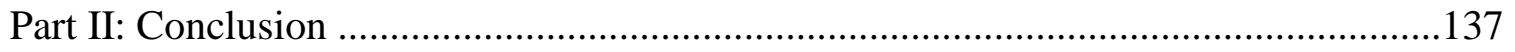

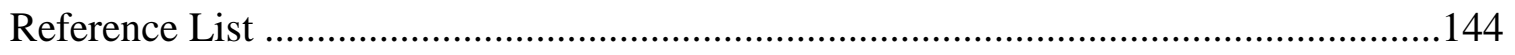

Appendices

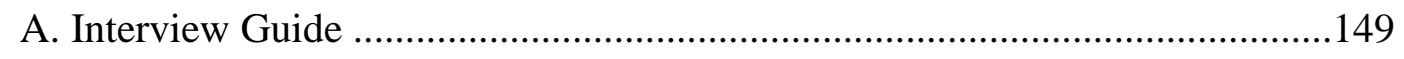

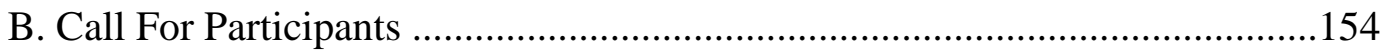

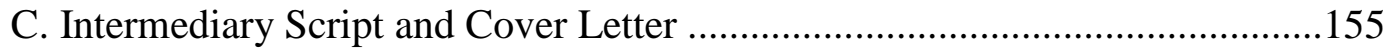

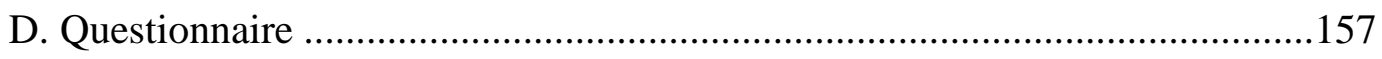

E. Cover Letter of Informed Consent .......................................................... 161

S. K. Lewis - Gendering the Body / Table of Contents 


\section{List of Tables}

Table 1: Selected Characteristics of the Sample .78

S. K. Lewis - Gendering the Body / List of Tables 
GLOSSARY

Cisgender: This term refers to individuals whose sex category is cohesively aligned with their gender identity (i.e., male/man, female/woman). Cis is a Latin prefix meaning "on this side" or "on the same side." In their article "Doing Gender, Doing Heteronormativity: 'Gender Normals,' Transgender People, and the Social Maintenance of Heterosexuality," Kristen Schilt and Laurel Westbrook defined cisgender as a label for "individuals who have a match between the gender they were assigned at birth, their bodies, and their personal identity" (2009: 440).

The term "cisgender" is also used to discussed the larger concept: just as "gender" can refer to both individual identity and a general social phenomenon, cisgender is at times used to collectively discuss those who consider their sex and gender to be cohesive.

Transgender: This term refers to individuals whose gender identity is not cohesive with sex category as assessed at birth. They do not identify with the gender traditionally ascribed to their sex category, and instead identify with the gender.

In the theoretical context, the term "transgender" is used to refer to the larger phenomenon of gender transgression, specifically as it relates to moving from one socially-accepted gender role to the other.

Sex: $\quad$ This term refers to biological sex, which can include consideration of anatomical genitalia, chromosomal karyotype, and/or endrocrinological/ hormonal typing. Culturally, "sex" is understood to be limited to an exclusive male-female dichotomy. However, this narrow conception neglects the true spectrum of human diversity and the prevalence (and, indeed, the existence of) intersexuality. Though presumed to be a naturally occurring "fact," sex is also a phenomenon subject to social interaction. As Candace West and Don Zimmerman (1987) write, "Sex is a determination made through the application of socially agreed upon biological criteria for classifying persons as females or males" (127). Herein, "sex" will be used to refer both to biological sex and to sociallyassigned sex categories in cases of intersexuality and/or "ambiguous" genitalia. 
Gender: $\quad$ Gender is a social phenomenon not empirically related to sex. To again quote West and Zimmerman (1987), gender "is the activity of managing situated conduct in light of normative conceptions of attitudes and activities appropriate for one's sex category" (127). Culturally, gender is understood to be limited to an exclusive male-female dichotomy, though many other gender identities exist. Herein, "gender" will be used to refer to the full spectrum of gender identities, including but not limited to male, female, trans, transgender, transsexual, androgyny, and genderqueer.

Sexual

Dimorphism: In this study, the term sexual dimorphism refers not to genital binary (i.e., male/female), but rather to the non-genital physical differential that is observed between the sexes of the same species. 


\section{CHAPTER ONE}

\section{Introduction}

Anatomy is destiny.

SIGMUND FREUD, COLLECTED WRITINGS, 1924

And yet we are told that femininity is in danger; we are exhorted to be women, remain women, become women. It would appear, then, that every female human being is not necessarily a woman; to be so considered she must share in that mysterious and threatened reality known as femininity. ... One is not born, but rather becomes, a woman. SIMONE DEBEAUVIOR, THE SECOND SEX, 1952

In her chapter "Night to his Day," Judith Lorber (1994) writes that in our culture, it is as easy for us to talk about gender as it would be for fish to talk about water. We are as immersed in gender as fish are in water; it surrounds us to such an extent that, like oxygen, one may never perceive its ubiquity until something occurs that abruptly makes its presence - or absence - apparent. Gender is a pervasive force in our lives; as perhaps the most primary method of social organization, it has a measurable influence upon behavior, action, and, as will be seen, even the physical nature of our bodies.

The feminist canon posits that gender is a social institution distinct from sex: whereas sex refers to genital anatomy, gender is a schema that, independently of sex, regulates appearance, dress, behavior, relationships, speech, aspirations, and virtually every other aspect of social being. In West and Zimmerman's foundational article, "Doing Gender (1987)," they write,

... there was sex and there was gender. Those of us who taught courses in the 1960s and 1970s were careful to distinguish one from the other. Sex, we told students, was what was ascribed by biology: anatomy, hormones, and physiology. 
Gender, we said, was an achieved status: that which is constructed through psychological, cultural, and social means. (P. 125)

The authors go on to describe their students' confusion; they write that the gender socialization theories of the time "conveyed the strong message that while gender may be 'achieved,' by about age five it was fixed, unvarying, and static - much like sex" (126). The authors used an ethnomethodological approach to demonstrate that although gender seems so firmly installed as to be immutable, it is in fact a routine, methodical, and recurring accomplishment (126) that is actively - though perhaps unknowingly - engaged by participants. The terminology they invoked to describe this voluntary yet complex action was, accurately, "doing gender." West \& Zimmerman ultimately conclude that doing gender is unavoidable on the basis that gender is unavoidably a legitimating factor in a person's social intelligibility. Their work aptly recognizes both the inherent plasticity of gender and its socially constructed impenetrability: "the doing of gender is undertaken by women and men whose competence as members of society is hostage to its production" (126). We can nevertheless extrapolate from their findings that gender, as a series of actions which are ingrained but nevertheless voluntary, may in fact be "done" in a variety of ways - "done" in ways, it would follow, that may be inconsistent with the implied limits of gender-cohesive sex category.

The oxygen-like quality of gender (or water-like, in keeping with Lorber's fish analogy) is well-served by the poststructuralist terminology metanarrative. A metanarrative is a "big" story, theory, or ideology that posits itself to be above ordinary 
("small") accounts of social life; it is an over-arching view that unifies and describes taxonomically smaller stories. John Stephens and Robyn McCallum (1998) describe it as "a global or totalizing cultural narrative schema which orders and explains knowledge and experience" (6). As a part of this ordering and explanation, metanarratives endeavor to prevent micro-narratives deemed as marginal from upsetting or subverting the cultural order. Gender is, in a way, the ultimate metanarrative: it is a big story that organizes all the little stories, a finely woven mesh fabric encircling all aspects of social life, acting, as Judith Butler (1999 [1990]) writes, as a grid of intelligibility. Bodies, the people who occupy them, and the actions they produce are all socially unintelligible without conformity to or participation in the gender metanarrative.

The central theme of the Western gender metanarrative is that of inviolable gender binary: man/woman, male/female, masculine/feminine. In the tradition of sociobiology, the metanarrative holds that gender flows naturally from sex, to the extent that no distinction can be made between them; gender is in fact used as a metonym for sex: gender is presumed a cohesive attribute of sex, and gender in fact refers (and infers) anatomical sex as much as it does the social enactment of gender roles. The precept that there are two and only two genders, cohesively aligned to two and only two anatomical sexes, is widely broadcast and firmly regulated. The two genders are thus metanarratively operationalized as the discrete derivatives of sex.

Similarly manifest in the metanarrative are notions of essential, naturallyoccurring, fundamental and (it is implied) insurmountable differences between the 
dichotomous cisgenders. The metanarrative instructs that there is an organic physical disparity between sexed bodies which establishes and makes inviolable the boundaries of male/female. Simultaneously, the difference between the genders was pejoratively construed so as to mean privilege and subjugation. Narratively, men and women are different, and through no fault of their own; behaviors, emotional capacities, logical capacity, and, above all, bodily physicality all naturally occur disproportionately between the genders. Men are bigger and stronger where women are smaller and physically less capable; women are empathetic and emotional where men are logical and calculating. Our cultural metanarrative tells us that these differences are biological in origin and are untouched by culture, and then uses them as the allegorical basis for the gender myth: because men are bigger and stronger, they are more naturally suited to be the ones to forge out ahead and perform the backbreaking labor necessary to subdue the earth in the agricultural era; to initiate industry in the industrial era; to work outside the home and serve as the provider and head of household in the modern era. Because they are smaller, softer, and nurturing, women are naturally suited to make a home and rear children.

The metanarrative remains clearly attached to this idea: a proliferation of popular, pseudo-scientific, psychological, and/or behavioralist literature bombards us with insidious claims that the genders male and female are fundamentally and ontologically discrete unto themselves -- from You Just Don't Understand: Men and Women in Conversation (1990) by Deborah Tannen, to Men are from Mars, Women are from Venus (1992) by John Gray, to Boys and Girls Learn Differently!: A Guide for Teachers and 
Parents (2000) by Michael Gurian and Kathy Stevens, to Why Men Don't Iron (2003) by Ann and Bill Moir, to Why Gender Matters: What Parents and Teachers Need to Know About the Emerging Science of Sex Differences (2005) by Leonard Sax, to The Female Brain (2006) by Louann Brizendine.

The cosmogony of inviolable physical differences which segregate women from men lends the metanarrative - and its patriarchal posturings - power and validity. The physically different bodies and physically different brains said to exist between the sexes "naturally" extend to create gender roles that mirror the stratification and difference attributed to the bodies. What is rarely considered, however - by theorists and laypeople alike - is that the causal link may occur not between physical bodies and gender (i.e., the belief that physical bodies [specifically, sexes] 'cause' gender by natural extension), but may instead occur as a result of the complex interaction between the body and the gender metanarrative's prescribed, compulsory participation in the repetition of gendered actions, behaviors, and choices in the body. While sex and gender are conceptually distinct, the two are far from mutually exclusive and share a complex, interdependent relationship that is contrary to the naturalized linearity inherent within the metanarrative model of biological determinism.

In a series of theoretical works, Judith Lorber (2005), Judith Butler (1999 [1990]), and Nancy Tuana (1996) each establish that individuals do gender; that the doing of gender creates gender; and in so doing, also creates the (gendered) body. Gender is a primary mechanism by which the construction, creation, and maintenance of sexual 
dimorphism between the genders occurs. It is gender, rather than sex, which dictates actions (both physical and mental), diet, dress, grooming, exercise, body language, etc; all of these elements in combination affect and contribute to the creation of our physical, social bodies. All three theorists argue that essential to this understanding of "doing gender" is the realization that doing gender differently results not only in different genders (i.e., gender identities which somehow differ or depart from normative conceptualizations of male and female), but also differently gendered bodies (i.e., bodies which may no longer display sexually dimorphic attributes previously assumed to be inherent and thus impervious outside influence). The theorists' acknowledgement of the plasticity of both gender as a social construct, and of the bodies which simultaneously interact with the social construct, subversively challenges the assumptions of ontological difference which lay behind metanarrative gender boundaries.

Lorber, Butler, and Tuana each imply that imbued with their gender paradigm is the potential for radical foundational change. Their understanding of the body as a dynamic construction (i.e., an ongoing product of interaction and interrelation), rather than a wholly predetermined ontology, renders the metanarrative construction of binary and inviolable physical difference "nonsense" (Tuana 1996: 57). Tuana's discussion of embodiment specifically engages the physicality of the gendered body as an ongoing construction, a perpetual series of "intra-actions" which contain aspects both material and semiotic (57). She argues that the body is not infinitely plastic (meaning that it cannot take any form), but nor is it infinitely rigid, as the metanarrative's story of biological 
determinism suggests. As all three theorists assert (and as the literature will also establish), gendered behavior is a causal factor in the sexually dimorphic physicalities of gendered bodies. As such, when the behavior changes, so does the body: what the body does in part creates the body.

The theorists' arguments threaten to compromise the structural foundation of the gender metanarrative. The sexual dimorphism of the human species has been used as a primary justification for traditionalist gender roles - the very roles which are in fact implicated in the creation of the selfsame physical differential in the first place. If the myth of naturally occurring sexual dimorphism were to be debunked, so too would be the mainstream justification for the gender roles which are considered to be its natural extensions. On this basis, Lorber, Butler, and Tuana each argue that a new way to discursively engage the sex-gender relationship is required, and, in turn, a new way to engage the realities of sex and gender themselves.

The three theorists each argue that operationalizing gender in this way has implications for feminist theory in particular. Feminist theory has been often criticized (i.e., Butler 1999 [1990]) due to its assumption of a unified subject (i.e., unity across women), when the 'members' of this imposed category may in fact have very little, if anything at all, in common with one another when the complicating factors of race, ethnicity, socioeconomic status, able-bodiedness, and sexuality, among others, are considered. From the standpoint of intersectionality, feminist theory is also admonished that it does little to achieve comprehensive, intersectional social justice (Butler 1999 
[1990], hooks 2000 [1984], Lorde 1984). Whereas the mainstream feminist agenda seeks to achieve male-female equality at face value (that is, providing women with the same benefits men have typically enjoyed), intersectional critics point out that this leaves the larger social structure - which was built upon the foundation of the hierarchical gender binary - without a ready architecture. If not women, some other group will still experience exploitation when women join the ranks of men without seeking to adjust the classist, racist, and misogynist paradigm in which the institution operates. Audre Lorde (1984) iconically invoked this idea: the master's tools will never dismantle the master's house. Deconstructing the gender metanarrative from the bottom up as Lorber, Butler, and Tuana prescribe - that is, addressing the faulty foundation of the sex/sexual dimorphism/gender relationship - provides an opportunity for feminist theory to reengage the nature of its membership and advocacy, perhaps prompting an imagining of a gender ideology that could be beneficial to all sexes, genders, races, ethnicities, classes, and sexualities.

My contribution to this ongoing theoretical discussion is a small-scale, close look at the lived experience of bodily difference. Through ten qualitative, open-ended interviews with voluntary respondents who identified as transgender, genderqueer, intersex ${ }^{1}$, or otherwise gender-transgressive (collectively referred to simply as "trans"), I engage the theories of Lorber, Butler, and Tuana in an exploration of individual narrative experiences of gendered bodily change. My research explores the individual subjects'

\footnotetext{
${ }^{1}$ It should be noted here that it is not the case that all - or even most - intersex individuals identify as trans, but it happened that the two subjects I interviewed who identified as intersex also self-identified as trans.
}

S. K. Lewis - Gendering the Body / Chapter One: Introduction 
experiences of their identities in terms of their physical bodies. The data consists of personal narratives which relate how these individuals experienced, created, and enacted gender in spite of contrary sex - that is, their experience and consciousness of the performativity of gender (Butler 1999 [1990], 1993), and the bodily changes they subsequently experienced.

Transgender offers a uniquely relevant window into the study and discussion of gender; by its very viability it suddenly reveals as transparent what previously appeared to be opaque. More specifically, most trans individuals have consciously engaged the embodiment of gender in ways in which few cisgender individuals have. Rather than entertaining the metanarrative's tacit notion of organic dimorphism, the transgender narrative actively engages and acknowledges the available/possible ways to willfully construct sexual dimorphism.

This research thus assesses two guiding hypotheses:

H1: Individuals who consciously engage gender via the desire to change or otherwise transgress normative gender roles (e.g., trans people) gain a heightened awareness of the physically performative aspects of normative gender roles, and are able to utilize this awareness in the embodiment of the desired gender role.

H2: Trans individuals experience sexually dimorphic bodily change to be a direct result of changes to their gender identity.

This research is an exploration of the social construction of sexual dimorphism as a material-semiotic interaction and the ways in which it can be engaged by the study of firsthand gender transgressive experiences. It is my goal to produce an engaging 
analysis, to demonstrate support for the hypotheses, and suggest future avenues for further research.

Chapter Two, Part I addresses feminist and social constructionist theories of sex and gender; the (inter)relationship between them; and their interrelation with embodiment. In particular, the theories of Judith Lorber, Judith Butler, and Nancy Tuana are discussed.

Part II of the chapter discusses the production of the gendered body. I discuss anthropological literature which documents gender difference across world cultures, including the incidence and treatment of third genders, to establish the true fluidity of gender that lurks behind culturally restrictive, narrative boundaries. The history of gender transgression in the West is presented to establish that neither biological sex nor its correlating sexual dimorphism prevents the "successful" enactment of transgender. The definition and social process of assigning sex are discussed in concert with the writings of Anne Fausto-Sterling, Suzanne Kessler, and other theorists who engage the social construction of the body. Anthropological literature on anatomical adaptation is presented in concert with sociological examinations of gender-prescriptive personification to establish the impact behavior and other repetitive activity can have on the body. This impact is considered epigenetically; that is, richly situated in the emergent interplay among body, culture, and environment. I also specifically address the currently popular metanarrative claim that sex differences, and thus gender, are "hardwired" in the structure of the brain. I evoke feminist deconstructions of the biased epistemology used 
in such neurobiological claims, specifically utilizing the works of Lise Eliot and Cordelia Fine.

Chapter Three addresses the methodological process used for the primary research. I discuss the rationale for selecting the interview population for this research. I also discuss my choice to perform a qualitative study and examine the strengths and limitations of both the general form and my particular study. My methods are described in detail, including subject recruitment, the interview questions and process, the method of data collection, and method of analysis.

Chapter Four presents the findings of the primary research. I explore the bodily experiences of transgender, androgynous, and/or genderqueer-identified individuals specifically as they relate to sexual dimorphism and consciously constructing a gendered, or intentionally non-gendered, appearance. The interviews are quoted at length in order to present respondents' gender experiences in their own words.

Chapter Five, Part I provides a discussion of the findings in synthesis with the theory and literature discussed in Chapter Two. Part II of the chapter discusses the implication of the findings, particularly in terms of feminist theory. 


\section{CHAPTER TWO}

\section{Part I:}

Theoretical Review

Gender is a fanatical cult.

KATE BORNSTEIN, MY GENDER WORKBOOK, 1998

Of all difficulties which impede the progress of thought, and the formation of well-grounded opinions on life and social arrangements, the greatest is now the unspeakable ignorance and inattention of mankind in respect to the influences which form human character. Whatever an portion of the human species now are, or seem to be, such, it is supposed, they have a natural tendency to be: even when the most elementary knowledge of the circumstances in which they have been placed, clearly points out the causes that made them what they are.

JOHN STUART MILL, THE SUBJECTION OF WOMEN, 1869

The Western conceptions of sex and gender are located firmly within a discursively naturalized metanarrative, which relies on a metaphysic of biological determinism, sociobiology, and oppositional binarism. The theory engaged in this chapter acknowledges, critiques, and departs from the Western canon of thought and its assumptions therein.

Inherent in the Western canon is the assumption of ontological binary: two wholly discrete factors posed in opposition, one of which preexists the other (Butler 1999 [1990]; Tuana 1996; Lorber 2005). These binaries - between human/environment, nature/nurture, body/culture, mind/body, sex/gender, male/female - are operationalized as ontological opponents whose divisive, one-directional positionalities legitimate the metanarrative status quo. In this canon, differences in gender roles - e.g., social inequalities - are attributed to a congruence with differences in anatomy, the former springing from the latter. Freud famously put its deterministic view of gender into words 
when he wrote that anatomy was destiny: gender is framed as being created by, and limited to, the biological capacity of sex.

Social constructionism: Simone de Beauvoir and Judith Lorber

By contrast, the feminist canon presents a model of social construction that frames gender as a social institution located outside of the body. In her introduction to The Second Sex, Simone de Beauvoir (1953 [1949]) addresses the metanarratively presumed ontology of gender when she writes of "the extreme importance of social discriminations which seem outwardly insignificant but which produce in woman moral and intellectual effects so profound that they appear to spring from her original nature" that is, gendered effects so pervasive that they appear to spring from biology (1953 [1949]: xxxii). The Second Sex's treatment of gender presupposes West and Zimmerman's (1987) breakthrough that gender, as separate from sex, is "done;" as Beauvoir writes, "one is not born, but rather becomes, a woman" (281). Like Beauvoir, West and Zimmerman make the distinction between sex as a physiological "fact," and gender as a social process which operationalizes sex as a site of meaningful difference. In this model, gender practices are framed not as the linear result of sex differences, nor the result of biological determinism. Rather, they are the product of the paradigm of social determinism that uses perceived sex differences as a site of primary societal division. Through the manufacture of gender, a primary relationship which limits and regulates behavior, labor, power, and agency is also created. It is thus gender, and not sex itself, that is framed as the root of sex discrimination, oppression, and exploitation. 
The social constructionist distinction between sex and gender has allowed generations of feminists to articulate the metaphysical role of culture in the manufacture of gendered difference, discrimination, and oppression. Nancy Tuana (1996) writes that the conceptualization of gender as a social construct was central to feminist refutations of the biological determinist model of male superiority:

At a time when feminists felt that we had to confront socially dominant arguments for the biological basis of male superiority, "gender" was a useful tool to explain male privilege as a result of complex structures of oppression and privilege that were historically variable and culturally constituted. Along with Beauvoir we gloried in arguing that women were made, not born. (55-56)

In the social constructionist view, women and men are "made" by the placement of discursively legitimating marks upon otherwise neutral bodies and in their conformity to discursively legitimating roles. Thus, social constructionist feminists imply that difference is often only the perception of difference, a result of the cultural production of gender inequality.

In a series of articles and books that began in the 1990s, Judith Lorber began to approach the social constructionist model of gender in a new way. Like other feminist social constructionists before her, she invokes the inscriptive and regulating power of gender on the body. However, rather than treat the body as a blank slate passively receptive to the marks of gender, Lorber conceives the marks of gender not as superficial obscurants of an ontological similarity between male and female bodies, but as actions, 
rituals, and practices that affect physical embodiment ${ }^{2}$ - truly creating gendered bodies (1993, 1997, 2000). In "The Social Body," she and Patricia Yancey Martin (1997) write,

Members of a society construct their bodies in ways that comply with their status and accepted notions of masculinity and femininity. That is, they try to shape and use their bodies to conform to their culture's or racial ethnic group's expectations of how a woman's body, a man's body, a girl's body, or a boy's body should look. This point does not deny the distinctiveness of material bodies, with their different physical shapes, sizes, strengths, and weaknesses. It does emphasize, however, that members of a society, not genes or biology, determine the proper shape and usage of women's, men's, boys', and girls' bodies, beyond dress, hair style, cosmetics, and other adornments. (185)

They go on to elaborate that men's and women's bodies are shaped by both the intentional and unconscious ways we pursue gender conformity; even though the physical consequences of some actions - i.e., bodybuilding - are more obvious than others - i.e., choice of footwear - each have very real implications. While Lorber and Martin do assert that there is a great deal of physical similarity between the sexes - a difference which they believe is carefully and deliberately obscured by the social practices which regulate the appearance of gender, to the benefit of the hierarchal structure found within the gender metanarrative - they also believe there is more to the story (202). The ideas and practices of gender have bodily outcomes, not just appearances: gendered bodies are not just socially, but also physically, produced.

Lorber $(1997 ; 2000)$ argues that virtually all social practices reinforce, make salient, and in fact create physical otherness between the genders: the body is subject to

\footnotetext{
${ }^{2}$ Throughout this chapter and the remainder of this text, the term "embodiment" is used to refer to gender in a way that attends not only to the performative aspects of gender, but also to the physical, bodily manifestations of gender and gender difference, which are inextricable from considerations of performativity.
} 
transformation through gendered social practices. Upon critical observation, every aspect of gendered society displays an investment in physical otherness while simultaneously posing such difference as "natural." Lorber argues that the physical manifestation of gendered difference is a deliberate social process, no matter how undeliberate it might feel to individual actors. She writes that "the transformation of bodies that might be less differentiable into bodies that are markedly masculine and feminine is typical of the pressures of gender" (2000: 4). In so framing the bodily consequences of social construction, Lorber here invokes the concept of a pre-gender ontological body, which is transformed into a socially intelligible body through the marks of gender. ${ }^{3}$ As the physical difference between the sexes is one of the main arguments behind the metanarrative's hierarchical metaphysic, Lorber argues that the limited extent of "true" (i.e., ontological) sexually dimorphic differences are not enough to justify the systematic assumption that women are so physically different than men that they are by their very nature inferior.

Lorber and Martin (1997) engage the bodily consequences of gender semiotics, gendered behavior, action, and ritual, perceiving that a life lived within culturally prescribed gender boundaries does not occur without an effect on embodiment. They argue that gender expectations and normative gender pressure affect virtually all social and personal actions (sometimes in intersection with other prevailing statuses), and give the example of military service in the Marine Corps. In addition to special requirements

\footnotetext{
${ }^{3}$ Tuana and Butler will later criticize this reliance on the nature/nurture binary.
} 
regarding dress and cosmetics, female recruits are required to attend classes on makeup, hair care, poise, and etiquette as part of a "feminization requirement." A female drill instructor is quoted:

A lot of the recruits who come here don't wear makeup; they're tomboyish or athletic. A lot of them have the preconceived idea that going into the military means they can still be a tomboy. They don't realize that you are a Woman Marine. (190)

Evident in this example are methods both superficial and insidious by which gendered difference is produced: first, by rules requiring female Marines to appear different than male Marines by use of dress and makeup; and second, by placing a limitation on the definition of "Marine" to accommodate the presumption that women cannot perform the role the same way (e.g., 'as good as') men can. Female recruits were also assigned lesser physical challenges than male Marines, or given aids to obstacles, like a ramp or stool in a wall-climbing exercise - though they were docked points when they used it. In addition to setting up the women to underperform the men (by losing points), thereby reinforcing a hierarchy of ability, this practice helps create the very physical difference it decries by denying women the same physical experiences as the men. Lorber and Martin are quick to note that this is not to imply that if the women climbed the walls without ramps, their bodies would become identical to male bodies; but rather is an acknowledgement that the enactment of gender expectations has a physical consequence. In discussing a four-yearold female who already "throws like a girl," Lorber and Martin write that,

The girl who experiences her body in such a limited way at an early age is a product of her culture and time. As she learns to restrict her movements, she simultaneously closes out opportunities to develop the fluid, whole-bodied, 
unconstrained moves that are associated with outstanding achievement in sports. (191)

It is not just gendered movement which affects embodiment; Lorber and Martin point out that gendered divisions in risk-taking behavior (including things like habitual drug or alcohol use), dieting, breast enhancements, face-lifts, and hair transplants are all things which affect embodiment, and perhaps in ways more than the sum of their parts: the authors note that these practices may lead to addiction, illness, such as eating disorders, infections, and systemic damage from leaking silicone implants (186). While these are all choices made and actions undertaken for cultural reasons, they all have very real effects on the body - in terms of not only observable gender conformity, but also ablebodiedness, health, and life expectancy.

Acceptable gender behavior changes over time, and Lorber and Martin demonstrate corresponding changes in gendered physical embodiment:

Have female bodies changed in the last 100 years? Yes, they have. Women did not run in marathons until approximately 20 years ago. In 20 years of marathon competition, women have reduced their finish times by more than $11 / 2$ hours. They are expected to run as fast as men in the 26-mile marathon by 1998 and might catch up with men's running times in races of other lengths in the next 50 years because they are increasing their speeds more rapidly than are men. ... When the opportunities for competition are available, training begins when athletes are young and it is more serious than has been in the past. The result is more developed musculature, greater lung capacity, and increased strength, speed, and stamina - for women and for men. (192-193)

The longitudinal nature of this particular example demonstrates that as gender expectations gradually change (in this case, in terms of the acceptability of running marathons), so do bodies change with them. Lorber and Martin invoke the body as 
plastic, as literally (physically) constructed by the enactment of prescribed gendered action. In their theory, the body is receptive to the inscriptions of culture but at the same time limited to the possibilities of material reality ("Bodies are born and bodies die" (202)).

The material-semiotic intra-action: Judith Butler and Nancy Tuana

In Gender Trouble, Judith Butler (1999 [1990]) frames gender as a limiting and regulative discursive construction which individuals engage through ritual performativity in order to gain social legitimacy and intelligibility. Butler writes that

performativity is not a singular act, but a repetition and a ritual, which achieves its effects through its naturalization in the context of a body, understood, in part, as a culturally sustained temporal duration.

The view that gender is performative sought to show that what we take to be an internal essence of gender is manufactured through a sustained set of acts, posited through the gendered stylization of the body. ...[W]hat we take to be an 'internal' feature of ourselves is one that we anticipate and produce through certain bodily acts, at an extreme, an hallucinatory effect or naturalized gestures. (xv)

For Butler, this performativity constitutes identity: "There is no gender identity behind the expressions of gender; that identity is performatively constructed by the very 'expressions' that are said to be its results" (33). Butler argues that both sex and gender are constructions, positing that the ostensibly natural facts of sex are discursively produced by "various scientific discourses in the service of other political and social interests":

As a result, gender is not to culture as sex is to nature; gender is also the discursive/cultural means by which 'sexed nature' or 'a natural sex' is produced 
and established as "prediscursive," prior to culture, a politically neutral surface on which culture acts. (11)

Butler believes the "prediscursive" conceptualization of sex to be fallacious and in fact nonsense: we cannot perceive of one without the other; they are non-separable and thus no one can preexist the other. Butler in fact protests the Western canon's at-large reliance on a binaries, which she believes inevitably establishes a pervasive ontological bias.

Butler engages the metanarrative bias towards binarism in her deconstruction of the conception of "a subject before the law" (4) - a phrasic cultural fragment Butler uses to demonstrate the discursive construction of the universal human subject and external phenomena as two whole, independently existent entities. "A subject before the law" implies that the subject is an entity which autonomously pre-exists the law, when in reality, the subject and the law are not mutually exclusive, but exist only as the result of interaction. Butler writes,

[T] he subjects regulated by such structures are, by virtue of being subjected to them, formed, defined, and reproduced in accordance with the requirements of those structures. ... The performative invocation of a nonhistorical 'before' becomes the foundational premise that guarantees a presocial ontology of persons who freely consent to be governed and, thereby, constitute the legitimacy of the social contract. (4-5)

Butler unpacks this phrase to reveal the binary notion of "before," using this example as a microcosm of the foundational bias which pervades the metanarrative. When we perceive ourselves as subjects before the law, we understand that in our creation of the law, we have consented to be governed. When we conceive of sex before gender, we understand sex has created gender, and the ontological linearity between the two legitimates gender difference and inequality. 
Nancy Tuana (1996) presents something of a synthesis between Lorber and Butler. Like Butler, Tuana engages the ontological bias in metanarrative and social constructionist notions of sex, gender, and identity, but Tuana extends and further explores what she considers to be Butler's underdeveloped treatment of physical materiality. Though Butler often invokes the "metaphysics of substance" (27), a phrase she aptly borrows from Nietzsche, her analysis often fails to engage the visceral, fleshy substance central to Tuana's material-semiotic intra-action (57). Butler's discussion alludes to the active and interrelated role of the body:

If bodies cannot be said to have a signifiable existence prior to the mark of their gender; the question then emerges: To what extent does the body come into being in and through the mark(s) of gender? How do we reconceive the body no longer as a passive medium or instrument awaiting the enlivening capacity of a distinctly immaterial will? (13)

However, she subsequently focuses almost exclusively on the discursive, non-material construction of the legitimacy and intelligibility of bodies. Hers is a largely abstract discussion that neglects the substantive reality of the body; Tuana writes that Butler is "overly focused on discursive elements, which too often leads her to ignore or obscure the materiality of the intra-action" (63, emphasis added). Whereas the metanarrative operationalizes the body as a sexed (and sexually dimorphic) entity independent of and before culture, and feminist theory constructs the body as a uniformly blank slate before culture (which then inscribes its meanings on the 'passive' body), Tuana argues that the body cannot be said to pre-exist culture. Butler argued this in the abstract terms of legibility; Tuana brings it to the flesh: the material body and culture create each other in complex and non-separable "intra-action" (57). 
Tuana argues against the social constructionist polarization of sex and gender precisely because it relies on the same nature/nurture ontological bias as the theories feminism seeks to refute, thus maintaining and perpetuating the idea of a sexed body that pre-exists culture:

it is pernicious to simply critique theories of biological determinism on their own terms, for doing so leaves the metaphysic underpinning them in place. ... Our ongoing reliance on the dichotomy between sex and gender is also epistemically irresponsible for we continue to make the distinction in a way that replicates the metaphysic that provides the foundation for biological determinism. (54)

Tuana is quick to note that she does not completely deny the value of this distinction, especially insofar as it has framed feminist inquiries into science and epistemology. These inquiries were devoted to "exposing the ways in which theories of biological determinism have been used to justify a range of sexist and racist practices" and ultimately revealed the way theories concerning sex and race differences "both arose out of and in turn reinforced socially held biases about women and about people of oppressed races" (54). Tuana herself employed this construction in her work The Less Noble Sex (1993).

Nevertheless, Tuana criticizes that many feminists, once having made the distinction between sex and gender, feel compelled to minimize the body. Willing to engage only the semiotic aspects of gender, when "[f]aced with the body, feminists too often embrace meaning rather than flesh" (56). Tuana invokes both flesh and meaning through the example of male body builders, demonstrating the complexity of the interrelated factors which produce the body builders' hypermasculinized physiques, 
which are situated in and produced by the discursive constructs of power, strength, heterosexuality, masculinity, and maleness. Body builders themselves see their bodies "as a form of highly resistant plastic" that can be transformed at will. But as Tuana notes, "[w]hen male body builders attempt to inscribe their bodies with the (currently) perfect form of masculinity, the body has a say" (60). The body builders' prolonged use of steroids often causes gynecomastia - essentially, breast tissue produced by the estrogen the body produces to counteract the massive doses of what it perceives to be testosterone - and a range of other bodily manifestations, including the shrinkage of the penis, sperm count reduction or eradication, and the inability to have an erection. Tuana uses the bodybuilders to demonstrate that masculinities and femininities are "performed - and embodied": "To say that the body is 'always already' culture is not to deny that it is 'always already' material; just do not make a dichotomy out of it" (60). As inaccurate as it is to conceive of one factor pre-existing the other, it is just as pernicious to assume there are only the two factors in play.

Tuana argues that the constructionist practice of embracing only semiotics and denying materiality confines us to the incomplete and fallacious epistemology the metaphysics of biniarism allows.

By keeping in place a fixed, biological given, feminist theorizing leaves itself open to the critique that this biological body is more significant than we hoped, that this body is our unchanging destiny. Unfortunately, the last ten years has witnessed a dramatic increase in popular acceptance of the view that sex differences and race differences are biologically caused and thus inevitable. I believe that we feminists have been epistemically irresponsible in leaving in place a fixed, essential, material basis for human nature, a basis which renders 
biological determinism meaningful. We have not attended sufficiently to the body, to the ways in which it is formed and transformed by social institutions. We must turn our attention to the sexing of the body and to fleshing gender to understand both how the body is socially constituted and how its materiality in turn informs the parameters of its configurations. Let me be clear. I do not advocate disproving biological determinism. I advocate rendering it nonsense. (57)

To depart from the insufficiencies of constructionism, Tuana formulates a feminist epistemology of material-semiotic intra-action, which refers to the interminable process of the interrelatedness among phenomena, both material and semiotic. She writes that this intra-active process "will be mischaracterized as long as we attempt to understand it through the false dichotomy of sex/gender or through the related binarisms of biology/culture, essential/constructed" (57). The body is shaped in concert with the effects of the environment, and the environment in concert with the effects of the body. As Tuana writes, "we will never understand bodies fully without also attending to flesh, and doing so in ways that do not render it separate from the discursive" - nor will be able to approach the discursive as separate from the flesh (57).

The material-semiotic intra-action Tuana describes renders the idea of biological determinism meaningless. The essentialist constructs of pre-existing and/or independently existing entities - whether they be body, sex, environment, culture, gender - are nonsensical, as no one can be defined apart from its intra-actions with all the others (and indeed, its entire positionality). There is no ontological material form that preexists culture: such an construct is strictly a figure of the imagination. Culture and environment have inexorable roles in physical embodiment, creating and transforming the body materially as well as semiotically; and in turn, bodies have inexorable roles in the 
creation and transformation of the environment - and we cannot fully nor accurately engage any of these phenomena without engaging an intra-active epistemology. 


\section{Part II:}

\section{Literature Review - The Production of the Body}

Notions of essential characteristics or fixed natures (Kantian noumena) are, on such a metaphysic, nonsense. Although a dichotomy between nature/nurture or separate genetic and environmental mechanisms is rendered inadequate by this intra-active model of the dynamic relation between gene, environment, and organism, a process metaphysic of phenomena does not preclude making distinctions, even distinctions between the environment and the organism, or between sex and gender. But the making of such distinctions must always be richly situated and acknowledge the complexity of the developmental intraaction. What is rejected is the claim that these distinctions signify natural and unchanging boundaries. But do not trip over that refusal into thinking that these distinctions are then arbitrary divisions of a prior oneness. Revealing distinctions and constructing boundaries between sex and gender are important, but they will be time, situation, and value relative, and must re-fuse dichotomization. What thus is needed is the adoption of a metaphysic adequate to a critical understanding of the complexities of the material-semiotic intra-action of phenomena. (Tuana 1996: 62, emphasis added)

At the risk of reverting to the social constructionist model, this section addresses the ways embodiment in particular (specifically, gender embodiment) is affected and interactively constructed by social and environmental factors, utilizing Tuana's model of distinctions which are made and utilized within an epistemological framework of material-semiotic phenomenology.

The social construction of embodiment is invoked not to negate the agency of the body, but rather in order to demonstrate that when the cultural content of gender changes, so does the body. This gendered bodily plasticity undermines the metaphysic of ontological sexually dimorphism which legitimates the biological determinism of the hierarchical gender metanarrative - in so doing rendering it nonsense. 


\section{The inscriptive effect of the intangible}

As Lorber, Butler, and Tuana have all argued, the cosmogony of inviolable physical differences which segregate women from men lends the metanarrative - and its patriarchal posturings - power and validity. As such, the metanarrative reflects a vested interest in the maintenance and continued production of the nature/nurture, culture/environment, and in particular, mind/body, sex/gender binarism, leading to the policing and regulating structures that limit and rigidly define socially intelligible gender. Butler (1993) believes that gender is discursively constructed through the compulsory, ritual iteration of performativities that are located within the social matrixes of intelligibility; but at the same time, she acknowledges the complex interrelationship that nevertheless exists between the de rigueur of gender and the subjectivity of the body. In

Bodies that Matter (a title which is a subversive and well-thought-out pun), she writes,

'performance' is not a singular 'act' or event, but a ritualized production, a ritual reiterated under and through constraint, under and through the force of prohibition and taboo, with the threat of ostracism and even death controlling and compelling the shape of the production, but not, I will insist, determining it fully in advance. (95)

Tuana's writings take Butler's theory of performativity to the logical extension of physicality: the discursively constructed realms of intelligible gender prescribe the boundaries of possible (i.e., legible) identities, thereby regulating which actions, behaviors, and activities are available to each gender. These restrictions thus define the physical parameters available to sexed, gendered bodies, in so creating a gendered subtext - and embodied consequence - to each and every action. So, even though Butler's 
theories of performativity initially seem to divorce the body from gender entirely for the sake of demonstrating how sex and gender are discursively, not bodily, defined, the two are in fact married again as the gendering discourse prescribes the performativity which acts as a catalytic agent in the manufacture of the observable gendered body (which, as Butler points out, does not necessarily need be sex-coherent).

The restrictive parameters of socially legible gender thus create performative 'scripts' of the actions, behaviors, and activities permitted within the boundaries of intelligible gender, which are rigidly policed, as Butler suggests above, in ways that place transgressors in great peril. The limits of intelligible gender are manifest in virtually all social interactions. One example is found in common behavioral admonitions: if pressed as to why one does not like a raunchy female comic, for example, a repulsed observer may disdain that it's not funny when women are raunchy - it's not "ladylike." (Such criticisms of comics like Jenny McCarthy and Chelsea Handler are rampant; although both of these women are still successful and even "popular," I find it salient that the content of the criticism they face is more often their perceived nonconformity to expectations of femininity than it is statements about the complainant's sense of humor [i.e., "I just don't find bodily fluids funny"], when criticisms of male comics typically contain only the latter.) Women and girls are admonished to cross their legs at the ankle, speak politely, accept chivalrous gestures, and the like. Likewise, men are advised to "man up," "sack up," and to "be a man." The normative pressure to perform unambiguous gender legibility is similarly betrayed in many insults, especially for men: 
in addition to references of the testicles as a metonym for pulling yourself up by your bootstraps ("have some balls;" "I thought you had a pair"), male insults are peppered with references to being "pussies," "girls"/"ladies," or being "whipped." Each of these insults calls the masculinity of the actor into question, suggesting in no uncertain terms that he needs to become 'more' male. In their policing of masculinity and femininity, these admonitions show how individual actors are compelled to consciously engage socially constructed notions of maleness and femaleness in order to embody legible conformity.

The social constructionist model of gender is thus useful in explicating the real role that intangible measures play in the regulation of gender performativity, and thus gender embodiment. Another example of this is the way in which conceptualizations of masculinity and femininity are applied to ideas of occupational prowess and ability. Lorber $(1994 ; 2005)$ points out that while women long ago proved themselves physically and mentally capable of the work traditionally confined to the male sphere of work (e.g., women's employment in defense plants, steel mills, and other heavy industry during WWII (1994: 9)), the gender segregation of jobs has subsisted on the basis of the metanarrative stories of masculine- and feminine-appropriateness alone (e.g., the firing of virtually all women employees at the end of WWII):

At the present time in the Western postindustrial world, the gendered social order persists without much rationale. Women and men have legal equality, supported by a public rhetoric of equal rights and equal responsibilities for family support, household maintenance, and child care, as well as for individual economic independence. ... There are still occasional claims for men's "natural'" domination and women's "natural" subordination, ostensibly backed by research on brain organization, hormonal input, or personality structure, but these claims are 
increasingly delegitimized by the presence of women prime ministers, governors, and university professors.

Unfortunately, the rhetoric and legality of gender equality mask the underlying structure of gender inequality. Modern machinery and computers even out the discrepancy in physical capabilities between men and women, but jobs are assigned as if upper body strength mattered. Women are often better educated than men, but the postindustrial gendered social order still reproduces gender inequality in the job market and in wage scales. Men can run vacuum cleaners and change diapers, but women are still the main household workers and managers and the primary parents. Heterosexual men still think they have a right to women's bodies and exploit them sexually. Laws made by governments dominated by men restrict women's procreative choices. (Lorber 2005: 18)

The prescriptions and limitations posed by the gender metanarrative, though intangible, unquestionably have a real effect on the individual's experience in terms of the accessibility, intelligibility, and legitimacy of possible personification. As we will continue to explore in this chapter, the cumulative emergent reality of ritualized performance makes it clear that such prescriptions and limitations cannot affect personification without also affecting embodiment.

-Threats of transgression: masculinity, femininity, and mixed messages

The limitations of legible gender are firmly situated in the metanarrative cosmogony of ontological binary. There is at the same time, however, a confused and foggy hypocrisy found in the metanarrative's tributary stories about gender. We simultaneously receive messages of apparent contradiction: while the sexually dimorphic gender binary is framed as an ontologically divisive intractability, popular culture nevertheless meets us at every turn with references to the work required to upkeep one's gender. From depilatory to podiatry, from facial cosmetics to body fragrance, we are 
reminded of everything one must do (and buy) in order to be a man/woman. All this begs the question: if gender roles were naturally occurring, why would so much work be required?

Our culture is rife with such contradictory statements, which inevitably surface upon observation of actions that are considered to be gender transgressive. Though the cultural chatter is at all other times full of exhortations of naturally-occurring gender, its tenor changes notably when a gender subversive or transgressive act is perceived, however mild. Beauvoir (1952 [1949]) aptly noted this narrative contradiction in The Second Sex: women were instructed that the female gender role was simply an organic manifestation of the sex's natural abilities - while they at the same time faced reproach regarding the shortfalls of their performance as female. She writes, "And yet we are told that femininity is in danger; we are exhorted to be women, remain women, become women" (xli, emphasis added). She again raises the question: why would someone be admonished to be something unless they were not that already? And if they were not women before admonishment, what were they? Are we to understand that women are born, or made?

The gender-policing uproar is especially righteous when children are the transgressive actors. In March 2010, the perceived boy-like appearance of Shiloh JoliePitt (the daughter of celebrities Brad Pitt and Angelia Jolie), then aged three years, was the cover story of Life \& Style Weekly. On the magazine's website, the corresponding article asserts that the child's appearance has caused "a firestorm of controversy" and 
quotes Glenn Stanton, director of Family Formation Studies at Focus on the Family: "Little girls have never been women before. They need help, they need guidance of what that looks like. It's important to teach our children that gender distinction is very healthy" (Life \& Style Weekly 2010). In a similar media outcry, a Spring 2011 J. Crew catalog featured a picture of a five-year-old boy with his toenails polished in neon pink, prompting Erin Brown of the right-leaning Media Research Center to refer to the ad as "blatant propaganda celebrating transgendered children" (James 2011).

In his vehement criticism of the J. Crew ad, psychiatrist and Fox News blogger Keith Ablow (2011) writes that the ad was "a dramatic example of the way that our culture is being encouraged to abandon all trappings of gender identity." He goes on to prosthelytize that

In our technology-driven world ... almost nothing is now honored as real and true. ... [E]ncouraging the choosing of gender identity, rather than suggesting our children become comfortable with the ones that they got at birth, can throw our species into real psychological turmoil-not to mention crowding operating rooms with procedures to grotesquely amputate body parts. ... Why should we hold dear anything with which we were born? What's the benefit of non-fiction over fiction?

Well, the benefit is that non-fiction always wins, in the end.

Ablow's essentialist refutation of the ad's "hostil[ity] to the gender distinctions that are actually a part of the magnificent synergy that creates and sustains the human race" is rife with contradiction; he at once admonishes us to honor what is "natural" while simultaneously arguing for the coercive conformity to what he has just claimed was ontological. It stands to reason that if gender were truly natural, children wouldn't need 
to 'become' comfortable with it, as they already would be; it would not need to be taught or regulated; and there would be no such thing as a fictive gender.

The social construction of sex and the social construction of science

As previously discussed, Butler (1999 [1990]) argues that sex, like gender, is also a concept subject to social construction. This is important to address, as the idealized notion of non-ambiguous sex evident in the physical body is the site of polarizing nature/nurture, sex/gender binarism. Utilizing a feminist epistemology, Butler coconceptualizes body and culture, sex and gender: since neither pre-exists the other, any one simply cannot be conceived (or "discovered," which implies a nonexistent objective neutrality) without the other. She writes,

The task of distinguishing sex from gender becomes all the more difficult once we understand that gendered meanings frame the hypothesis and the reasoning of those biomedical inquiries that seek to establish 'sex' for us as it is prior to the cultural meanings that it acquires. Indeed, the task is even more complicated when we realize that the language of biology participates in other kinds of languages and reproduces that cultural sedimentation in the objects it purports to discover and neutrally describe. (139)

Butler's argument falls within an established canon of literature (Fausto-Sterling 1985, 2000; Fox Keller 1987; van den Wijngaard 1997; Kessler 1998; Dreger 1998; Kitzinger 1999) which similarly contests the discursively constructed notion of sex as an exclusive category restricted to the two and only two "true" sexes of male and female. In How Sex Changed, Joanne Meyerowitz (2008) writes, "We might think of biological sex as a natural phenomenon, with unchanging categories, male and female, universally recognized in all cultures and centuries. But like gender and sexuality, biological sex has 
a history. Humans have imagined it differently at different times and in different places" (21).

Though ostensibly couched in the body, the narrative "story" of ontological sex dichotomy is a socially regulating factor just as metaphysical in nature as any other gendered construct, and like any other gendered construct, its interaction produces a very real effect in the body. A frequently cited illustration is that of intersexuality: though not wholly uncommon (Bloom 2002; Dreger 1998) ${ }^{4}$, is treated as anathema and a "mistake" that requires an immediate intervention and correction to restore the "natural" order of things. In the 1990 instructional film "Surgical Reconstruction of Ambiguous Genitalia in Female Children, Dr. Richard Hurwitz intones, "The finding of ambiguous genitalia in the newborn is a medical and social emergency" (Bloom 101). Intersexed babies are often subjected to surgical intervention shortly after birth to "normalize" their genital appearance. The decision-making process utilized to determine which genitals to construct is in fact rife with interaction between conditions of the body, medical ability, gender bias, and the role gender bias plays within the medical model. The decision is sometimes made on the materiality of the body alone based on perceived medical capability ("it's easier to build a hole than a pole" (Bloom 2002)) with no further testing to evaluate chromosomal or other indicators of sex; at other times, the materiality of the

\footnotetext{
4 "Far from being an exceptionally rare problem, babies born with 'genitals that are pretty confusing to tall the adults in the room,' as medical historian and ethicist Alice Dreger puts it, are more common than babies born with cystic fibrosis. Or, to think of it differently, there are probably at least as many intersexed people in the United States as there are members of the American College of Surgeons" (Bloom 102-103).
} 
body is filtered through the ideas of sex- or gender-appropriateness: if the penis is perceived as "too" small, the child is deemed a girl; if the clitoris is perceived as "too" big, the child is deemed a boy (Kessler 1998). In writing about the anathema of ambiguous sex, Bloom writes, "In modern America, we have done our own disappearing act on hermaphrodites: we have turned a lot of baby boys into baby girls, and a lot of healthy baby girls into traumatized ones" (111).

The example of intersex is given not to co-opt the subjective experiences of the intersexed as a theoretical tool, but rather to show one particularly salient site of the literal extent of the social construction of sex. While many have used intersexuality as an argument for a "Third Sex," Tuana (1996) in fact argues that the introduction of a third sex category would have the potential to be just as insidious as the existent two if it were to still rely on the assumption of ontologically "true" sex: there would just be three options for true sex, rather than two, and the essentialist underpinnings (nature/nurture, body/environment, sex/gender) of biological determinism would remain unchallenged. She writes, "we must reject the idea of difference as a lack, and replace it with an understanding of difference that allows for 'otherness' without hierarchization - that is, that one group of people can be different without that difference entailing superiority or inferiority" (1993: 172).

-The social construction of science

In The Less Noble Sex, Tuana (1993) argues that science as a whole is not the ontologically neutral and objective lens that the metanarrative makes it out to be; instead, S. K. Lewis - Gendering the Body / Chapter Two, Part II: Literature Review 
it must be perceived within the situationality of time, place, culture - and, yes, gender. She posits that culturally prevalent beliefs, such as woman's relative imperfection as compared to man, all find their way into science as a priori ideas: "sexist biases permeate the entire structure of science" (ix). Science is in itself social entity and is a site of the production and reproduction of the sexist world, "both in supplying legitimating ideologies and in enhancing material power" (Haraway qtd. in Tuana 1993: x). The prevalent scientific epistemology leaves us with an incomplete and inaccurate understanding of that which it attempts to measure due to its foundation in the restrictive metaphysic of binarism. It is fallacious to conceive of sex as "natural," ontological, or discrete, as is its meaning and embodiment are both obviously shaped by the social realities of gender. In rejecting this conceptualization of sex, the nature/nurture binary is rendered nonsensical, as is its location as the basis of the cosmogonic gender narrative.

The fallacy of gender universality: global gender variation, historical drag, and the implications of "passing"

Logic would dictate that if gender roles were naturally occurring, then gender roles would have to naturally occur identically across the globe. This, of course, is not the case. The definitions of masculinity, or maleness, and femininity, or femaleness, throughout the world show tremendous variation: what is in some cultures "obviously" feminine is in another "obviously" male. The strict gender binary also proves to be not as universal as the Western metanarrative would have us believe: the prevalence of "third" genders across the globe is well documented, and the implications of cultures that depart 
from the binary gender model well-theorized (Herdt 1993; Ramet 1996; Totman 2003).

From this canon, Lorber (1994) extrapolates that

gender cannot be equated with biological and physiological differences between human females and males. The building blocks of gender are socially constructed statuses. Western societies have only two genders, "man" and "woman." Some societies have three genders - men, women, and berdaches or hijras or xaniths. Berdaches, hijras, and xaniths are biological males who behave, dress, work, and are treated in most respects as social women; they are therefore not men, nor are they female women; they are, in our language, "male women." There are African and American Indian societies that have a genders status called manly hearted women - biological females who work, marry, and parent as men; their social status is "female men." They do not behave or dress as men to have the social responsibilities and prerogatives of husbands and fathers; what makes them men is enough wealth to buy a wife. ... These odd or deviant or third genders show us what we ordinarily take for granted - that people have to learn to be women and men. (17-18, bolding added)

It thus seems that an empirical observation of global gender variation would lead any logician to conclude that the premise underlying the gender metanarrative - that gender roles, as the Western world currently conceives them, are naturally occurring as a result of ontological categories of sex - is at best an absurd construction, and at worst simply untrue. Instead, the self-reproducing gender metanarrative here intersects with the social construction of race and ethnicity. In concert with other notions of superiority and privilege, the operationalization of gender co-created the Western anthropological conceptualization of global peoples: rather than let encounters with differently gendered cultures inform a new gender metaphysic, indigenous peoples' failure to demonstrate soperceived "natural" gender roles was likely a factor in the subsequent Western construction of racial, ethnic, and cultural inferiority. 
-Historical drag and the implications of passing

Gender variance is nothing new: in The Riddle of Gender, Deborah Rudacille (2005) writes,

Far from being a product of the modern world, gender variance has been documented across cultures and in every epoch of history. Male-bodied persons dressing and living as women were known in ancient Greece and Rome, among Native American tribes prior to the arrival of Europeans, on the Indian subcontinent, in Africa, in Siberia, in eastern Europe, and in nearly every other indigenous society studied by anthropologists. According to historian Vern Bullough, 'gender crossing is so ubiquitous, that genitalia by itself has never been a universal nor essential insignia of a lifelong gender.' ... Moreover, the deathbed discovery of a gender reversal is a far more common occurrence in Western history than one might suspect. (3)

Particularly salient in historical literature is the not entirely uncommon phenomenon of soldiers who were discovered to have female genitalia only upon injury on the battlefield (e.g., Deborah Samson or Fa Mulan, the latter of which is the subject of the Disney film Mulan). Such individuals show that female-bodiedness does not preclude successful male embodiment, and a variety of other historical figures similarly show that malebodiedness does preclude female embodiment, even in the spheres that are constructed as especially sex-restrictive (i.e., combat).

Drag, transgenderism, and transsexualism are the bête noire of the gender metanarrative and its underlying metaphysic of ontological binary precisely because they embody the "impossible": they reveal the very possibility of departure from the restrictive cisgender model. In the discursive construction of difference, our culture is filled with messages about the physically inviolable boundaries of gender. This self-fulfilling 
prophecy simultaneously functions to justify the hierarchal status quo and naturalizes conformity, thereby discouraging transgressive acts and eventuating in a materiality that embodies those very boundaries. Departures from cisgender conformity are rigidly policed and punished as unnatural aberrations; as sick, wrong, or sexually deviant in origin.

What is so striking, then, is the relative ease by which transgressive acts of "passing" are accomplished. In addition to its prevalence in historical accounts, instances of drag are found throughout the Western canon of literature and drama; gender switching, per say, happens remarkably often in the works of Shakespeare, particularly in his comedies. Female transvestitism occurs in at least five comedies, and the transgressors are never suspected until they ultimately reveal themselves. Situated almost a half-century later, Norah Vincent's 2006 book Self-Made Man: One Woman's Year Disguised as a Man presents a modern account of a rather Shakespearean situation. In her one-year (part-time) embodiment as "Ned," Vincent was never once suspected of being female: though often perceived as a gay male, she was nevertheless discernibly male. She passed flawlessly in environments which ranged from strip clubs, bars, bowling alleys, and a monastery. At several points in the book, Vincent attempts to get the people she's gotten to know as Ned guess her "real" gender. She describes this interaction at the monastery:

We walked a little farther in silence, and then I turned to him. At this point, since I was on the verge of leaving anyway, I wasn't wearing my beard anymore. I hadn't been wearing it for several days. To me it should have seemed obvious 
that something wasn't quite right. But this was the test of perception that continually arose with Ned. People saw in him what I had conditioned them to see. (116)

Even though she so easily slipped into the embodiment of a male, thus suggesting the superficial and arbitrary nature of gender distinctions, Vincent still believes that her "true" gender "should" be obvious. Her bewilderment is present throughout the whole book, but she never critically engages its potential implications: that if gender is so easily transgressible, perhaps its transgression could be - and should be - engaged so as to destabilize the rigid masculinities and femininities she decries in the book.

More recently, situational transvestitism has infiltrated movies, notably in pop culture films like Sorority Boys and White Chicks, much in the same manner: though supposedly limited by indelible sexual dimorphism, men are shown to easily pass as women once donning wigs, makeup, and falsies. How is it that our culture can hold two such paradoxical ideas at the same time - one of the physically inviolable boundary between gender, and one of the ease of drag?

In a roundabout way, this most recent treatment of drag provides a site for interaction with the moralizing content of the social construction of gender. These depictions of drag are in fact one method by which our culture "explains away" the subversive potential inherent in the ease with which transgressive passing can occur. In the end, all of these drag stories serve as allegories which reify the notion of "true" gender identity, the location of which is posed as the cisgender embodiment. In showing how transgenderism "just doesn't fit" the protagonists, the metanarrative message of 
ontological cisgender identity is reinforced. These narratives are pejoratively evoked in ways that engage the moral operationalization of "natural," much as Keith Ablow does in his criticism of J. Crew's pink toenails advertisement. When faced with information contrary to the metanarrative story, we are admonished to continue believing it, not because it is infallibly true, but because we should believe it.

In these films and other cultural artifacts, cisgender presentation is further framed as a matter of trust, again evoking a moral subtext: as Lorber noted earlier, in our culture, genitals are not generally socially viewable, and thus we rely on superficial marks to convey our gender identity (which is presumed to be self-identical to one's sex). As such, gender allows sex to hide in plain sight; the ambiguity or incohesiveness of the genitals is invisible. When such an ambiguity or incoherence is revealed, then, it is framed a personal affront that implicates the observer's own gender identity and sexuality. Like the bio-men in the campfire scene in the film Priscilla, Queen of the Desert or the men depicted in Boys Don't Cry who later beat Brandon Teena to death, the metanarrative is superior, righteous, punishing, and sexually threatened.

\section{Bodies: material-semiotic intra-action and gender embodiment}

Though they must be understood in terms of their own positional bias, anthropological and archaeological data provide a useful site to explore the ways material bodies reflect their differing material-semiotic positionalities. A wide range of anthropological studies demonstrate the pervasive effects a lifetime of behavior have on the body; this section addresses a select few examples. 
Ingold (2004)'s research explores the ways in which humans walk - and the type of ground we walk on - can affect human anatomical evolution. He writes,

As people, in the course of their everyday lives, make their way by foot around a familiar terrain, so its paths, textures and contours, variable throughout the seasons, are incorporated into their own embodied capacities of movement, awareness and response - or into what Gaston Bachelard (1964) calls their 'muscular consciousness.' (333)

Ingold frames his inquiry within a complex interrelation of factors and produces a rich conceptualization of bodily muscularization, writing, "For my part, I wonder how there could be a cultural history of bodily techniques when the technology of footwear is already implicated in our very ideas on the body, its evolution and its development" (336337). This understanding of muscularity is particularly salient in a cultural environment in which the genders are encouraged to wear radically different footwear, as will be discussed further in the second example below.

Paleontologists are able to extrapolate the types of activities done repetitiously in an anthropological specimen's life by studying the ways in which these activities - for example, running or heavy lifting - affect the morphology of the bones. Molleson (2007) documents the ways activities and behaviors are manifest the skeletal embodiment:

If an activity was time-consuming or arduous, especially when begun at an early age and the bones still growing, the bone morphology can be modified [by the activity] and techniques of production used in the past are recorded. The predisposing requirements for bone morphology to be distinctively modified are a restricted series of movements that are energetic and carried out for long periods probably on a daily basis and from a young age. (5)

She goes on to note that 
[B]one is remarkably pliable and responds to stresses and pressures exerted on it by muscular activity or weight loading. The growing skeleton is particularly responsive. Pressure imposed on bone can easily distort the form and robusticity. The muscles involved in repetitive movements carried out over a restricted range can be greatly developed and their enlarged insertions distinctively imprinted on the supporting bones. (6)

Molleson was able to observe the skeletal, and to some extent, muscular materialities that occurred upon the ritualized production of labor-intensive activities, such as distance running, load bearing, cereal grinding, horse riding, and acrobatics.

Neither Ingold nor Molleson specifically extrapolate their findings to gender, or, in Molleson's case, even to the present day (she writes that she can imagine few situations in modern life that would so alter the skeletal morphology); but I argue that these are limitations self-imposed by their positionality within their discipline and their subsequent lack of sociological imagination. Gender-compulsory footwear is just one example of a ritual which has the great potential for bodily impact - in the feet, musculature, and skeleton, since feet and thus shoes bear the entire weight of the body. We already know that such footwear can cause nerve problems in the feet and legs, back problems, and affect the likelihood and types of injures that can occur upon falling (high heels project women forward or tip them sideways, the latter often resulting in ankle injuries). Pointed-toe and high-heeled shoes have the potential to dramatically impact women's embodiment, especially when children's use of these styles is considered: in any display of children's shoes, a shocking amount of girls' shoes have an elevated heel - and virtually all boys' shoes are flat-soled. Leaving the embodied aspects of such rituals unexamined is both short-sighted and pernicious in that it obscures a site of production. 


\section{- Epigenesis}

Tuana (1996) evokes Beauvoir as the ultimate constructionist: one is not born, but is made a woman. Tuana's argument, by contrast, is that all bodies are 'made,' just not in the way we think - they are complex products of epigenesis ${ }^{5}$, made in ways that disregard and subvert the strict biology/culture, nature/nurture, male/female binaries. In particular, Tuana dismisses the conception of an ontological body that independently preexists culture or environment. Approaching phenomena with any other epistemology results in the infinite chicken-and-egg loop implicit in its fallacious linearity: which came first?

Even before sex or gender can be determined/assigned (i.e., by ultrasound in utero, or observation of genitals at birth), the materiality of the fetus interacts with its environment in ways which affect embodiment, both personally and in the production of the endemic. Gender in fact interacts with embodiment to the extent that it can determine whether or not the body exists at all, as evidenced by the history of female infanticide in cultures which disproportionately value male offspring. This phenomenon continues today; with the recent advent of the widespread use of ultrasound imaging during pregnancy, it is estimated that India is "missing" more than 44 million girls as a result of

\footnotetext{
${ }^{5}$ Epigenesis is a relatively new science (Rudacille 2005). While initially rather narrowly defined as "the concept that an organism develops by the new appearance of structures and functions through the interaction of gene and surrounding conditions" (Tuana 1996) - that is, how certain genes are switched 'on' or 'off' due to specific environmental stimuli - it is now more broadly conceived as the interplay between the human organism and the environment at large and is studied as the epigenome (as opposed to the genome) (Eliot 2009; Fine 2010). Though Tuana argues that epigenesis "retains an additive model that does not undercut the division between nature/nurture" - and while it is certainly true that many scientists still retain the additive model of epigenesis - I think Tuana would find the recent ways the concept has been co-opted, as it were, by feminist philosophers to be a useful site for the discussion of the material-semiotic co-creation of phenomena (60).
} 
sex-selective termination (Sahni et al 2008). Feeding infants soy-based formula - itself a phenomenon inexorably situated in the gendered contexts of medical authority and capitalist industry - results in infant consumption of high levels of phyto-estrogens in the form of soy isoflavones. Infants who are exclusively fed soy formula are widely estimated to consume quantities of estrogens equivalent to three to five birth control pills per day. Emerging research links this exposure to a wide range of phenomena, including age at puberty, the 'feminization' of male bodies, and increased risk of breast cancer (Setchell et all 2011). Endocrine-disrupting chemicals are rife with our environments and even in our foodstuffs (Rudacille 2005). These are all sites of interrelated social, environmental, and even economic phenomena, and all share their interrelation with the materiality of embodiment.

The gendered differential in physical activity is also undeniably a method of material-semiotic bodily production as notions of gender-appropriateness and gender ability define and regulate the ways boys, girls, men, and women are encouraged, discouraged, and prohibited to use their bodies. Verbrugge (1997) addresses the gendering of physical education in her research. She writes,

Through sex-coded activities, physical education marks and patrols the border between 'masculinity' and 'femininity.' Boys play football, girls learn rhythmic gymnastics; schoolboys perform 'regular' push-ups as measures of strength, while girls do 'modified' push-ups. ... The primary and most durable concept by which physical education has gendered the body is the science of sex differences. Amidst the changing foci, even fashions, of the discipline, the principle of sexual dualism has been notably constant. From the late nineteenth century to the present, physical educators have regarded the structure, motions, and abilities of males and females as being markedly and, in many cases, inherently different; further, they have claimed that the social and psychological nature of physical activity varies by sex - that is, that males and females have distinct motives and 
behaviors when they play. To understand the construction and meaning of gendered bodies in physical education, then, scholars would do well to start with the notion of sex differences, because physical educators themselves began there. (275-276)

Gorley et al (2003) also study physical education and argue that there is compelling evidence which suggests "many girls are underserved by existing provision" and found that physical education, sports, and other physical activity was often framed in ways that reproduced the dominant gender order, in particular hegemonic masculinity $(429,445)$. The patterns of gender-appropriate physical activity, and the naturalization of notions of gender-capable physical activity, are internalized when actors are children and then replicated throughout their lives and adulthood, thus continuing the production of this embodiment. In her research, Dworkin (2001) applies the concept of the "glass ceiling" to the level of muscularity that may be acceptably achieved by women in fitness. She found that many women found their bodily agency to be limited "not by biology but by ideologies of emphasized femininity that structure the upper limit on women's 'success'" (333). These women uniquely negotiated the glass ceiling by "avoiding, holding back on, or adjusting weight workouts" (333). In ways both intentional and unconscious, the cultural discourses on masculinity and femininity affect the embodiments of men and women.

Engaging the materiality of the material-semiotic intra-action involves the recognition of the potentiality of both bodily difference and bodily sameness. We know from studies which manipulate, control, and/or account for both biology and the environment that the body - in combination with these phenomena - has the physical 
capacity to perform and embody similarly regardless of sex. Newborns and infants have been shown to demonstrate remarkable similarity across the board, in any conceivable measure (Eliot 2009; Fine 2010). Even in adults, biological phenomena once thought to be sex-specific (e.g., lactation and the maternal flood of the hormone oxytocin) can in fact be observed in the "opposite" sex: though lactation rarely occurs spontaneously in men, the glandular tissues which produce milk are present in both male and female bodies, making it possible to induce male lactation under stimuli; male rats, when left with newborn litters from which the mothers had been removed, were unsure at first but soon embodied maternal rat behavior and were shown to have hormonal levels comparable to maternal rats, versus the hormone levels in male rats who were in cages with newborn litters and the mothers. Similar findings were observed when human males who were the primary caretakers of infants were studied (Fine 2010). Even when they do not have the same biological stimuli as female bodies (e.g., pregnancy and birth), these findings suggest that male bodies are nevertheless capable of the same of producing the same effects when prompted through an interaction of environment, culture, and the body.

Rats aside, we must retain a similar acknowledgement with humans: male/female bodies are different, but we must recognize that the difference is a material-semiotic production which can never be reduced to pure forms - i.e., the "biological" and the "social" cannot be considered separately in the extent of their effects, but must always be perceived as an interrelation. Simply insisting on the capacity for bodily similarity, as many social constructionist feminists have done in the past, not only relies on the 
ontology of the body but also dishonors the real subjectivity of the differently gendered and differently situated body, and this can have dangerous consequences (for example, using only male subjects in medical research and pharmaceutical trials, which was common practice until only very recently). At the same time, it is important to note that the metanarrative has a vested interest in creating difference rather than sameness; as such, intra-actively produced similarity is a site of metanarrative subversion.

\section{The gendered brain: 'hardwiring' versus plasticity}

As individuals slowly but increasingly transverse the naturalized distance between male and female which was purportedly a product of their disproportionate abilities - i.e., women's (slowly but steadily) increasing proficiency and accomplishment in sport and the presence of women as supreme court judges, military officers, and Fortune 500 $\mathrm{CEOs}^{6}$ - the last ten years have seen a shift in the cultural framing of difference. Though still firmly located in a metaphysic of organically different bodies, the cultural imagination is now fascinated with the notion that the real gender difference lies with the brain (Eliot 2009; Fine 2010; Fausto-Sterling 1985).

Several decades ago, Anne Fausto-Sterling determined that there had to be limits to biological influence on the genders by discovering that the majority of neural pathways and brain patterns are established after birth and during the process of cultural assimilation. Her discovery, though, has had little effect on the subsequent propagation

\footnotetext{
${ }^{6}$ This is not to imply that these positions are held by women in equal numbers to men, or that such positions are common, easily accessible, or achieved without the presence of harassment and discrimination; but rather simply to acknowledge their subversive, though rare, effect: in showing that women can perform these roles, women "explode" the metaphysic of the inherent limitations of gender (Lorber and Martin 1997; Tuana 1996).
} 
of "hardwired" difference in the brain as the authentic source of difference between men and women.

Lise Eliot (2009) and Cordelia Fine (2010) have both recently published books that survey the research and literature regarding how the brain develops, the study of neurobiology, its implications, and the ways in which neurobiological findings have been misappropriated by the popular media and charismatic individuals alike in ways which justify existing prejudices, stereotypes, and beliefs. They each present a fascinating synthesis of the scientific and social psychology literature surrounding the brain, particularly in relation to the assertion that gender differences are ontological to the brain.

Both authors explain that until relatively recently, the brain was presumed to develop according to the same additive model that was projected onto biological development at large: that is, a model which inherently holds as ontological a uniform, ideal, or essential body which pre-exists any other factor. The stages of development simply add maturity and stimuli which 'awaken' and activate structures and pathways that already existed in the brain and/or body - i.e., development followed a linear path of biological determinism.

This model has proved fallacious, however, as avant garde scientists have begun to recognize, prompting the studies of epigenesis in the body, and plasticity in the brain. Eliot defines plasticity thusly:

Every physical feature of the human nervous system - the brain cells, or neurons, that transmit information; their axons and dendrites that reach great distances to connect with one other; the tiny synapses that are the actual sites of connection and the supporting cells, or glia, that keep it all going metabolically - responds to life experiences and is continually remodeled to adapt to them. The brain changes 
when you learn to walk and talk; the brain changes when you store a new memory; the brain changes when you figure out if you're a boy or a girl; the brain changes when you fall in love or plunge into depression; the brain changes when you become a parent.

... Simply put, your brain is what you do with it. Every task you spend time on... reinforces active brain circuits at the expense of other inactive ones. Learning and practice rewire the human brain, and considering the very different ways boys and girls spend their time while growing up, as well as the special potency of early experience in molding neuronal connections, it would be shocking if the two sexes' brains didn't work differently by the time they were adults.

So it's all biology, whether the cause is nature or nurture. Sex differences in behavior must be reflected as sex differences in the brain. (6)

The plastic nature of the brain means it is a production, a constantly emerging synthesis of all the factors in play (from the presence of sex hormones to socially enacted gender roles). When combined with the observation that male and female brains are virtually identical at birth in every way, the plastic nature of the brain suggests that the differences we observe in adult brains are the result not of "hardwired," ontological difference, but are rather the cumulative product of a lifetime immersed in gender. As Fine writes, "And so, when researchers look for sex differences in the brain or the mind, they are hunting a moving target. Both are in continuous interaction with the social context" (236).

It is in fact the similarity of the male and female infant brain that drew Eliot to this research in the first place; she writes that she suddenly realized that all these popular claims about neurological discoveries which "proved" hardwired difference were based exclusively on adult, thirty-something brains. "Who's to say such differences are caused by nature and not learning - by the thirty or so years of experience as a male or female that any research subject invariably carries into the MRI scanner?," she wrote (9). If the differences were truly hardwired, she deduced, they would be apparent from birth. But as 
her research soon showed, they were not; neither were they particularly salient after the hormone storm of puberty, which many have theorized to have gendering effects on the brain $^{7}$.

Fine and Eliot engage the concepts of associative learning, implicit assumption, and priming to demonstrate the ways gender and its accompanying scripts pervade the brain. Amazingly, when researchers have manipulated these concepts - in ways as subtle as placing or removing a male/female checkbox at the top of a math test, and as blatant as telling outright lies to the research subjects - the difference in the performances between women and men on any task is statistically negligible, and is in fact smaller than the range of difference displayed within any one gender. This includes tasks and measurements of spatial reasoning and rotation, mathematics, empathizing and perceiving others' emotions, and language, auditory, and visual processing - all areas which have been claimed in times more recent than not to be "hardwired" disproportionately into the brains of one gender and not the other. What does this imply? Fine writes,

the insight that thinking, behavior, and experiences change the brain, directly, or through changes in genetic activity, seems to strip the word "hardwiring" of much useful meaning. As neurophysiologist Ruth Bleier put it over two decades ago, we should "view biology as potential, as capacity and not as static entity. Biology itself is socially influenced and defined; it changes and develops in interaction with and response to our minds and environment, as our behaviors do. Biology can be said to define possibilities but not determine them; it is never irrelevant but it is also not determinant." (177)

\footnotetext{
${ }^{7}$ The differences observed between males and females after puberty was not "salient" in that assessments of subjects before and after puberty did not show any difference in brain structure, etc, thereby measuring the effect of puberty alone (Eliot 2009, Fine 2010).
} 
Fine and Eliot both ultimately land on the Butler-esque theory of performativity: within a context of interrelation with other factors (notably, the biological and physical environments), performance in fact creates the differences that are said to necessitate the performance, and yet the cultural metanarrative misappropriates the directionality of this relationship, holding up the difference as evidence of ontological disparity. Eliot engages how the messages of gendered expectations are disseminated and internalized by children, citing studies that measured parental assessment of their child's motor skills or math abilities. In terms of the studies that measured gendered math performance, Eliot notes that

parents in the United States, China, and Japan all stated that six-year-old boys were better at math even though there were no actual differences in performance at this age. Similar attitudes have been reported in other studies, and while things have begun to change, there's little evidence we've reached an era of truly genderblind expectations.

This message is not lost on girls. As early as first grade, girls express less certainty than boys that they can succeed in math. By eighth grade, girls are some 30 percent more likely than boys to agree with the statement "I am just not good in mathematics" - even in countries such as Hong Kong and New Zealand, where girls actually score higher than boys on standardized assessments. Many researchers, including Beth Casey, have found that girls' lower confidence in math is a significant factor in their scores on high-stakes exams, including the math SAT. (236, emphasis added)

Eliot clearly asserts that a lifetime of receiving messages about gendered ability and suitability cannot not have an effect on the brain, especially since the literature shows that when gendered messages are manipulated in research settings, the performance of men and women changes in relation to the positivity or negativity of the gendered messages they were primed with. Over and over again, in the laboratory men and women have 
overcome the neurological divisions said to make male brains distinct from female brains, and vice versa, resulting in remarkably similar outcomes. When outside of the laboratory, however, the expectations continue to anticipate - and produce - the results, and the cultural imagination perceives this to be hardwiring.

Fine notes that even well-educated and feminist-leaning parents fall back on biological explanations for gendered difference with surprisingly little resistance, so pervasive is it in our epistemological orientation. She cites Emily Kane, who "suggests that the rapidity with which highly educated and privileged parents fall back on biological explanations reflects their position at the vanguard of a limited sociological imagination.' Harsh but, I think, fair" (231). Fine also provides the following anecdote:

The gendered patterns of our lives can be so familiar that we no longer notice them, as this anecdote reported by legal scholar Deborah Rhode slyly makes plain: One mother who insisted on supplying her daughter with tools rather than dolls finally gave up when she discovered the child undressing a hammer and singing it to sleep. "It must be hormonal," was the mother's explanation. At least until someone asked who had been putting her daughter to bed. (216)

In the mainstream metanarrative model, the doing of gender is opaque and invisible, thus obscuring the sites of production. As is typical of its binary bias, one factor - "nature" - is positioned as the sole causation of phenomena and we are encouraged to ignore the complex interactions and positionalities which contextualize its full meaning. As Fine and Eliot both demonstrate, however, the brain is far from an ontologically linear entity; it is in fact a product of richly situated epigenesis - its own material-semiotic intra-action as it appropriates, internalizes, and utilizes the immaterial as well as the material. Fine cites Harvard University psychologist Mahzarin Banaji: 
there is no "bright line separating self from culture," and the culture in which we develop and function enjoys a "deep reach" into our minds. It's for this reason that we can't understand gender differences in female and male minds - the minds that are the source of our thoughts, feelings, motivations, and behavior - without understanding how psychologically permeable is the skull that separates the mind from the sociocultural context in which it operates. ... In other words, the social context influences who you are, how you think, and what you do. And these thoughts, attitudes, and behaviors of yours, in turn, become part of the social context. (xxvi)

\section{Conclusion}

When the metanarrative holds up sexed bodies as evidence of organic, divisive difference, it myopically addresses only the superficial materiality of embodiment, spuriously attributing the physicality it sees to a single factor couched in biologically determinist myths which posit sex/gender, mind/body, biology/culture, nature/nurture against each other - when in fact, such factors are not opposites, but interrelated phenomena that cannot exist separately. In their essential forms, they simply do not exist. The bodies we observe are in fact the material-semiotic sums of their total experience: from the genetic history of its sperm and ovum, to its time in the womb, to its current development, the body embodies its experience.

Due to the regulating structures of our gendered culture, some degree of bodily similarity has occurred within normative sex and gender categories. But what we must acknowledge before fallaciously concluding that such differences are ontological is the presence of different bodies which are the product of different experiences - the outliers. Transgender and genderqueer bodies, along with the multitude of individuals who fall however slightly outside of the rigid metanarrative boundaries, are testaments to the 
plasticity inherent in the material-semiotic intra-relationship that occurs when the discursive norms are subverted.

Transgender and genderqueer individuals are integral to efforts to subvert and destabilize the metanarrative and its biologically determinist, binary underpinnings specifically because their identities acknowledge, subvert, and transgress the ostensibly natural linearity between sex and gender, and sex and sexual dimorphism. While our culture adamantly insists that the male and female sexes necessarily constitute nontransgressable and fundamentally different bodies, transpeople prove that transgression of these sexually dimorphic roles is possible: bodies are not so ontologically limiting, and bodies are not so static, as the metanarrative would have us believe.

That it is not impossible for a man to become a woman or a woman to become a man, and to then perform in those roles successfully in society, indicates the absurdity of our culture's sexually dimorphic, binary logic. The reconstruction of trans bodies makes transparent the notion that while the concepts of sex and gender are indeed distinct, they are far from being mutually exclusive and can nevertheless share a complex, interdependent relationship, even when not cohesively aligned. As I hope to show through the analysis of in-depth interviews, trans people actively engage transformation and reconstruction in a conscious appropriation of the material-semiotic model. 


\section{CHAPTER THREE}

\section{Methods}

\section{Introduction}

Everyone experiences gender. Whether cognizant of it or not, every social individual participates in the discursive, cyclic process of gender acquisition and performance: as one receives and emulates, one is simultaneously perpetuating and endorsing. And, as the previous chapters have argued, the perpetuation of gender has a physical component; the gendered actions we undertake have real physiological consequences and, over time, create gendered bodies. Herein, the lived experience of gendered bodily differences is explored.

In order to explore the construction of the physically gendered body for the purposes of this study, I chose to conduct qualitative, open-ended interviews with a relatively small sample of transgender, genderqueer, and otherwise gender-transgressive individuals. Though every person is gendered, the experiences of transgender individuals provide a unique lens through which to approach the discursive gender model and the assumptions about physicality that lie within. Transgenderism and other forms of gender transgression are emerging cultural visibilities (the visibility being the emergent factor, not the existence) that allow a window, of sorts, into the minutiae of the external acquisition and projection of gender. (This distinction - external acquisition - is made because the vast majority of trans individuals never identified with their cisgender, and always internally trans-identified.) When critically engaged, the narratives of trans 
individuals provide the opportunity to explore lived experiences of the creation of physically gendered (sexually dimorphic) bodies.

\section{Research Design}

\section{-Population selection}

The narratives of individuals who transgress gender invite an exploration into the ways in which individuals can engage sexual dimorphism as constructed - and reconstructed. Trans experiences engage sexual dimorphism as a plastic concept rather than a rigid, naturally occurring fact. The transgender experience is key to the discussion of the plasticity of sexual dimorphism precisely because transgender is in and of itself subversion, recognition, and conscious construction (or reconstruction) of sexual dimorphism. Transgender individuals and those who otherwise transgress gender have rejected the gender role socially ascribed to their anatomical (or, in the case on intersex individuals, medically assigned) sex and have thus also rejected the physical, sexually dimorphic attributes/markers associated with that sex-gender association. Interviewing the transgender population allowed the opportunity to capture personal narratives of awareness of the physical construction of sexually dimorphic difference. Additionally, the interviews provided an entrance to the viewpoint of people who did not let socially prescribed boundaries limit them.

\section{-Research Methods}

My research used semi-structured, open-ended interviews with individuals who self-identified as trans, transgender, intersex, and/or genderqueer, a population I will 
hereon refer to collectively as "trans." The label "trans" comes from my interview with Kip (pseudonym), who described "trans" as having distinctly different connotations than the terms transgender or transsexual, in that it is a more inclusive, generalized term: "Some people define it really narrowly, and I don't ... trans, two-spirit, genderqueer, gender bender, whatever. ... My definition is so broad it's almost hard to talk about."

The interviews, while semi-structured in that I used a prepared interview guide (the complete version of which is found in Appendix A), were conducted in a manner strongly influenced by grounded theory (Strauss and Corbin 1998). Grounded theory refers to the practice of letting the information the respondent reveals guide the subsequent questions and direction of the interview. My goal in the interview process was to stick to a few common themes as identified on the interview guide, but to follow each participant's lead when it came to discussing the specificities of those themes. This was important in order to promote a conversational environment conducive to selfreflection, but it was also as a measure consciously elected so as to establish and maintain respect of the respondent's narrative subjectivity. Culturally, we are often primed to perceive interview situations as evaluative experiences in which an academic "expert" measures a respondent's knowledge by quantifying answers as "correct" or "incorrect." Qualitative research, and in particular feminist qualitative research, departs from this traditional quantitative model. Rather than attempting to glean objective facts from an interaction with respondents, or to evaluate a respondent against an objective ideal thereby creating an evaluative power dynamic between the researcher and the subject - 
the "facts" that are sought in qualitative interviews are the experiences, perceptions, and narratives related by the respondent. The respondents are the experts of their own lives, and as such I designed the interviews to be respectful of each respondent's subjectivity.

As the interviewer, I made every attempt to maintain awareness of my role in the collaborative nature of the interviews. Mindful of my position as an academic researcher and as a cisgender, non-trans person outside of the queer and/or trans communities ${ }^{8}$, I took measures to create an interviewing environment that was equitable and nonjudgmental, and to establish a rapport with each interview subject. Without a rapport with the subject, I was aware that some of the interview's themes might invoke a defensive, rather than introspective, response. It was imperative to avoid situations in which judgment was perceived or feared, and to maintain an environment of trust. I worked to employ a non-evaluative, friendly, empathetic, and deferential tone throughout the interview process, and to avoid the notion of the 'academic-as-expert' (Wahab 2003).

In addition to the open-ended style of interviews, measures included an earnest conversation with each respondent before the interview commenced; this conversation began with a self-introduction, in which I consciously disclosed a degree of personal information about myself to contribute to an atmosphere of camaraderie and familiarity. A detailed description of the interview followed, including a discussion of the vocabulary that would be used. Each respondent was invited to request specific usage of preferred terminology and/or pronouns; to ask for clarification, examples, or for me to rephrase any

\footnotetext{
${ }^{8}$ The positionality of my identity is further discussed in Limitations of the Research later in this chapter.
} 
question; to skip questions if desired, for whatever reason; to tell me if they felt they'd already addressed a question; and to provide only the amount of information they were comfortable sharing. At the end of the interview, each respondent was asked if they thought there were any additional topics they would like to discuss.

Since the interviews were largely exploratory, it was not my intention to amass quantitative generalizations across the subjects; but rather to use as data the subjects' narrative fragments (both in the form of direct quotes and paraphrase) to engage and elucidate the research's points and arguments. Used in this fashion, the narratives and experiences of the subjects become pieces of qualitative 'evidence,' so to speak, in that they provide real, raw data that can be qualitatively analyzed, dissected, and unpacked.

\section{-Sample Selection}

Subjects were recruited from a fairly broad and/or diverse range of gender identity: individuals who practice or have experienced gender in nontraditional ways, namely members of the transgender community. Specifically, the Call for Participants (Appendix B) asked for individuals who identified as "trans, androgynous, or genderqueer." Due to Human Subjects regulations, only adult subjects over the age of 18 were considered. However, there were virtually no other restrictions placed on the demographics of the sample as far as age/generation, ethnicity, race, sexuality, or gender (particularly because 'gender' as it is found within this sample tends to be fluid, changing, or unable to conform to binary definitions). It was important that these criteria for inclusion were so flexible in part because of the nature of this population; the 
transgender community can be hard to find, hesitant to participate, and sometimes hesitant to reveal themselves to members outside of the community. In addition, demographic criteria like age and race, while important in that they will unavoidably influence the subjects' experiences, are not a primary concern of this research.

The subjects were collected through three methods: random sampling through placing a Call for Participants in online classified ads; a small snowball sample through a contact who had personal and professional ties to the trans community (a speech pathologist who works primarily with transgender patients); and by directly contacting, via email, a few visible members of the Portland trans community who are very public about their trans identity due to the fact that they work in the fields of health care and advocacy. The first method, random sampling through online classifieds, secured the majority of my respondents; I placed online classified ads on the websites of the Willamette Week and the Portland Mercury, and on the Portland page of Craig's List. Paper fliers were also posted in Portland State's Queer Resource Center. Snowball sampling through my contact resulted in two interviews, and my direct contact of public members of the community resulted in one interview.

My contact maintained confidentially by supplying a letter I had written with a description of my project and a contact information to her clients and acquaintances she knew identified as trans. (As with the rest of this research design, this process and the intermediary letter were approved by the Human Subject Review Board; a copy of the 
letter is found in Appendix C). It was then up to the individual recipients of the letters to initiate contact with me if they were interested in participating.

When I contacted two visible members of the trans community, I obtained email addresses from each individual's professional/personal website and then composed an email that closely resembled the original Call for Participants, asking if they would be interested in talking to me about their experience with gender transgression. These two emails resulted in one response and one subsequent interview.

Two respondents to the original Call for Participants were unavailable for personal, face-to-face interviews. These respondents contacted me via email after viewing one of my classified ads over the internet, even though they were not physically present in Portland. Both of these individuals expressed desire to participate in my research even though we would not be able to meet for a face-to-face interview. (Phone interviews were ruled out due to lack of technology for phone recording/transcription.) As a result, I created a questionnaire version of my interview guide and emailed it and a copy of my consent form to these two individuals, and invited them to write as much or little as they would like in response. A copy of this questionnaire is provided in Appendix D. Both returned completed questionnaires and invited me to respond with any additional questions. I sent follow-up questions to one of these respondents, and these questions were answered and returned in the same format.

Though both a phone number and an email address were included in the Call for Participants, all potential respondents contacted me via email to express their interest in S. K. Lewis - Gendering the Body / Chapter Three: Methods 
participating. All ten individuals who contacted me expressing interest in participating were ultimately included in the study: eight via interviews and two via written questionnaires.

\section{Data Collection}

-Interviews

Individuals wishing to participate in the study contacted me via email. When I responded, I first verified they met the age criteria and then provided some additional information about the study. Upon confirmation that they were still interested in participating, I scheduled interviews by inviting respondents to pick times, dates, and locations that would be both convenient and comfortable to them. I conducted interviews in respondents' homes, at restaurants, coffee shops, bars, and on the Portland State Campus. A total of eight interviews were conducted.

The interviews ranged in duration from just under an hour to almost three hours, with the average being about an hour and a half. The variation in length occurred due to the respondent-led flow of the conversation and the general comfort level of the interviewee. Prior to meeting for the interview, I emailed each respondent a copy of the Cover Letter of Informed Consent (Appendix E) so they would be able to review it in detail and present any questions before the interview began. When we met for the interview, each respondent was given a hard copy of the Letter of Informed Consent, which explained the nature of the research, the nature of their involvement, confidentiality, and all other pertinent information. The letter was read and discussed 
verbally, and the subject was asked if they had any questions or concerns. None of the participants presented any questions or concerns at this point. I then asked the subjects' permission to audio record our conversation; all eight interview subjects gave me permission to record the interviews. I then recorded the subject's verbal consent to participate and proceeded with the interview. No written consent was collected, per Human Subjects approval. At the conclusion of the interview, I asked each subject if they would like a copy of the research once completed.

\section{-Questionnaires}

The two respondents who participated via written questionnaire versus in-person interview were asked their age to verify they met the study's criteria. Upon verification, they were both emailed a copy of the Letter of Informed Consent and asked if they had any questions. Both respondents replied via email that they gave consent to participate in the study; neither had questions. They were emailed a questionnaire version of the interview guide (Appendix D) and were asked to return it at their convenience, and to contact me if they had any questions or concerns as they proceeded. Both respondents returned the questionnaire within a few weeks, and both invited me to contact them again if I had additional questions or required any clarification. I sent the original questionnaire with follow-up questions to one of the respondents; they in turn replied with additional information. 
$-B \log s$

During the course of the interviews, two participants mentioned that they kept online blogs, both of which specifically discussed and chronicled their transitions. Both of these participants volunteered their blog URLs and invited me to use the blog content in this study if desired. I accessed and printed and both blogs. For the purposes of data analysis, these documents were treated as extensions of the interview transcripts.

\section{-Interview Guide}

The interview questions sought to connect several thematic areas that together comprise our culture's gender paradigm through the narrative, lived experiences of trans individuals. The gender metanarrative attributes gendered bodies not to gendered actions, which have their origin in social constructions, but rather to an innate sexual dimorphism. This discursive construction presents a directionality of the cause-andeffect relationship between sex, gender, and gendered bodies in which the gendered body is offered up the as evidence of an original, naturally occurring, sexually dimorphic physical differential. The ubiquitously "natural" physical differential is then simultaneously used as the justification for gender roles which prescribe sex-segregated actions and behaviors. The interviews were designed to test the directionality of this logic in the context of individual lived experience: isn't it possible that, rather than sex, a lifetime lived within the boundaries of gender - and thereby within gendered action and behavior - is in fact the catalyst which produces the physically gendered body? The interview questions thus primarily sought to elicit personal narratives of the respondents' 
everyday experiences of gender, gendered actions/behaviors, and any resulting bodily changes.

The interview guide consisted of approximately fifteen main questions, and several contingency questions for each to elicit more detail when initial responses were brief, and to help direct the conversation to productive areas. In keeping with the grounded theory methodology, the guide was used as a frame, and its role varied for each participant. The questions were not always presented chronologically, as I allowed the interviewee's responses to direct the conversation; for the same reason, some questions were omitted when I felt the interviewee had already volunteered that information as part of a previous response. Several respondents led the conversation into topical areas that were not addressed in the interview guide, but were nonetheless largely productive in terms of both establishing rapport and in the data produced. In cases in which the respondent seemed confused by or ambivalent towards certain topics, questions were omitted or deemphasized. The complete Interview Guide is found in Appendix A.

As part of the research design, the guide was designed to oscillate between two "scenes" - "general" and "personal." I chose to switch between questions of a personal nature and those that were more general and theoretical in order to create rapport and an environment conducive to disclosure. It would be unfair to expect an interviewee to immediately (much less honestly) respond to a barrage of intensely personal, detailed questions asked by a perfect stranger; as a result, the order of the guide was designed to create periods of conversation about general, theoretical topics in between series of more 
probing, personal questions, to give the interviewee a chance to feel like they knew me better, and to form the impression that the interview was a safe and nonjudgmental place to disclose personal information.

The guide began with a brief personal scene. The respondents were several topical questions about current identity, past identities, and if respondents felt their current identity conformed to mainstream gender expectations. I asked how the respondents felt their gender was perceived by others, and asked if passing was important (some respondents responded to this question in a general context, others in a personal context).

The second part of the guide moved to a general scene, including questions designed to assess the respondents' personal operationalizations of some of the terminology and larger themes utilized in this research: respondents were asked to define masculinity, femininity, and transgender or genderqueer; sex, gender, and the difference between them; and what they personally believed the differences between men and women to be. I also asked if they felt that our culture at large projects a narrative of naturally occurring difference between men and women, and if so, what their perception of that stereotype was. As a transition back into a personal scene, I asked if they had ever experienced socially-imposed limitations on their actions or behaviors based on others' perceptions of their gender.

The third and final portion of the guide returned to a personal scene. The questions attempted to assess the minutiae of the respondents' gendered experience. In the case of the MTF and FTM transgender respondents, I asked the interviewees to S. K. Lewis - Gendering the Body / Chapter Three: Methods 
describe their successful ${ }^{9}$ appropriation of the new and/or altered gender and the embodiment of its corresponding gendered physicality (the aspects of which include body language, body movements, diet, exercise, grooming, dress, etc). Respondents were asked to self-report bodily changes and their implications. I asked if respondents felt gender was performative in any way - in a general context, in terms of their current identity, and in terms of any previous identities.

\section{Data Analysis}

All subjects were assigned pseudonyms. The interviews were transcribed from the digital audio recordings. I analyzed the data manually through in-depth, critical readings of the transcripts (or questionnaires). The first step of my analysis was to code the responses into summation categories. I identified nine summation categories:

\section{Identity}

This category pertains to aspects of identity: current gender identity, past identities, and how the respondents situate their identities in the context of the mainstream metanarratives of masculinity and femininity. Several respondents also made comments that addressed the stability (or non-stability) of aspects of their identity as they went from pre-transition lives all the way through to post-transition.

\footnotetext{
${ }^{9}$ The term "successful" is somewhat problematic in the context of this study, as it pejoratively implies the "passing" of the trans subject - i.e., the average observer would assume the trans individual to be someone who was in fact cisgender. Whether or not someone "passes" can be a source of contention in the trans community, but it is not an aspect of trans identity concretely measured in this study. As noted elsewhere in the thesis, no attempts were made to objectively verify the subjects' self-assessment of passing, or of any other data provided, since the data elicited by this research was of a personal, reflective nature. When the term "successful" is used, it is a reference to the subject's self-assessment.
} 


\section{Conscious action undertaken to conform to cisgender expectations}

Responses in this category reflected the interviewees' experiences of actions intentionally taken in order to appear to conform to cisgender expectations.

\section{Conscious action undertaken to conform to transgender expectations}

This category contained responses that detailed the interviewees' experiences of actions consciously taken to conform to their desired gender: in the case of the trans subjects, their responses dealt with successfully embodying the "opposite" gender; in the case of the genderqueer subjects, their responses dealt with actions taken with the specific intention of departing from identification as either male or female, and presenting either a genderless, ambiguous, or blended gender.

\section{Experiences of social/peer pressure to conform}

Responses in this category explored the respondents' experiences with pressures to conform to normative gender roles, as found in a variety of social contexts, including family, the workplace, and interacting with total strangers.

\section{Passing}

This category contained responses that describe the interviewees' thoughts about whether or not they pass as their desired gender, and if they feel passing is important. 


\section{Male and female gender roles}

Responses in this category expressed ideas of male and female gender roles, both in terms of what the respondents personally believed, and in terms of the stereotypical models they felt were reflected in the mainstream culture.

\section{Physical difference between men and women}

This category contained responses that expressed the interviewees' views of physical difference between men and women.

\section{Sex and Gender}

Responses in this category dealt with definitions for sex and gender, as well as ideas on how they differ, and how they interact.

\section{Bodily Change}

This category contained responses that detailed and explored the physical, behavioral, and superficial (i.e., style of dress, cosmetics) changes the respondents have experienced as they have altered their gender.

After identifying these nine summation categories through in-depth manual analysis of the interview transcriptions and questionnaires, I created a spreadsheet that allowed me to group responses by both subject and category. This allowed me to view the responses collectively to get a sense of the larger emergent themes across individual experience. As part of this process, I revisited each interview transcript, audio recording, 
and written questionnaire to also maintain my sense of each as an individual, whole narrative.

I identified four major themes that organized my findings: Sex, Gender, and Male/Female Identity; Normative Pressure and Passing; Personal Experiences with Engaging Gender for Conformity; and Gendered Bodily Change. In organizing my findings, I worked to stay loyal to the intact narratives and personal nuances found in the interview transcripts and questionnaires; I avoided molding responses so they would fit

more cleanly into any given category. Instead, I was fascinated by the variety of experiences apparent in the responses, and I have tried to accurately reflect the full range of experience in my analysis of the findings.

During the final phase of analysis, I approached my findings in the context of feminist theory and the larger theoretical framework of the study.

\section{Limitations of the Research}

As a small, exploratory study with ten participants, the findings of this research are not generalizable to the larger trans population. The trans, genderqueer, and intersex communities are extremely diverse and doubtlessly contain narratives and experiences that are not necessarily reflected this small study. One particular limitation of this research is found in the racial, ethnic, and socioeconomic backgrounds of the subjects; as mentioned earlier, other than establishing a minimum age, no restrictions were placed on the demographics of the sample as far as age/generation, ethnicity, race, sexuality, or 
specific gender identity. This was due to concerns over the ability to otherwise recruit a full sample; because of the nature of this population; the transgender community can be hard to find, hesitant to participate, and sometimes hesitant to reveal themselves to members outside of the community. However, as it turned out, all ten respondents were Caucasian and also indicated that they came from middle-class backgrounds during the course of the interviews/questionnaires. While the limitations found in the racial, ethnic, and socioeconomic identities of the participants in no way decrease the legitimacy of their responses, they are important to acknowledge here in that these identities unavoidably had an effect in shaping the subjects' experiences, and that subjects with different identities and backgrounds may have had radically different experiences.

The limitations posed by my identity as cisgender and heterosexual must also be noted. They are both undeniably positions of privilege, and, because I was interviewing individuals who were not imbued with such privilege, we were speaking across a hierarchical status divide. This was a major concern as I approached the research design, and is the reason so much thought was put into creating an interview environment of personal disclosure, rapport, and collegiality, rather than an environment which could by default engage the mainstream power dynamic that would posit me as a socially intelligible actor (legitimate person) and the respondent as a socially negligible outsider ('freak'). I felt that the latent power dynamic was successfully diffused in my interactions with the respondents, but there are still two caveats: 1) that is only my perception, and the respondents may have felt very differently; 2) even if the respondents 
also felt the power differential had been diffused, its very ubiquity doubtlessly had an effect on the interaction, even if unintentional.

Another limitation found in my identity as cisgender and heterosexual lies in my own ability to accurately receive, interpret, and contextualize the responses of the participants. Among others, Leslie Fienberg (2001) has written about how trans research that is conducted by non-trans people is potentially problematic in terms of bias and simple lack of experiential knowledge. My positionality had an affect both on how interviewees responded to/interacted with me, and in my ability to accurately receive and interpret their responses, and this must be considered in the apprehension of this research.

Lastly, I wish to again address an aspect of the research that is not necessarily a limitation as such, but which must be taken into account in any interpretation of the findings. To assess bodily change, the study relied on the self-reporting of the participants; in keeping with the principles of qualitative methodologies, no objective measures were taken to measure, quantify, or otherwise verify the information respondents provided in the interviews and/or questionnaires. The goal of this study was to explore individual narrative experiences of gendered bodily change, rather than to provide statistics or other quantitative "evidence." The subjectivity of the narrative assessments of physicality, physical change, gender role conformity, and "passing" was honored. 


\section{CHAPTER FOUR}

\section{Findings}

Introduction

In sharing their narrative experiences, the participants presented a series of compelling portraits of gender engagement, performativity, and embodiment. The participants related how they as individuals experienced gender in cisgender, transgender, and genderqueer contexts, and how these experiences have pertained to their own gender embodiment and bodily change.

This chapter discusses the findings of the research. The discussion is organized by four major themes: Sex, Gender, and Male/Female Identity; Normative Pressure and Passing; Personal Experiences of Engaging Gender for Conformity; and Gendered Bodily Change, informed by the nine summation categories laid out in the previous chapter (identity, conscious action undertaken to conform to cisgender expectations, conscious action undertaken to conform to transgender expectations, experiences of social/peer pressure to conform, passing, male and female gender roles, physical difference between men and women, sex and gender, and bodily change).

\section{Sample Characteristics}

Ten respondents participated in the project: eight by in-person interview and two by written questionnaire. The participants identified as trans, transgender, transsexual, and/or genderqueer. Within those umbrella terms, five respondents identified as female; 
two identified as male; and three identified as genderqueer ${ }^{10}$. Additionally, two participants identified as intersex. Though age was not specifically requested as part of the study, all but two respondents disclosed their age during the course of the interviews/questionnaires, and the other two respondents gave a general range. As mentioned earlier, race, ethnicity, socioeconomic status, and other structural locators were not probed in this study, but much of this information was nevertheless disclosed over the course of the interviews/questionnaires; all the respondents were white and indicated they were predominantly from middle-class backgrounds (although they did not necessarily retain that status; several respondents mentioned current poverty).

All the respondents had transitioned or were somewhere in the process of transitioning at the time of the interviews/questionnaires except for one. The situation of one respondent, Kerry (who was one of the subjects to participate via written questionnaire), was unique from the other subjects for a variety of reasons, foremost in that she self-identified is female, but felt forced to remain living as a male. (While many of the other trans respondents reported having felt similarly trapped in their cisgender contexts, they had all since overcome those feelings and gone through with transitioning.) Kerry was born in 1949 with an intersex condition, probably either Congenital Adrenal Hyperplasia $^{11}$ or, given the era, DES or other synthetic-progestin exposure in utero. ${ }^{12}$

\footnotetext{
${ }^{10}$ The gender neutral pronouns ze (he/she), zher (his/hers), and zhem (him/her) are used to refer to the genderqueer respondents in this research.

${ }^{11}$ According to the Intersex Society of North America, CAH is the most prevalent cause of intersex among people with XX chromosomes (ISNA 2011). CAH is a condition in which a developing fetus compensates for insufficient cortisone production by releasing other virilizing hormones, including testosterone. The increased testosterone can then virilize XX fetuses, sometimes resulting in ambiguous or masculinized genitalia.
} 
The doctor who attended the birth wrote in his notes that the newborn had a vaginal opening and "an organ much like a penis." Kerry wrote,

the doctor took it upon himself, to do no further testing ... but instead proceeded to surgically alter my labia [to look like a scrotum] ... and to close the vaginal opening. My mother remembers nothing about any operation on me, or any questionable organs etc.

Kerry was raised as a male and did not discover she was genetically female until adulthood, when she and her spouse underwent fertility testing after failing to conceive. Although she had always identified as a girl and was initially "thrilled" to learn of her chromosomal sex, under pressure from her spouse she opted to retain her male role and start a regimen of testosterone therapy. Kerry and her spouse ultimately went on to have a child conceived through artificial insemination. Even though the marriage has since ended, Kerry felt trapped in her decision to continue to live as a male:

After her mother \& I divorced, I was afraid of going back to my natural state for fear I would somehow be barred from seeing my daughter. I work for a state government in an occupation that makes me very visible. This state has no language to ensure job protection for gays, lesbians, transgenders etc, so I feel kind of in a shadow in the closet. I realize even with my unique situation, that if I try and "transition" back, my job likely would be taken away. Now that might not be such an obstacle except that I have a rare blood disease that was caused by taking testosterone, and without my job, I would lose my insurance and who knows what would happen to me.

\footnotetext{
${ }^{12}$ DES and other progestin-based drugs were intended to prevent miscarriage and were distributed widely among those who received prenatal care in the $40 \mathrm{~s}, 50 \mathrm{~s}$, and $60 \mathrm{~s}$, often without the patient's knowledge; they were often referred to by doctors as "vitamins" (Rudacille 2005). While the drugs were ultimately shown to have no effect on miscarriage, they did produce a wide range of birth defects and health problems in women, and in the children whose mothers took the drugs, including predilections towards rare cancers. In some cases, the progestin was converted into an androgen by the metabolism of XX fetuses, thereby virilizing the fetus and producing ambiguous or masculinized genitalia. The children affected are now collectively referred to as "DES Daughters" and "DES Sons," and studies are underway to determine the drugs' effects on the third generation.
} 
In her questionnaire, Kerry wrote that it was her everyday goal to simply survive, but her ultimate goal was to free herself from "the societal shackles that bind me and imprison me." She hoped to do this upon retirement in only a few years. She wrote, "If I didn't think it was doable in a fairly short time period, I'd probably do something drastic. And I'm not into anything more drastic than what I've already felt forced to do." For the purposes of this discussion, Kerry's cisgender will be referred to as male, because that is the sex she was assigned (and which was constructed for her) at birth.

Selected characteristics of the sample are presented in Table 1.

\section{Organizational Themes}

-Sex, gender, and male/female identity

\section{--Identity}

The interviews began with a conversation about gender identity. Eight of the respondents (Lindsay, Jamie, Devin, Jordan, Kerry, Sidney, Avery, and Stacy) reported a lifelong and building unease with their cisgender identities, often invoking the concept of doing "drag" to describe how they felt in particularly gender-salient situations, such as dressing up for the first day of school (Devin), attending a baby shower (Jamie), or dating (Sidney). In each of their narratives, the extent of the dysphoria surrounding their cisgender identities was clear; unprompted, five of the respondents disclosed that they had been suicidal prior to making the decision to transition. Lindsay attempted suicide and had been institutionalized as a result. It was shortly thereafter that she decided to transition: "It finally got to a point where I couldn't take it no more. And...it was either 
this or die. So... I'm like, I don't want to die." Though fraught with fears of "letting everyone down," familial alienation, and social unintelligibility (many of which were realized for some respondents), choosing to transition was ultimately framed as a life or death decision.

Table 1. Selected Characteristics of the Sample

\begin{tabular}{|c|c|c|c|c|c|}
\hline SUBJECT & PSUEDONYM & $\underset{13}{\mathbf{A G E}}$ & $\begin{array}{l}\text { GENDER } \\
\text { IDENTITY }\end{array}$ & $\begin{array}{l}\text { HORMONE } \\
\text { USE }\end{array}$ & $\begin{array}{c}\text { SURGICAL } \\
\text { ALTERATION }\end{array}$ \\
\hline $\mathbf{A}$ & Lindsay & 47 & $\begin{array}{l}\text { Female } \\
\text { (MTF) }\end{array}$ & $\begin{array}{l}\text { Yes: } \\
\text { Estrogen }\end{array}$ & $\begin{array}{l}\text { SRS; facial } \\
\text { feminization } \\
\text { upcoming }\end{array}$ \\
\hline B & Kip & 25 & $\begin{array}{l}\text { Trans/Intersex } \\
\text { /Genderqueer }\end{array}$ & $\begin{array}{l}\text { Yes: } \\
\text { Estrogen }\end{array}$ & No \\
\hline C & Jamie & 27 & Genderqueer & No & $\begin{array}{l}\text { "Top" surgery } \\
\text { (breast removal) }\end{array}$ \\
\hline D & Devin & 32 & $\begin{array}{l}\text { Transgender, } \\
\text { queer male }\end{array}$ & $\begin{array}{l}\text { Yes: } \\
\text { Testosterone }\end{array}$ & $\begin{array}{l}\text { "Top" surgery } \\
\text { (breast removal) }\end{array}$ \\
\hline $\mathbf{E}$ & Jordan & 56 & $\begin{array}{l}\text { Transgender } \\
\text { (MTF) }\end{array}$ & $\begin{array}{l}\text { Yes: } \\
\text { Estrogen }\end{array}$ & $\begin{array}{l}\text { SRS; facial } \\
\text { feminization }\end{array}$ \\
\hline $\mathbf{F}$ & Kerry & 58 & $\begin{array}{l}\text { Female/ } \\
\text { Intersex }\end{array}$ & $\begin{array}{l}\text { Yes: } \\
\text { Testosterone }\end{array}$ & $\begin{array}{l}\text { Genital } \\
\text { corrective } \\
\text { surgery as an } \\
\text { infant }\end{array}$ \\
\hline G & Sidney & 30 & $\begin{array}{l}\text { Trans Male } \\
\text { (FTM) }\end{array}$ & $\begin{array}{l}\text { Yes: } \\
\text { Testosterone }\end{array}$ & No \\
\hline H & Hawthorne & $\begin{array}{l}\text { Mid- } \\
20 \mathrm{~s}\end{array}$ & Genderqueer & No & No \\
\hline I & Avery & 33 & $\begin{array}{l}\text { Female } \\
\text { (MTF) }\end{array}$ & $\begin{array}{l}\text { Yes: } \\
\text { Estrogen }\end{array}$ & $\begin{array}{l}\text { SRS; facial } \\
\text { feminization } \\
\text { and breast } \\
\text { augmentation } \\
\text { upcoming }\end{array}$ \\
\hline $\mathbf{J}$ & Stacy & $\begin{array}{l}40 s- \\
50 s\end{array}$ & $\begin{array}{l}\text { Trans Female } \\
\text { (MTF) }\end{array}$ & $\begin{array}{l}\text { Yes: } \\
\text { Estrogen }\end{array}$ & No \\
\hline
\end{tabular}

${ }^{13}$ Age at the time of the interview/questionnaire. Interviews were conducted in 2007.

S. K. Lewis - Gendering the Body / Chapter Four: Findings 
Many of the participants framed their cisgender identities as a "mistake" of biology, using phrases like "I always knew I was a girl;" "I should have been a boy." Jordan, who is a medical doctor, referred to transgenderism as a birth defect: "throughout the world it's considered a birth defect, you have the brain of one gender and the body of another. That's actually been found to be true, biologically."14 Operationalizing the incidence of transgenderism as a 'mistake' or 'defect' was for some respondents a way to legitimize and explain the need for a 'correction' or 'fix' to their cisgender identity, especially in terms of surgical intervention. This was in fact the attitude the American medical community and mainstream culture adopted when sexual reassignment surgery came onto the popular radar in the 1930s; in her book How Sex Changed, Joanne Meyerowitz (2002) writes that transgender was often considered a type of intersex condition, and that the medical and popular literature

depicted sex-change surgery as unveiling a true but hidden physiological sex and thus tied the change to a biological mooring that seemingly justified surgical intervention. In this vision of sex, science could and should correct nature's "rare blunders," creating an unambiguous sex, either male or female, from sexual ambiguity ${ }^{15}$, a condition cast and contained as tragic but correctable. (33)

These respondents viewed transitioning (and, for those who could afford it, the corresponding surgery) as the opportunity to correct the erroneous facade and as a gateway to their true selves. As Lindsay said, "I mean, I always felt, I knew I wanted to

\footnotetext{
${ }^{14}$ Jordan's assertion that "That's actually been found to be true, biologically" is, of course, up for some debate.

${ }^{15}$ As sex and gender were not yet perceived as distinct, "sexual ambiguity" was used synonymously for gender ambiguity; transgenderism was often phrased - as it still is sometimes today - as having the body of one sex, and the brain of the other (thus operationalizing transgenderism strictly in terms of sex and its biological associations).
} 
be a girl. That was just a no-brainer. I knew...I should have been a girl. OK? Well, go for a walk, look in the mirror, it's like, well, (psst) that ain't a girl." Now, the mirror reflects an accurate sense of self.

These narratives indicate the importance of embodiment in the transgender experience. For example, while the respondents reported an almost-immediate feeling of release, ease, and freedom to act, behave, and move in ways intuitive to them upon assuming their transgender identities (ways they felt had been restricted by cisgender expectations), several respondents mentioned that they would feel more concretely located in their identities once they were finished with surgeries. Avery said that while she identified as trans female at the time of the interview, she hoped to identify simply as "female" after undergoing facial feminization surgery and eventual breast augmentation: "But eventually, I think, once all surgeries are finished, I think I would definitely identify as female." Sidney, who is FTM and who stated he cannot afford surgery, approached it similarly:

I'm kind of trans right now because I'm in the process, but ultimately male. ... I mean, ultimately, I'd like to be just male, but part of me will always have to be trans just because of, you know, social interaction and you know, if I ever want a partner. I don't see myself getting any surgeries any time soon, so.

Sidney explained that while he would like to be "just male," he didn't feel that identity was attainable for him, and expected that his identity would remain transgender male (which, although not ideal, he did not view as a negative thing; he went on to discuss the many positive aspects of this identity, as will be discussed later). 
As Sidney's narrative suggests, the importance of embodiment was true even when these bodily characteristics are not visible in social contexts. Jamie, who is genderqueer, had been dysphoric about zher breasts since puberty and bound them as an adult prior to undergoing "top" surgery. Even though ze didn't think zher appearance to others changed post-surgery (there wasn't much outwards difference between binding plus layered, baggy shirts, and zher reconstructed chest in non-layered clothes), ze still reported feeling strangely more comfortable and confident in zher social interactions, even though zher surgery didn't explicitly resolve any awkwardness in frequently encountered gender-salient social situations (for example, public bathrooms labeled men/women). Jordon (MTF) stated, "You know ... in our society, people can't see your genitals. They have no idea what you look like. Nobody goes down the sidewalk with their legs spread apart on a trolley. So, it's what they see." She acknowledged that gender presentation is largely superficial in that no one is verifying the cohesiveness of one's sex and gender - but at the same time, she spoke of having $\$ 25,000$ worth of surgery, a good portion of which concerned areas of the body invisible the common observer.

Kip's narrative also focused on the role of embodiment in zher gender identity. Kip identified as genderqueer and intersex due to acute Polycystic Ovary Syndrome (PCOS), which, while a relatively common condition, can vary radically in its presentation and severity across individuals. For Kip, PCOS meant severe hormonal and metabolic changes upon the onset of puberty, including an influx of testosterone. The 
testosterone zher body began to release caused several physical changes, including facial/body hair, fat redistribution, and the partial virilization of zher genitals. Ze said, "Basically what's happening with the testosterone in my body is that I'm physically transitioning in the slowest possible increments ... which is almost excruciating." $\mathrm{Ze}$ directly related this physical experience to zher gender identity:

I feel like my gender is way related to my physical experience. I just think my physical experience is not necessarily like your typical physical experience, but my gender has very much fallen in line with the physical changes; I feel like the gender just adjusts to meet the sex, you know, over and over. [Researcher: Do you think you wouldn't identify as genderqueer if you weren't intersex?] I'd probably still be - I mean, I'd still be, I'm still wicked queer so there probably would be some gender bending just because I think that's kind of part of being queer in a lot of circumstances... But, probably not, I mean - probably I wouldn't. But, you know, I wouldn't be surprised. For me, I think in that way it's been really, really different than all the trans people I know. Cause I don't know anybody else that just grows, that their body just starts changing, and they're just like, 'kay. Everybody else I know made the conscious choice and are taking synthetic hormones and are choosing their dose, choosing how much testosterone they have, and it's being monitored.

Kip also identified as fat, and spoke at length about zher belief that size is a dichotomizing force in our culture similar in scope to gender; and, like race, ethnicity, or able-bodiedness, it was a factor that intersects with and cannot be completely separated from gender. "That's body - and to me, that's gender. Because my gender and my size, are the same."

--Sex and gender

The participants presented a wide range of beliefs about sex and gender. Some respondents presented a relatively typical model of sex and gender: sex is the biological 
body, either male or female, and gender is an extension of sex, either male or female. (These respondents tended to be the same ones who framed transgender as an error/mistake requiring correction.) The other respondents, however, described a gender spectrum that included not only wide variation in what it means to be male or female, but also the presence of genders in addition to male and female, which may or may not relate to sex. For some, the spectrum included the genders of male, female, queer male, queer female, trans man/boy, trans woman/girl, and genderqueer. Many respondents expressed resentment that people are pressured to "pick one" of the two established genders, which devalues and delegitimizes gender identities which lie outside of those boundaries. In describing her view of the gender spectrum, Kerry wrote, "perhaps let folks know that life isn't just black \& white, but many shades of gray \& pink \& blue \& red \& yellow." Kip also engaged the diversity of the gender spectrum in relation to social pressure when ze joked, "I'll take one of those, and one of those....the problem is not which one I want, but that I can't have all of them."

Jamie, who is genderqueer, used a metaphor to describe zher view of gender:

If you imagine that there's a universe of genders, right - ok? So, there's a universe of genders, and there's two boxes. Male and female. And, everybody falls within the universe, but the universe is bigger than the two boxes. And people can hang out in one box their entire life; they can sit in the middle of the box, if they like. Some people choose to hang out kind of on the edges of the box. Some people choose to go between boxes. However frequently they want. And some people are kind of outside of the boxes. That's how I see gender. And I find myself outside of the boxes. 
Most respondents also imbued gender with a sense of non-permanence and fluidity in terms of its ability to change. This view seemed at first paradoxical for some respondents when considered in combination with their experiences of finding their own (trans) genders to be crystal clear, a singularly true identity for them, and their cisgender to be unlivable. But the picture became clearer as each respondent went on to describe their belief that in real-life contexts, gender enactment always blurs the metanarrative boundaries; all females have masculine traits and all males have feminine traits. When speaking about masculinity and femininity, Jordan, who is MTF and a physician, said, "Well, you know, we are all a blend." She related the anecdote of having her first posttransition portrait taken to hang in her practice's lobby (after successfully fighting to return to the practice she had founded as a male twenty years prior). (As a condition of her return, the practice's corporate attorney sent over twenty-four thousand letters to current and former patients, disclosing that Jordan was transsexual [so "the rest of the world wouldn't sue them"]; they also required all patients to sign letters of informed consent and posted letters in the exam rooms.)

I let my staff pick the picture which now hangs on the wall in my office. And I had people who came in and they would say, you know, I wasn't sure I could see you, and then I saw your picture and it was okay - and then I realized, was that most human beings, they need a framework of gender; gender is the framework that allows you to relate to another human being in our society. It dictates the rules, it dictates the method of communication, it dictates the interactions, the accepted and unaccepted behaviors, whether you're sexually active towards them or not. What's interesting is, we think male - Tom, female - Susan; male - Robert, female-Mary. When you take that away from people or disrupt it, they get very uncomfortable. What I didn't realize is transsexuals have no framework. We glide back and forth - I mean, I see people change every day. I don't think anything of it, and neither do they. We're as fluid as possible. 
For most respondents, the personal implications of "fluidity" were identified not as the intention (or perceived ability) to literally go back and forth between male and female identities, but rather the interrelationship of masculine and feminine traits, qualities, and attributes experienced within a singular identity: "we are all a blend." This realization was initially uncomfortable for some respondents; several stated that some days they would wake up with a horrible feeling of being more male than female (or vice versa), but that as time went on, they were able to expand their operationalizations of masculine/feminine to accommodate a greater blend of characteristics. In sum, even though these respondents framed the fluidity of gender identity to be one-directional in their own cases, they nevertheless acknowledged the capacity for multi-directional, sustained gender fluidity.

One interesting observation was that the two FTM and three genderqueer respondents generally had more flexible views of gender than the five MTF respondents. This was seen in terms of comfort with genders which lie outside of the boundaries of male/female, and in the ways conformity to archetypical male/female roles was selfassessed. Whereas all but one MTF respondent (Stacy) did not desire to retain "transgender" as a permanent part of their gender identity (instead desiring to think of themselves as "just female," versus trans female), being trans was important facet of identity for the FTM and genderqueer respondents. To illustrate, Kip related something a friend had told zher. This friend transitioned to a female body in her fifties after working 
as a lumberjack for thirty years and who Kip described as someone who "will never pass."

She was like, 'I don't think that the war between the sexes will be solved until there are visible populations of people living outside of that.' She was like, 'I think trans people are here to live outside of that and heal that kind of wound that we have socially, ' you know.

Kip went on to say about zher own experience,

There have been situations where I could have passed, it's just that I think it's so fucked up that I would have to pass, that in those situations I typically just out myself, because - you know? I just think it's wrong. I mean, I just think it's dead wrong. I think it should have absolutely no bearing on how you treat people. No bearing whatsoever. ... My argument is, you shouldn't have to choose, and I'm not the one who should have to change, and nothing changes if people don't lay their lives out. I mean, if people aren't living their lives out - and trans and whatever - if people that aren't passing aren't paving the way for all the people who are passing and that do get that privilege - you know what I mean? Then it's not going to change.

Stacy, who is MTF and one of the questionnaire participants, wrote,

I work to belong in the world of women as a trans-woman. I want to be able to talk about my past, without having to sensor it, so I "out" myself. I have a past and I am proud of it. Also I lived many years hiding my secret, and to have to transition and worry that the secret of my past will be found out, is more that I wish to live with. I am out and proud. Being out enables me to be an activist.

By contrast, the remaining MTFs expressed great discomfort at the idea of genders outside of male or female, genderqueer, or even of not passing (and thus being perceived as a gender outside of male or female). Avery said,

In one world, I want it to be black and white, you know, male or female. That would just make it so much easier. There are people can exist in this fluid state, and be quite comfortable. I'm not one of those people. But, I know there are many of those people out there, who exist in this third gender spot, and that's cool -- for them. It would be nice, to be able to be in that space. But-I guess - too 
much socialization from where I grew up, and there's this role, and there's this role, and it doesn't separate - like, there's no middle. And that's comfortable to me. So, I guess I define gender as male or female.

This flexibility was also reflected in the ways the respondents characterized their masculinity or femininity; while the MTFs characterized their femininity as conforming to the mainstream - "vanilla" and "girly" were two adjectives used - the FTMs identified primarily with non-mainstream masculinity, namely "fag masculinity." Devin said that when he began to transition, he was often mistaken for a teenage boy - a gay one. And while it was "kind of weird to go from being a lesbian to being perceived as a gay man," he soon embraced the diversity of experience and expression fag masculinity offered. He found he was infinitely more comfortable with makeup and skirts when engaging drag or glam as a queer male than he ever was as a female:

I'm much more comfortable being kind of sort of a flamboyant gay man than I was ever being a feminine girl, like ever - like, I'm much more likely to put on a skirt now just because I'm more comfortable with like being - like, I don't know, It's confusing, like, I feel much more like, confident being a man and doing that like kind of a drag queen situation or whatever as opposed to like, this gender that doesn't fit me.

Kip also identified fag masculinity as a gauge of zher maleness; ze said,

I identify more as masculine now, I think, [but] there's a lot of pressure there, there's a lot of proving yourself. ... Like, I don't know how to fix things, I'm not mechanically minded, I'm way more on the artists center of the spectrum. So I think I identify with kind of fag masculinity a lot of the time more than like hetero man masculinity, just to gauge it, or whatever.

It is possible that the difference in conceptions of gender flexibility is attributable to something else several participants noted: that in our mainstream culture, it is much more acceptable for females (particularly girls) to adopt masculine dress, mannerisms, 
behaviors, play activities, or hobbies than it is for males (particularly boys) to adopt feminine dress, mannerisms, behaviors, play activities, or hobbies. Though all FTM respondents related extreme feelings of relief upon transition in that they could finally 'be themselves,' it seems possible that a lifetime of male socialization - and the rigid policing of gender boundaries that comes with it - still affects the ways they conceptualize gender. They have committed what some would consider the 'ultimate transgression' in transitioning, but it is relevant that they switched from one socially intelligible position to the other rather than completely departing from the binary. Even though they transgressed the sex-gender correlation, they maintain respect for the dichotomous gender boundaries by locating themselves firmly inside those boxes, never straying to the space in between.

--Male/female gender roles

Many respondents acknowledged the dichotomized nature of male/female gender roles in our culture, but felt the roles were largely artificially imposed and that real gender experiences were more diverse, each person experiencing aspects that were both masculine and feminine. Several respondents connected the rigidity with which these roles were enforced to be directly related to their trans identity: Sidney said,

And ideally, gender wouldn't matter, and nobody would have to transition, but that's not the way it is, so. [Researcher: So do you feel that you wouldn't have transitioned if there wasn't a social pressure?] Yeah... just if, you know, gender expression wasn't such a strict black or white thing, you know, if men were female minded, and females were allowed to be male minded without having to transition, I think that would be awesome. I mean I just don't think the differences should be such a big deal. Even though there are some very 
fundamental, basic differences between men and women, I don't think we should be forced to live inside a specific box, that bothers me. But I mean, that is the way it is, so if I want society to perceive me the way I feel myself to be, then this is what I have to do, but it would be cool if I didn't.

Sidney implied that the only way to personify the actions, behaviors, and personality which were intuitive to him - which were deemed "masculine" - as a female-identified person, and still be socially legible, was to no longer be female-identified.

When asked to define the archetypical female and male gender roles, the respondents had no trouble painting a picture straight out of Leave it to Beaver. What also emerged, however, was the feeling that many of the divisive qualities between the male and female gender roles were the product of socialization. Even the respondents who most strongly identified with traditional gender roles (Lindsay and Avery) mentioned the influence of social context and the gender socialization of children. Lindsay framed this in terms of how gender expectations have changed over time, first evoking an image from her childhood in the 1960s: " most of the neighborhood moms were all stay-at-home moms, you know. And the man went out and got the job, and the man... you know... did all the manly things (laughs). ... Things have developed a long ways since then." We draw from this the sense that the boundaries which define male and female roles are socially negotiated, allowing them to change over time. Jamie also cited the role of socialization in cultural gender assumptions:

The whole men are stronger thing... well, men take up more space. Uh, they have different speech patterns. Men are aggressive. Girls are passive. I think that most people assume that they're biologically innate. I don't think that. I think it's all related to the socialization. 
When asked about the difference between male and female gender roles, the respondents answered exclusively in terms of socially allowable behavior and social expectations (statements related to physical ability were conspicuously absent). Jordan said:

As I went through all this, I came to the conclusion that men 'do' and women 'are.' Men are defined by what they do, women are defined by who they are and who they're married to. A man can be successful at business, go home, beat his wife, abuse his kids, and nobody cares. A man who stays at home is a bum. A woman who stays at home is a homemaker. A woman doesn't have to do anything if she looks good. If she's beautiful-that's okay with most people. A man who succeeds is ambitious; a woman who succeeds is a bitch.

She also related how the social regulation of male/female roles was salient in her career.

You can cure a lot of people by hugging them, but you can't do that as a male doc. You can't touch them. You can't in the remote, be empathic. Because it's a kiss of death if someone accused you of indiscretion. I hug patients all the time [as a woman]. No one cares. Maybe I'll get sued someday, I don't know. [laughs] But as a woman doc, you have much more power to heal because you are not threatening, you are viewed as being sympathetic, people can form emotional rapport with you without fear - men cannot. You know, I had a guy come into my office once, who was really upset, "my brother died and I was crying in the funeral home." And I said, of course you have a right to be upset, with your brother dying, and he says, no, you don't understand, I cried in front of my family - and that was the sin, and that's what he was upset about. Yeah, not that his brother died - what bothered him was -. ... There are things you cannot do. You will not wear a dress. You will not wear makeup. You will not make overtures to another male. To do so, could cost you your life.

Many respondents addressed the metanarrative image of the stereotypical stoic, rational male in particular - calculating, logical, able to fix cars, but unable to empathize or emote. This image was seen as artificial and fraught with socially imposed limitations in other words, the respondents did not attribute this image to an ontological difference between the sexes, but rather to a lifelong saturation in a gender-policing culture. 
Both the FTM and genderqueer respondents invoked this treatment of the male gender role, each stating that they did not want to conform to the traditional male image. This was particularly striking in the case of the two FTM respondents, who explicitly identify as male - but, as mentioned earlier in the discussion of masculinity, they intentionally position their male identities outside of the severely limited traditional model and instead invoke more subversive or countercultural forms, like fag masculinity. On not desiring to conform, Devin said,

Oh yeah, the man is supposed to go and fix the car, or whatever, or be all macho about it, or like when I get hurt or something, like - if I get hurt and it hurts, then I'm gonna like fucking say something, you know. I don't think it's - I don't like to fit into the stereotypes as much as ... maybe some other people do, because I don't like the stereotypes.

Devin's sentiment - "because I don't like the stereotypes" - was echoed by Sidney, Kip, Jamie, and Hawthorne. In their conscious nonconformity, the respondents' male/masculine gender personification ${ }^{16}$ was simultaneously a reification and a subversion of the dichotomous metanarrative gender roles - a reification in that identifications of maleness/masculinity invoke and reference the metanarrative construction, thus contributing to its ongoing production; and subversive in that the male/masculine identifiers are aligned with potentially incohesive bodies and behaviors in ways that approach the borders of social intelligibility.

\footnotetext{
16 Though the genderqueer respondents did not wish to pass as male (or be male), each identified with aspects of masculinity, and it is the personification of that masculinity which I refer to here.
} 
Though addressed less frequently and with less vehemence than the male role, the respondents felt similarly about the female gender role, noting what appeared to be arbitrary limitations placed on individuals located within the role. Unsurprisingly, the three genderqueer respondents extended this observation to an opinion that the mainstream model of dichotomous genders should "blow up." When asked about the archetypical gender roles, Kip said,

I think they're largely irrelevant... I feel that's the conclusion everyone would come to if they had a different lens to experience life, you know? I think that's one of the benefits and one of the pitfalls, I think of not fitting physically into one of those categories, like not passing, you know? Because you see one side when you're passing that you never see when you're not passing.

When asked about the physical differences between men and women, the respondents were split: about half thought there were physical differences between men and women, whereas the other half said while they felt pressure to believe that there were such differences, they did not personally perceive them; found them to be the result of social emphasis; or believed they were simply the result of hormones, which, in this community, were seen as something one can have moderate control over. Sidney spoke about the metanarrative of physical gender difference:

Does society see differences, physically, between men and women? Well, yeah, I think it's like blatant, I mean, if you just look at celebrities, the women are always, the popular ones are always like skinny and big-boobed and do horribly super feminine things, and the men were are always like muscley, and tall - and I think it's obvious that society sees men in one way and women another. And I think, more so than they actually are different. I mean, they focus on physical differences a little too much. [laughs] I think in general, like - I mean, society in general, I just look at the way like, teenagers, dress, and the girls always have these little tight-ass little jeans and these tiny little shirts, and the boys are like always just completely drowning in just a sea of like, over-baggy clothing, you 
know. And it's just like, that's unfortunate that you guys are conditioned to dress that way, because there should be no reason that girls have to show off their bodies and guys get to completely hide theirs. Yeah, I think society sees way more - too many physical differences - and they should focus less on that and more on like, similarities. I don't know, I just - I think there's too much of a divide between men and women. I don't think there needs to be.

Sidney here expresses an opinion which many respondents echoed: while difference may occur between individuals of the opposite sexes (for example, that which would be observable if one was to pair a 5-foot-one-inch tall woman and a six-foot tall man), the degree of difference does not hold when applied to the genders at large. Physical similarity, rather than physical difference, was seen as the ontological norm, but these respondents at the same time noted the metanarrative of difference and the ways in which normative behaviors - like Sidney's example of teenage fashion - seek to emphasize and even create the perception of difference. As Kerry wrote, "society structures individual conditioning based on its "norms" that PROMOTE an implied Need to be different - male from female."

It was interesting to note that the respondents who did believe there was a physical difference between men and women in general described this difference almost exclusively in terms of the bodily modifications they themselves had engaged in the process of transition: the shape of the brow, jaw line, and trachea (facial feminization surgery); fat distribution (shifts with hormone use); and muscular strength (affected by hormone use and exercise/intentional lack thereof) were all mentioned. The other major physical difference noted was height, in the perception that men are taller than women. While many respondents conceded that this was an overgeneralization, the reality of this 
social expectation was reflected across the board, causing several respondents to note that it was palpably "easier" to be short as a transman than tall as a transwoman.

\section{-Normative Pressure and Passing}

All of the respondents spoke at length about passing, both in the cisgender and transgender/genderqueer contexts. It became clear over the course of the interviews that passing was approached in two distinct ways: passing in terms of the social pressure to conform to an intelligible gender category, and passing in terms of the respondent's own desire to present as an intelligible member of their gender. The former is discussed in this section; the latter is discussed in Personal Experiences with Engaging Gender for Conformity later in this chapter.

All the respondents reported first feeling pressure to conform to cisgender expectations as young children; this pressure was described as more overt by the FTM and MTF respondents, who all identified with the opposite gender at a very young age and had "inappropriately" engaged in play, dress, and behavior that was associated with that gender. Lindsay remembers being scolded to "sit on her hands" and told that "we don't do that" when she used expressive gestures as she talked. Lindsay, Jordan, and Avery all spoke of cross-dressing as children and of intuitively knowing it was an activity full of shame that they must keep hidden. Kerry, Stacy, Jordan, and Avery all remember being taunted by siblings and playmates about the perceived effemininity of the way they walked, ran, carried objects, spoke, or used their hands. Kerry felt explicit pressure from both her family and her peers; she wrote, 
When I was a child no one accepted me for a girl because they knew I was supposed to be a boy. To stay alive I hid my girlishness as much as I could (getting beaten isn't pleasant). ... Sometime after I started school, 2nd-3rd grade it became apparent to me that if I were to survive, I needed to at least appear to be that boy that my parents wanted. I became an actress.

Sidney also related school-age normative pressure from peers: "In school I got teased a lot, you know, for being a tomboy, and people were like, oh are you a boy or a girl, and... you know. I got picked on a lot at school." Hawthorne said that even though ze appeared to be a very typical girl in high school, ze was often called a "dyke" despite zher feminine appearance and heterosexual dating due to interests and personality traits that were considered masculine.

Kip mentioned normative pressure in terms of trying to become employed when living outside of the gender binary.

Like going to job interviews. I went to this job interview for a temp agency. And I'm like, a 4.0 student, you know what I mean? ... And I've got like three years of experience, and I type faster than they require, and you know - it was just ridiculous. I went in there, and I was dressed professionally, and we had an excellent interview, and it went on for half an hour, 45 minutes, completely amicable. And then she was like, well, I really want to hire you, but... And I was like, is there something I can do that would make me a more, a better-looking candidate, or whatever? And she was just like, 'we just [sigh]... need someone who looks more professional. Like this.' She does this to her face [mimics stroking her chin/pulling on beard hair].

The other aspect of normative pressure the respondents universally addressed was confrontation and, ultimately, concerns about safety. Jamie talked about how public bathrooms were problematized, particularly for individuals who fall visibly outside the gender binary. Though ze is often perceived as male, Jamie avoids male bathrooms when 
possible because it is zher impression that they hold greater physical danger. Women's

bathrooms were not without contention, however:

Women are very territorial about their bathrooms. And, feel the need to share with me when they feel I'm in the wrong one. And actually, my first traumatic gender experience was in a bathroom when I was eight. And uh, I was washing my hands. This is why I stopped washing my hands in bathrooms. And this woman - I was in a restaurant - and someone opens the door, and the door when you opened the door, the first thing you saw was the sinks. And I was eight - you know, washing my hands, minding my own business - and this woman opens the door and she kind of just stood there - for long enough to make me look at her - and so I looked at her, and she was making this obvious, slow motion look between me and the door, like the woman sign on the door - me and the door, me and the door. And finally was like, you're in the wrong room. Or something. Stupid. And you know, I was eight-what was I going to tell her, shut up? And then she said something to the effect of, if you don't leave I'm going to call the manager, or something? Which seemed a little bit harsh. I didn't have a lot of memories from childhood, but that one always kind of stuck with me because it was very upsetting. And built a lot of anxiety around bathrooms.

Ze described the ways ze continued to negotiate bathroom situations, particularly at zher workplace and in other public spaces, leading zher and zher partner, who is intelligibly female, to enact a code which indicates when it is safe for Jamie to enter a bathroom.

During the course of the interviews, seven of the ten respondents described, unprompted, measures they had taken to pass specifically for reasons of personal safety. Jordan described going on a cruise in the Baltic and being treated increasingly threateningly by the staff, who perceived her a male cross-dresser. After she returned from that trip, she underwent facial feminization surgery, although it had been her personal assessment that she passed "very well" without it. One of her first transgender patients, a "beautiful two-spirited girl from American Samoa," had recently been murdered and found in a ditch in Portland (at the time of our interview, the crime was 
still unsolved). Of her facial feminization surgery, she said, "And I would have never done it, but it became a matter of safety. You see, people like to murder you, they like to kill you up close, they like to see you die."

Kip also presented a narrative fraught with the awareness of danger. As someone visibly outside the gender binary, it was zher perception that ze was exposed to even more threat than the passing trans population. Ze described being raped, having the police decline to investigate the rape, several incidences of assault, and being verbally harassed in a threatening manner, particularly when using public transportation. Ze said,

I mean, goddamn, it gave me post-traumatic stress for sure. I had anxiety and all this stress and stuff and it was literally because I was being harassed every day. I mean, that's ridiculous. And I think that's a health consequence you have to take into account, too; I don't think it's just about taking testosterone or taking estrogen, but what kind of mental health medications are you going to need if you live as a non-passing person.

At the time of our interview, Kip's foot was in a walking cast, and at the beginning of our conversation ze explained ze had been in a car accident the week before. Kip brought up the accident again when we talked about passing. "Like after my car wreck, I went to my first response to getting in a car wreck, this is like sad but true, and I think it's really like a reality check - I was wearing a tie and I took it off before I called 911; that was the first thing I did." Kip's perception of normative pressure was such that ze feared zher gender unintelligibility would affect zher ability to get medical attention - a fear that is not unwarranted, as there are numerous documented cases of transpeople being denied life-saving treatment as well as routine healthcare (Stryker 2008; Davis 2001; Feinberg 2001). In fact, Jordan - herself a medical doctor - could not find a physician willing to 
treat her when she had kidney stones. She ultimately went to the surgeon who performed her SRS and asked for treatment.

A final aspect of normative pressure identified in the participants' responses was the regulation of the dichotomized gender model - specifically, the policing that occurs when individuals are visibly outside of that model. The genderqueer respondents located the source of this pressure in the mainstream culture at large, but - perhaps surprisingly also within the trans community, engaging once again the seemingly contradictory ways transgenderism both reifies and subverts the metanarrative gender dichotomy. Faced with what seemed like mounting pressure, Kip sought out the advice of a therapist and was able to secure a session with a counselor who is a well-known, out transman. After describing zher situation, ze was surprised at the counselor's response:

And he's like, well, you're going to have to make a choice. And I was like, what does that mean? And he was like, you're going to have to make a choice because people that don't pass - you'll just never make it. You're going either to end up a total alcoholic abusing substances or you're going to kill yourself. ... That's what a counselor said to me in my first appointment. A trans counselor. Like, 'you'll never make it like this.' ... I was like, wow, you're a really bad counselor. (Laughs.)

Hawthorne, who said zhe only came out as genderqueer relatively recently, relayed a narrative with similar themes:

I've been told already, like, pick one. Like, that kind of - yeah, totally, pick one. Like, 'oh, are you transitioning now to...?' It's still easier to, people really want one or the other, one or the other. And I even feel like a lot of people have been ... socially pushed into being transsexual, like going all the way because there's so much pressure going on there. And they over-embrace one set of stereotypes and almost reject the other entirely because they need to fit in that one to feel socially okay. More socially than internally, like, they might be like, well, I was 
still okay with that piece of me. And I feel the same way, like, I love my breasts, but - I'm already feeling that - pick one or the other-- and I'm going to continue to transgress as much as I - until I feel like I should pick. If I ever should.

These narratives were charged with a sense of frustration and the precarious situationality of gender unintelligibility, both within and outside of the trans and trans-friendly community (as discussed above, all were conscious of threats to their physical safety). On zher blog, Jamie described zher experience with top surgery as a genderqueeridentified individual:

The diagnosis for surgery on my paperwork was female to male transgenderism thus I was listed as male on all paperwork and on my wristband and was referred to as such by the staff. Although recognizing the importance of this for many other patients in these circumstances, it seemed to me another illustration of the idea that if you are trans identified you still have to pick male or female.

In our interview, Jamie echoed Kip's feeling that genderqueer individuals, by nature of their visibility, are at times subject to more discrimination and mistreatment than more legible members of the trans community. Ze summed it up at one point, saying, "You know, it's really shitty to live in a society in which you're kind of a second-class citizen."

-Personal Experiences with Engaging Gender for Conformity

Throughout the interviews, the respondents described their experiences of engaging gender in both cisgender and transgender/genderqueer contexts.

Over the course of the interviews, the notion of gender "performativity" was shown to be more problematic than I had anticipated at the outset of this study. When used in the interview questions, respondents' initial reaction to the term "performative" was slightly defensive; it was perceived as somewhat pejorative. However, the term was 
not meant to imply contrived action, just action - the actions, movements, behaviors, and other attributes associated with the embodiment of any particular gender (the doing of gender, as West and Zimmerman have termed it). I operationalize the term "performativity" as a way to refer to the actions of gender much in the way that Judith Butler (1999 [1990], 1993) uses the term in Gender Trouble and Bodies that Matter. The term's perceived implication of inauthenticity clashed with the respondents' gender narratives, which framed their individual gender enactment as the expression of the authentic self. All the respondents were clear that the personification of their selfidentified gender allowed them the lease to act, behave, move, speak, and play in the ways that were intuitive or "natural" to them, letting them present the authentic self that their cisgender identity had precluded. The unspoken but apparent mirror image of this axiom was that none of these aspects of self were artificial, constructed, or inauthentic.

The notion of performativity is salient in this context because while the impetus of the respondents' actions came from within, the respondents were still aware that most actions, movements, speech, and play interests are dichotomized by the masculine/feminine division that regulates socially acceptable behavior. Regardless of how natural or intuitive the action, the respondents were able to categorically gender (i.e., denote as male or female) each aspect of their embodiment, from "running like a girl" to "eating salad like a man." Once the intended use of the term became clearer, the respondents warmed to it. Devin said, 
Performative? Yes, right. I think I'm very conscious of how I'm acting, but I don't think I try and go overboard. ... I feel like trans people, we just study behavior so much, because we want to fit in, or don't, or feel like there's some kind of thing we need to do better or different.

Hawthorne also related being very conscious of the balance of femininity and masculinity transmitted by her personification:

I feel like I, just the way I feel like I have to portray more masculine is performative a lot of the time... I do feel like I'm being performative of this, in not wanting to be perceived as uber feminine and uber female and thus embracing these things that are masculine.

Even though their actions were "natural" in origin, the respondents were cognizant of doing them largely because they had been forbidden from doing so in their cisgender identities. The awareness of the gender-exclusivity of such actions was what these interviews ultimately measured. Because they were acutely aware of gendered behaviors, the respondents were able to report those behaviors, giving insight into the minutia of gendered being. (As will be discussed in the next section, the respondents were also in a unique situation to report the ways in which gender embodiment became embodiment - i.e., documenting the bodily changes which accompanied a shift in gender identity.) The respondents' initial list of actions done as part of gender enactment included depilation (including shaving, waxing, electrolysis, and laser removal) of facial and body hair; the lack of depilation (i.e., allowing body and/or facial hair to grow); alterations to the length and style of hair; the use of cosmetics, including consultation with professional makeup artists; voice and intonation lessons; binding breasts and/or 'packing'; nail hygiene (engaging in, or refraining from, buffing and/or polishing nails); and surgical alteration (sexual reassignment surgery; double mastectomy and 
reconstruction; breast augmentation; tracheal shave; facial feminization surgery; and, in Kerry's case, non-consensual genital reconstruction).

Each respondent also talked about the importance of dress and the 'right' kind of clothes; many spoke of layering clothing, wearing oversized clothing, or otherwise selecting garments based specifically on the characteristics they were perceived to obscure or emphasize. The genderqueer respondents described intentionally mixing gender markers so that clothing, makeup, and facial hair (for example) would be incongruous; Kip talked about favoring an outfit that consisted of zher beard, a shaved head, lipstick and mascara, a corset (emphasizing both zher cleavage and zher chest hair), a tie, fishnet stockings, and unshaved legs.

Several respondents described the ways in which they exercised. Devin, Sidney, and Hawthorne all specifically mentioned that it was important to them to be "strong" and "muscular," and all three designed their exercise with that goal in mind. Hawthorne and Kip both mentioned that their predilections towards physical strength to have caused considerable confusion in their cisgender contexts, and related stories in which recent observations of their physical strength - setting up big tables or lifting heavy boxes often caused unintroduced observers to subsequently "he" them (that is, their ambiguously presented gender was interpreted as male upon witness of physical activity). Avery described changing her manner of exercise upon transition; while she frequently lifted weights and engaged in other muscle-building activities while living in her 
cisgender (she was a college athlete), she stated that she now exclusively exercises aerobically and no longer lifts weights at all, specifically to avoid building muscle.

The respondents also described behavioral aspects of gender embodiment, in areas as far ranging as body language, posture, mannerisms, communication styles, display of emotion or - alternately - stoicism, display of affection, and courtesy/chivalry. Respondents described how transitioning allowed them to embody behaviors intuitive to them, and often they described what those behaviors were in terms of how they differed from cisgender expectations. Avery said that since transitioning to live as a woman, she was

comfortable with my hands more, sitting cross-legged, um. I usually try to take up as small amount of space as possible, and that just sort of lent itself to trying pass - as a man, those were uncomfortable things for me, as a male.

Most respondents evoked the way they walked; most MTF respondents said they had been harassed about "walking like a girl" or walking with a "wiggle" as children or teenagers; and the FTM and two genderqueer respondents said they had been harassed about walking in a masculine way, with a "swagger" or like they had "just gotten off a horse." Kerry, who identified as female but felt forced to live as a male, wrote in her questionnaire about the vigilance with which she monitors her walk (hers is the one with the self-described "wiggle"), body language, and overall persona, particularly when it comes to communication style and displaying emotions.

Normally I don't have the body language associated with males. In an "unsafe" situation, I am so tense \& stiff, and afraid of making the wrong move, saying the 
wrong thing, that I come across as just a tense controlled person. ... I hate conflict \& if I don't watch myself constantly, can become tearful immediately. I have to rethink anything asked of me. My initial response to almost any subject has to be scrutinized in my brain before I allow myself to answer. Why - well because I have learned that males \& females answer questions differently, they think things out differently. I studied the behavior of males since I was small in order to try and copy the ways they walked, run, spoke, laughed, used their hands, the way they stood, how they ate, sat, interacted just so I could stay alive. I guess it worked for the most part.

Jamie also spoke of zher awareness of the perceived masculinity of zher behavior, while simultaneously noting that the masculine-ness was not necessarily intentional:

I have adopted the body language of men, you know, I spread out [gestures to open legs while sitting in chair], which is more comfortable for me... And I was always kind of more masculine, you know what I mean. But, no, it wasn't a conscious choice.

Unsurprisingly, the trans respondents had insight into the performative expectations of their cisgender embodiments that was even more extensive than were their observations on transgender embodiment. In context of cisgender, the respondents embraced the terminology of performance, likening their cisgender personifications to a kind of cis-drag or a "game." In fact, the respondents uniformly reported that - excluding a period of overcompensation immediately following transition (which will be discussed in more detail below) - they were much more actively aware of/concerned with passing (and could more easily recall they measures they had taken to pass) in their cisgender identities than they ever have been as trans. A female person trapped in an inauthentic male embodiment, Kerry directly invoked the notion of performativity in the more pejorative sense. She wrote, 
I am a very good actress. In my world, I spend more time onstage than offstage. My situation dictates that I "appear" male, although people who know me well and personally absolutely understand that the image I portray is just that, an image and nothing close to who I really am.

Lindsay spoke about the limitations she felt in terms of embodiment:

I used to, [mimics noticing her own gestures] oh! You know, I'd catch myself being all feminine or whatever and around the guys I'm like 'oh shit!' ... Living as a male, I would occasionally pluck my brows, try to push the limits a little, seriously? ... It was like, 'ok, I'm getting a little too carried away here...' I would shave, I mean, even you know, my legs, I would shave all the time, and then it was like, now I gotta - can't wear shorts for like four weeks or whatever it would take for my hair to grow back, you know!

She also spoke about choices she made consciously in order to pass as male:

I mean, it was always there, I just thought I could do things to make it disappear; I thought I could get married, have a child - grow a beard, get a construction job - drive a big truck. ... I was like, ok, I'm doing all these manly things, look at me, ...you know?

Jordan's narrative was similar. When asked if she felt she had to be performative when living in her male cisgender, she said yes.

Well, if you've been doing it all your life - it was pretty hard and I didn't realize $i$, and the way I coped with it, is I did stuff. I could never sit on the weekend and not have 27 different things to do, and the day was judged by what I accomplished. ... bought a house, had a child, trying to be a doc, trying to be a dad - whatever that was, I had a pretty good example in my dad, but you know, I kind of faked it.

Several respondents also evoked performativity in a professional capacity at several points during the interview. Jordan related a story from her medical internship in which she watched a female resident calm an elderly, hyperventilating tuberculosis patient by embracing her and singing lullabies. Decades later, Jordan related the crushing feeling of realization that male doctors were not allowed to touch or comfort their patients in such 
ways, even though it seemed to her to be a very intuitive way of healing. In this anecdote, we see Jordon's realization that there was a qualitative difference between the roles of male doctor and female doctor, and that she had to perform accordingly.

Devin remembered having to dress up in a skirt or a dress for the first day of school all the way through high school and described this as a moment he became particularly aware of the performative expectations associated with his cisgender:

And I just remember that first day being like, okay, this is the game, this is how it's going to be - this isn't right, but I'm just going to have to play this game for you know, as long as I can handle it - and then... It just never felt-accurate, I don't know. It just felt weird. And I felt like, somebody else's body.

Sidney also spoke of divining 'the way things were supposed to be' and trying to act the part, at least in situations in which he was socially observable, like P.E. class.

I did wear a bra for a few years, even though I really never had a need for one. Because... I mean, I had to go to PE until sophomore year of high school, and like, all the other girls have bras, and I was like, I guess that's what I'm supposed to do too. ... I just did it for a while because it was what the other girls were doing, and I was like, well, if I'm a girl then I guess I'm supposed to do that. But it just never really - I always kind of felt like I was drag, I guess, although I didn't really know that at the time - I knew I wasn't comfortable, but I didn't know why. And now I'm like, yeah, because I felt like I was in drag and I wasn't comfortable that way.

Most respondents identified high school as a time during which they consciously made an effort to really embody their cisgender and conform to its expectations, in doing so satisfying familial, peer, and social pressure. Jamie, Devin, Hawthorne, and Sidney all consciously engaged in very traditional, heteronormative behaviors and (uncomfortably) invested in a corresponding appearance, cultivating long hair, applying cosmetics, 
wearing skirts, dating boys, and even (in one case) becoming a cheerleader. Avery said that she went through something similar in high school and college: "I went through a phase of being hyper-male [to kind of overcompensate]. Totally. ... I dated [girls] like crazy. ... And the whole time, I was doing the whole cross dressing thing."

As stated previously, the participants identified their overall gender presentation as a reflection of an authentic self. Even within that model, however, most respondents identified attributes of their current selves that they associated with their cisgender, which they consciously tried to eradicate; and attributes associated with their transgender which they consciously tried to adopt, however small or inconsequential. Lindsay acknowledged this and the active role of choice during our conversation about passing, saying,

You just start accepting, you're like ok, I can make changes, I can choose to eat healthier, I can choose to exercise, you know, I can choose to take care of myself better, you know. ... I can choose to go to voice lessons. You know, there's a lot of choices a person can make.

Devin described how he at times intentionally manipulates socially salient gender markers (e.g., body language) in order to pass as a more traditional male:

Like if there's some kind of situation where's someone kind of - like maybe if there's a drunk guy in the bar and he's kind of just being an ass or something and there's some kind of situation, then I'm going to be a bit, like more [flexes muscles like the Incredible Hulk] a little bit, and definitely have better posture and stuff like that - and it works, it's really funny - like people will back away.

Avery subtly acknowledged the way gender expectations affect her when speaking about gender that exists outside of the male/female dichotomy: 
For me, I don't think [gender] is changeable in the essence of back-and-forth, it's one direction. Um, you know, for others, it is, but not - I admire their ability to be in that space. It wouldn't be so much about finishing this transition process, it would just be about living out my life.

Implied in Avery's statement is the possibility that "just living out my life" could entail difference from "finishing this transition process," which in turn indicates that concerns about gender conformity (passing) have a conscious bearing, however small, on Avery's personification, in that the gender-appropriateness of an action, behavior, or appearance is gauged before it is enacted.

Although largely referenced in terms of small, everyday actions - from elevator "performance" (men are supposed to hang back and let women exit before disembarking themselves) to eating salad "like a woman" - this form of performativity was most often invoked when respondents spoke about "overcompensation," which most identified as a phase they went through when they first transitioned. Avery said that upon transitioning to living as a woman (after taking estrogen for two years while living as a man), "[I] was just hyper feminine, and over the top, and garish, to some degree. And now, it's justthis is me. In Gap. This is my style now. I shop at Gap and Old Navy, tee shirts and jeans. And that's me."

Sidney talked about this in terms of actively engaging "fag masculinity," which he was attracted to but hesitant to embody because he was afraid he would be perceived as female.

If I was more comfortable in my masculinity I might... you know, fag it up a little bit, but I'm not right now. [laughs] I feel like a lot - there's still some 
overcompensating, is necessary. I feel like I need to do things like, wear more typically male clothing and cut my hair shorter, and...you know, a little bit of the overcompensation because I don't feel as masculine as I would like to be. I mean, I do feel like there are certain things I have to do to appear more masculine. ... Yeah, sometimes I feel like I'm trying -- trying - to act stereotypically male, like making goofy - like making obscene jokes, or like joking around, like my girlfriend should go make me dinner, or something like that, but I'm not really serious, but.

Kip related frequently observing what ze perceived as overcompensation in the trans community:

And then, as they start to pass, there's some trans men that I've known-it's like, 'I want to date a really feminine woman,' or they have more of a tendency to date people that kind of make their gender seem more gendered, make them seem more masculine, in comparison, or whatever. I hate to say it, but I feel like I've known a lot of people who went through kind of a trophy phase, like, 'I want a girlfriend that makes me look more like a man,' then they kind of get through that, and then they're like, 'oh actually, I'm interested in men.'

Kip here articulates a phenomenon that most of the other "overcompensating" respondents also related: that the inauthenticity of complete conformity was often the doorway to further realizations of authentic self. These and other experiences imply that, although secondary to the model of identity that is defined by the authentic self, the notion of performativity as a consciously elected enactment is still somewhat salient as we approach transgender embodiment.

\section{-Gendered Bodily Change}

All respondents reported significant bodily change upon change in gender identity. The bodily change most often noted by the respondents was the sense of being at ease. Whereas they reported being tense, awkward, rigid, and clumsy when 
cisgendered and having vigilantly policed their movements, mannerisms, behaviors, and appearance; transitioning to their transgender identities freed them to relax and use their bodies more intuitively. The respondents reported this freedom as altering their physical relationship with space; each described the ways in which they took up more space (particularly in terms of hand gestures and the accessibility of affectionate touch for MTFs, and in terms of "spreading out" while sitting, style of walk, and general posture for genderqueer and FTM respondents) and, alternately, less space (particularly in terms of crossing legs, hunching shoulders, and posture for MTFs, and in terms of hand gestures, emotive touch, and other social interactions for FTMs) than they did in cisgender embodiments.

One of the ways Jamie addressed the physical effects of gender embodiment was in terms of the unintended physical consequences of zher genderqueer embodiment namely, binding and/or obscuring the appearance of zher breasts, prior to undergoing surgery. On her blog, she wrote,

The development of breasts was deeply upsetting to me and I tried to hide them as much as possible through wearing baggy clothes, sports bras, and hunching over. Unfortunately, this last technique to hide them has led to me having awful posture and a weak lower back that often tires and hurts a great deal.

Avery, who likes to say she's "5-12" [five feet, twelve inches - or, in layman's terms, six feet tall], described similar problems related to hunching her shoulders and stooping to deemphasize her height, which she felt was an impediment to passing. Though not necessarily in the traditional sense, both Jamie and Avery's actions were gendered and 
had very real implications on the body in terms of health and able-bodiedness as well as gender presentation.

Five of the respondents reported physical change attributed to elective surgery (not including Kerry, whose genital reconstruction surgery was done as an infant and was non-consensual). Surgeries utilized by the population included MTF sexual reassignment surgery, "top" surgery (double mastectomy and masculine chest reconstruction), breast augmentation, and facial feminization surgery, which included alterations to the brow, jaw line/chin, cheekbones, nose, and sometimes the trachea.

Eight of the respondents used either estrogen or testosterone; six respondents used these electively as part of their transition, and two (Kip and Kerry, who both identified as intersex) received them as treatment for a medically diagnosed condition. Though both Kip and Kerry said the use of hormones as treatment was ultimately a decision they made themselves, their decisions were framed in the contexts of medical diagnosis, medical advice, and familial pressures. The authority our culture attributes to medical doctors in particular cannot be ignored in assessing these respondents' choice to use hormones. Kerry experienced great distress when the effects of the prescribed hormone (testosterone) began to manifest. Upon discovery of her status as a genetic female, the fertility specialist Kerry was seeing gave her a massive dose of testosterone (without first explaining what was in the syringe), which catapulted her into puberty and started her menstrual cycle at the age of 32 . In light of health concerns and her own evident desire to identify as female, subsequent doctors advised discontinuing testosterone, but Kerry 
ultimately elected to continue using it in order to save her marriage and her relationship with her unborn child. Kerry experienced significant bodily change and wrote,

My whole body changed. I began growing from my height of 5'8" to 6'1". My body mass shifted, my feet grew (and as they did caused me considerable pain). My entire body grew and changed, and where I was almost hairless on my body before, dark course hair began to appear. ... My beautiful hair (on my head) began falling out. And facial hair appeared where there was none before. My voice changed.

At the time of our interview, Kip had recently begun taking estrogen as treatment for the hormonal "imbalance" attributed to PCOS (though ze mentioned ze had yet to start taking testosterone-blockers as zher doctors wanted her to). Ze said that every doctor ze'd seen since zher diagnosis at the age of 18 had pressured zher to take hormones and seemed to think that dangling the carrot of weight loss would make Kip automatically jump onboard with their proposed treatment. Kip did initially submit to treatment, taking a slew of medications, and had an extreme adverse reaction in which ze hemorrhaged and loss consciousness.

Like the whole thing was insulting. It was like, you're on this medicine because a), you're not woman enough, b) you're too fat, you know, it's all about fitting into some ideal that has nothing to do with who people are, that basically exists to try and simplify things that aren't simple, and sell you shit that you probably don't need, and I almost - died, you know what I mean?

Zher recent decision to take estrogen was tempered by zher mother's influence, which Kip said wasn't about disapproval, but about her concerns for Kip's safety and ability to make a living. However, Kip also mentioned being exhausted from the constant strife of living outside the gender dichotomy as playing a role: "it's fucking tiring, you know. So part of it too is just kind of oppression vacation. I feel like I'm on oppression vacation." 
The term "oppression vacation" referred to the fact that the estrogen almost immediately made zher appear more intelligibly female (in part because ze shaved zher face, having been warned zher facial would likely fall out otherwise). Kip also noted changes to zher weight, fat distribution, breast development, and subtle changes to zher overall silhouette. Ze also talked about changes in zher skin and face:

The skin is more sensitive - the skin change is almost immediate, that's probably the most obvious thing. ... When your skin's rougher, everything feels completely - like your physical experience of touching things is completely different. And how things feel in relationship to you - things that feel soft in relation to your skin are different, you know. ... And my jaw line changes somein four months my jaw line has changed some. And my eye structure has changed. And you can just tell, from pictures from before and from now, that certain facial things have shifted. And it's subtle, but it's really noticeable if you look at it over a period of time.

Many of these changes were echoed by other respondents. Also reported were changes to the vocal chords; hair growth and/or male pattern baldness; weight gain, changes in appetite, and changes in diet; changes in muscularity and subcutaneous fat; increase in height and/or foot size; differences in facial bone and musculature; breast development, and partial virilization of female genitals. Sidney's narrative detailed the changes he'd experienced:

Obvious things like facial hair, and ... then there's like muscle structure, just noticing - I mean, looking at myself and looking at some of my MTF friends like, our bodies change. They just do - I mean, like, you know, we, FTMs loose like the subcutaneous layer of fat, and like our fat kind of redistributes itself-like, I had kind small breasts to begin with, but now they're like gone ... your hips kind of slim out, you tend to get more of a, a little more of a gut if you're prone to that kind of thing. ... [And now] I just eat a lot. And I actually stopped being a vegetarian. And actually, so did my roommate - like, my roommate actually used to be vegan, and I used to be vegetarian. And he still doesn't eat dairy because he's allergic to it, but yeah, we both started eating like red meat again and white 
meat, because like, we just weren't getting enough protein, we just weren't. Yeah, hungry all the time. Yeah, lots of - I eat a lot of protein, and starch, and really filling things - I mean, I ate vegetables and stuff like that too, but yeah, a lot more protein than I used to eat. A lot more. Way more.

Many respondents listed appetite, weight change, and changes in diet (as related to appetite); all but two respondents reported weight gain (both Kip and Avery both reported losing some weight). The FTM respondents reported that their gain was mostly muscle mass.

The two respondents who did not use hormones (only one of whom used surgical alteration) also reported experiencing physical change, including increased muscle mass, diminishing secondary sex characteristics, and a more ambiguous silhouette. Jamie related the changes ze has experienced in addition to zher surgery mainly to zher relationship with space (and the freedom to use her body within it as is intuitive). Hawthorne also related feeling a great deal of physical change:

I feel a little bit awkward, a little bit bumpy, like I said, the physical, like I feel kind of awkward in my body, because of what's been going on. My breasts have calmed down, like, I have like $38 \mathrm{D}$ breasts, and like, I'm wearing bras that I didn't used to wear because I'm feeling my chest has actually like gotten smaller. It feels smaller, it feels like it's not taking up so much space. And, that's - that's definitely had to do with it, feeling where I'm at. Other than that, it's things likeI've noticed that because I'm not doing the things I used to do-like, I used to wax my face - like, I have quite a bit of facial hair - I grow facial hair more so than some men, and like -I've just taken note of it, and instead of reacting like I used to, which was like 'oh my god I've got to go get waxed' - I don't care. This is okay. And that is a physical characteristic change for me. I've waxed since I was in fourth grade. My mom started removing my body hair very young, because I was very hairy - like, I was one of those girls with the mustache and the side burns and so... noticing that again is a physical trait that has come with my masculinity. ... Is it a physical manifestation or is it, is it this biological acceptance of... [impersonates her body talking to her] 'you're not personally 
into that, so I can just be - more' - like, I feel more stable in my identity as my body kind of goes a long with it.

Even without hormone use, these respondents experienced bodily change in concert with their gender identities.

\section{Conclusion}

The ten participants in this sample each provided deeply personal narratives of gender identity, gender embodiment, and physical change. Respondents at times engaged size, sexuality, and socio-economic status as factors which intersected with gender in the formation of identity, but they each ultimately used the notion of an authentic sense of self to frame their personal identities. The transgender respondents' narratives explicitly framed their post-transition gender identities - and gender enactments - as the expressions of this authentic self.

An extension of the phenomenon that the respondents were more cognizant of the actions taken to pass as cisgender than as transgender, a fascinating theme emerged from the respondents' narratives when asked about the differences they perceived in themselves since moving from cisgender to transgender selves. Even though each had felt suffocated and restricted by the expectations associated with their cisgender and now felt 'freed,' the respondents often had trouble articulating exactly what was different about their lives outside of the superficialities like dress, hair, mannerisms, and depilation. Overwhelmingly, they expressed the sentiment that they were essentially "the same 
person," expressing a stability in aspects of identity across gender. Lindsay articulated this by saying,

I just behave the way I behave. (Laughs) So I don't know how I act different, you know? I like, do everything the same, pretty much. I do the same kind of work, I'm pretty much the same person. So what's different? I got an innie instead of an outie. (Laughs). ... I don't know how I'm different - I mean, back then, I used to get up, get in my truck, and go to work. Now I get up, get in my truck, and go to work. (Laughs)

Jordan also marveled at how her life was so much the same and yet so different at the same time.

It's always been intellectually fascinating to step back and marvel that someone could be raised as a male, live as a male for 47 years, be accepted in the community in a fairly commanding position, can so easily slide into being a female, like they've been that way all their life. I mean, I don't have any trouble being a girl. I mean, I still do some unladylike things - I've been told I don't eat salad very well. But, no, it's like I've always been this way.

Stability in identity across - or in spite of - gender identity invokes the absurdity of the metanarrative gender binary, which posits that only one type of person is suitable in a given gender.

This study refers to gender enactment as performativity (a term which, as discussed earlier, was initially problematic, but eventually resolved). The use of this term is not meant to imply that gender enactment is contrived or inauthentic; rather, it simply refers to the doing of gender, as gender is done both when it is authentic and when it is not. However, the doing of gender is usually so ubiquitous that the doers cannot identify it. Due to the trans population's uniquely situated positionality in respect to the gender binary, the respondents were aware that their actions, movements, speech, and interests 
are dichotomized by the masculine/feminine division that regulates socially acceptable behavior, and thus constitute doing gender. The respondents' awareness of the gendered content of such actions was what these interviews ultimately measured. Because they were acutely aware of gendered behaviors, the respondents were able to report those behaviors, giving insight into the minutia of gendered being. The respondents were uniquely able to report the ways in which gender embodiment - the doing of gender became embodiment.

Chapter Five will examine the findings in terms of the theoretical lenses presented in chapter two and will apply them in terms of the potential implications for feminist theory. 


\section{CHAPTER FIVE}

\section{Part I:}

Discussion

It's a privilege to not have to think about how you are embodied ... in the same way that white people never have to think about race.

SUSAN STRYKER, QUOTED IN THE RIDDLE OF GENDER, 2005

As far as I'm concerned, being any gender is a drag.

PATTI SMITH, 1998

My point is that every writer writes across gender. ... When Danny DeVito writes dialogue for Arnold Schwarzenegger, that's cross-gendered.

KATE BORNSTEIN, MY GENDER WORKBOOK, 1998

The narratives of the trans individuals discussed in the previous chapters give insight to the first-person, subjective experience of gender transgression and also provide a site to engage the postmodern feminist epistemology of material-semiotic intra-action (Tuana 1996). Throughout the interviews, the ten participants invoked the ways in which they consciously and unconsciously constructed their bodily and metaphysical identities; gauged notions and embodiments of masculinity and femininity; and did gender. Each of these actions was richly situated in the complex and interdynamic situationality of the respondents' lives; and in approaching the narratives with an inclusive, feminist epistemology, a picture of the respondents' gendered, sexually dimorphic bodies as material-semiotic productions emerged.

The first part of this chapter will assess the findings from the interviews in terms of my hypotheses (below). Part II concludes by evaluating this assessment in terms of its application to and implications for the feminist theory discussed in Chapter Two. 
The hypotheses follow:

H1: Individuals who consciously engage gender via the desire to change or otherwise transgress normative gender roles (e.g., trans people) gain a heightened awareness of the physically performative aspects of normative gender roles, and are able to manipulate this awareness in the embodiment of the desired gender role.

$H 2$ : Trans individuals experience sexually dimorphic bodily change to be a direct result of changes to their gender identity.

The goal of this research was to serve as an exploration of the role social construction plays in bodily sexual dimorphism and the ways in which it can be engaged by the study of firsthand gender transgressive experiences. The interview questions sought to examine, dissect, and deconstruct gender and how it was enacted by the respondents, in turn leading to an examination, dissection, and deconstruction of the ways in which sexual dimorphism was perceived, created/constructed, and reconstructed. The narratives of trans subjects offer access to a unique perspective because they embody a gender that may not typically correspond to their sex category; many have had experience living in both genders, and even more importantly, have had the experience of changing genders, or living beyond the gender binary. In the following analysis, I will discuss the findings insofar as they demonstrate support for, or departure from, the hypotheses, and I will suggest future avenues for further research.

Individuals who consciously engage gender

The view that gender is performative sought to show that what we take to be an internal essence of gender is manufactured through a sustained set of acts, posited through the gendered stylization of the body. ...[W] hat we take to be an 'internal' feature of ourselves is one that we anticipate and produce through 
certain bodily acts, at an extreme, an hallucinatory effect or naturalized gestures. (Butler 1999 [1990]: xv)

At the outset of this study, I hypothesized that trans individuals, through their desire to change or otherwise transgress cisgender roles, gain an awareness of the physically performative aspects of normative gender roles (H1). However, through the course of the interviews, it became apparent that my initial conceptualization of awareness was both undertheorized and situated in my own bias as a non-trans person and academic researcher. My initial usage of the term implied that the desire to change genders creates the awareness of genders (as if at that moment in time), when trans narratives revealed that it is, in fact, the other way around: the awareness of the genders specifically, the awareness of the rigid boundaries associated with each - coexists and cocreates the decision (and perhaps even the desire) to change genders. Awareness is not a separate entity from the decision; the awareness that one's intuitive identity is incompatible with one's cisgender is an inextricable part of the impulse to transgress the binary of sex-gender congruity.

Everyone in fact can be said to have an awareness of the boundaries - and thus the contents - of normative gender roles; as Eliot (2009) and Fine (2010) demonstrate, all brains and bodies are primed by immersion in the cultural metanarrative and a lifetime of associative learning as to male/female gender roles, including embodiments. The male and female scripts are imprinted in the brain by virtue of its immersion in them. (This is not to say that each brain is socialized as both genders, obviously - meaning that while 
both men and women can identify a mannerism or an article clothing as 'male' or 'female', it doesn't mean that a man knows not to wear a backpack with a skirt or that a woman can gesture like a man on cue.) But as Eliot and Fine also point out, the implicit associations that are the result of priming and associative learning are not the same as a conscious awareness or recall of this information; we are often simply left with a sense of "it just $i s$ that way." This is where my initial operationalization of awareness was half right: while still finding it difficult to articulate, the trans individuals who participated in this study displayed a greater degree of awareness of performativity than nontransgressive cisgender individuals typically display. However, my assumption that trans individuals would engage conscious performativity in their transgender embodiments - rather than in their cisgender embodiments - proved to be false. The respondents overwhelmingly framed their trans embodiments as expressions of an authentic self, and instead located conscious performativity largely in the context of their pre-transition cisgender identities.

The notion of performativity proved to be salient in this context because while the impetus of the respondents' actions came from within, the respondents were still aware that most actions, movements, speech, and play interests are dichotomized by the masculine/feminine division that regulates socially acceptable behavior. Regardless of how natural or intuitive the action, the respondents were able to categorically gender (i.e., denote as male or female) each aspect of their embodiment, from "running like a girl" to "eating salad like a man." 
And, as indicated above, cisgender performativity initially proved to be a much more productive site of discussion than transgender performativity. The trans respondents had insight into the performative expectations of their cisgender embodiments that was more extensive than were their observations on transgender embodiment. In context of cisgender, the respondents embraced the terminology of performance, likening their cisgender personifications to a kind of cis-drag, a "stage," or a "game." In fact, the respondents uniformly reported that - excluding a period of overcompensation immediately following transition, they were much more actively aware of/concerned with passing (and could more easily recall they measures they had taken to pass) in their cisgender identities than they ever had been as trans. Once it became clear to the respondents that the operationalization of performativity did not necessarily imply the inauthenticity, just the acknowledgement, of actions, the respondents were able to engage the term in the contexts of their transgender embodiments as well (though to a lesser extent). While their trans-embodied actions were "natural" in origin, the respondents were cognizant of doing them largely because they had been forbidden from doing so in their cisgender identities.

As they approach trans embodiment, trans individuals are not approaching difference for the first time. The differences are already crystal clear. Trans people are always aware of the limits of gender roles because throughout their lives, it has been made clear that their predisposition to certain behaviors, activities, or aesthetics are permissible for one gender but not the other. Their performative awareness was thus 
forged through a deeply personal process of elimination, trial and error, and negative and positive reinforcement.

The respondents' narratives are thus filled with clear-cut awareness of cisgender doing and lesser awareness of transgender doing. Jamie, who is genderqueer and does not identify with either male or female, felt incredibly restricted by the expectations of zher cisgender and gave several poignant anecdotes of trying to fit in, evoking performativity. But when speaking about the ways zher current identity is performed, ze said, "it's hard for to me to recognize the ways I don't have gender, because it's who I am and it's my everyday experience and sometimes I forget that it's different." As Judith Butler (1993) notes, it is exceedingly difficult to identify the doing of naturalized performance. This does not mean, however, that we cannot assess the performativity (again, in the non-pejorative sense) of gender in trans narratives: rather, we are given two sites imbued with information. The cisgender performativity the respondents evoke is stark, and provides the first site. By contrast, the full richness of trans performativity must be read not only in the articulation of the respondents, but also in the negative spaces left by the cisgender narratives of performativity that is intentionally not done.

As such, the findings in relation to $H 1$ are mixed. While the interviews demonstrated that the respondents did indeed possess an awareness of gender performativity, this awareness was engaged as an implicit rather than active agency in the process of transgender embodiment. Subjectively, the respondents identified their trans 
embodiments as expressions of an authentic self free from the contrived performativity experienced in their cisgender embodiments.

Nevertheless, there was evidence that performativity, in the more active sense, still played a factor in trans embodiments, particularly in that the participants described trans embodiment largely in terms of what they were told not do when in their cisgender embodiments, and in what they perceived to be cisgendered remnants that they avoided doing in their trans embodiments. Trans embodiment was thus largely described in terms of what was not done rather than what was done. Though I was left to extrapolate the active manifestations of trans embodiment from the negative space left behind, the respondents' conceptualization of not doing still demonstrates their conscious reference to and utilization of gender norms in terms of seeking intelligible conformity, and thus constitutes the intentional - though relatively marginal - use of performativity, which supports $H 1$.

Individuals who experience sexually dimorphic change

The second hypothesis conjectured that trans individuals experience sexually dimorphic bodily change as a direct result of changes to their gender identity $(\mathrm{H} 2)$. When engaged through a feminist epistemology of material-semiotic intra-action, I found strong support for $H 2$ in the narratives of the interview participants.

The respondents' narratives revealed their embodiments to be complex materialsemiotic intra-actions. The gendered body is a complex construction: we are often 
temped to attempt to separate the aspects that are bodily (i.e., sexual dimorphism) and those that are superficial (e.g., style of dress, hairstyle, makeup, depilation, body language/mannerisms, vocal cues, etc). The intra-active epistemology, however, argues that it is in fact impossible - not just difficult - to separate factors, since neither of these things exists in an essential form outside of its interactions with the others. As Butler observes and Tuana later reprises, the body is "always already" informed by culture and culture is "always already" informed by the body. As such, both bodies and culture are always each other, and each phenomena must be considered an interaction rather than an individually agentic actor. The narratives of trans individuals provide a richly accessible site for the observation of material-semiotic phenomenon in that their changing identities make the dynamic production of the trans body transparent, whereas the cisgender production of the body is usually opaque. The respondents were uniquely able to report the ways in which gender embodiment - the doing of gender and the not doing of gender became embodiment.

All ten interview respondents reported physical change upon transition to their trans identities. They attributed their physical changes to the change in their identities in a variety of ways: the respondents evoked changes in exercise, diet, and spatial orientation; body language, posture, and mannerism; hormone use; and surgery. Each of these measures may be seen as located within, and in fact co-produced by, a matrix of complex interrelation with metanarrative gender expectations, subculture expectations (i.e., the trans community), environment, socio-economic status, sex, sexuality, and body. Hormone use is engaged as an example of material-semiotic intra-action below. 
Eight of the ten interview/questionnaire respondents used either testosterone or estrogen. Again, from the metanarrative perspective, it is tempting to attempt to conceptualize the physicalities resultant from hormone use as separate from the physicalities resultant from the active embodiment of gender, even though both of these factors tend to commence simultaneously and unavoidably intersect. However, it is precisely the intersection of factors that is engaged in this study's exploration of gender embodiment. It is Tuana's (1996) argument that even if we could separate the influences of the two factors - which we cannot, since they do not exist except in relation to each other - we shouldn't want to, since addressing only one set of (artificially) binary factors leaves us with an incomplete and inaccurate rendering of the actual interaction that has occurred. Furthermore, she implies that no one factor is more important or more "natural" than another: since the concept of a pre-existing "natural" state with its own agency and determinism has proved false, we understand that the body does not exist independently of culture. Ergo, we cannot hold what we perceive to be bodily-driven factors to be more important or more "natural" than factors wrought from what we perceive to be strictly cultural constructions. The body's biological release of hormones does not supersede in relevance or meaning an individual's choice to alter those hormones based on ideations of gender conformity or physical change; both are factors in the production and definition of identity and embodiment. Jamie addressed this when we spoke about physical difference between men and women; ze stated ze did not see physical difference as such: 
I think hormones - well, maybe, ok. It's maybe not still a physical difference; it manifests a physical difference. ... [G]iven, the main hormones that you're on, that manifests a physical difference, be it breasts or facial hair or voice or fat distribution. But I wouldn't - I make the qualification that [the physical difference] is not between biological "men" and "women," because obviously, if you do have somebody on hormones, they manifest that. It's mostly biologically related, but anyone's who on hormones could, too.

Jamie here intuits the role of hormones as an agentic choice that interacts with the body: it is a choice when cisgender individuals opt not to alter their hormones just as it is a choice when trans people choose to take synthetic hormones; either way, the choice affects embodiment.

Many critics dismiss the significance of transgressive passing on the basis that the use of synthetic hormones or surgical alteration are somehow "artificial" agents of change, thereby valuing "natural" as the sole factor in legitimate change. However, we see that "natural" is also a construction: in fact, those very same methods - synthetic hormone use and the surgical alteration of genitalia or facial features - are seen to normatively restore naturality when given by medical professionals to patients with hormone "imbalances" (like Kip, who felt like ze was told zher condition rendered zher "not woman enough"), when used to treat and surgically reconstruct intersex babies (like Kerry), or when individuals who do not conform to normative ideals of beauty undergo plastic surgery. Hypocritically, when these methods are approached in ways that are culturally legitimated, their "naturalness" goes uncontested. It is thereby evident that the real issue with transgressive passing is not that it is not "natural" - since "natural" is a culturally-specific construct just like any other - but that it is subversive to the metaphysic that legitimates the entire metanarrative structure of gender hierarchy. A 
trans person's choice to use hormones or surgical alteration is no less authentic than any of the other factors which together produce embodiment. The choice to use hormones cannot in fact be separated from any other factor of gender embodiment; the gendered body is a richly material-semiotic, epigenetic object that may only be considered in the context of the intact narrative.

As such, the narratives provided support for H2. All ten respondents experienced far-ranging bodily change (including, it is worth noting, the two respondents who did not use hormones). Their narratives of personal embodiment were richly contextualized in constructions of personal safety; their perceived locations on the continuums of normative masculinity and femininity, and their fluidity within; authentic expression of self and performativity; passing; and identity. The complex interaction of all these factors - social, cultural, environmental, body - together form the ongoing production of the gendered body.

Kip's presentation of identity is in itself a salient illustration of the materialsemiotic interaction in the way ze explicitly frames zher gender identity as an interaction with zher intersexual body. While the perpetual, everyday plasticity of the body is usually opaque to most people due to what is at times the excruciatingly slow nature of change, Kip's PCOS and its dramatic bodily changes brought zher conceptualization of bodily agency into focus. Kip was queer-identified prior to the virilization of zher disease and stated that though nonconformist, ze was not sure if ze necessarily would have come to the genderqueer identity if zher body had stayed within the range of 
"normal." But it did not, and Kip largely embraced zher emergent embodiment; zhe said, "That's body - and to me, that's gender." Thus, Kip considered zher body the primary informant in the construction of her gender identity, though she acknowledged the interplay of other factors, including zher sexuality and her corresponding social position as queer.

Kip's presentation of identity frames the material-semiotic in precisely the subversive light Nancy Tuana intends: Kip's emergent identity relied not on the binary of purportedly ontological boundaries of nature/culture, mind/body; sex/gender, but called out the binary metaphysic for what it is: nonsense.

If you had asked me when I was seven if I was a girl, I would have yeah, but I think that's also kind of misleading if you haven't really been presented with anything else at that point. ... I think if children were given more options about how to identity, they'd choose more things, but because you're just sort of ingrained, girls act like this and boys act like this, and they've got cooties, and you know? ... because your gender, your sex shouldn't be determining anything about your personality or how you behave in the social realm. ... I would much prefer it if it just - I would just like to see it all blow up.... But that's probably - I mean, I feel that's the conclusion everyone would come to if they had a different lens to experience life, you know? I think that's one of the benefits and one of the pitfalls, I think of not fitting physically into one of those categories, like not passing, you know? Because you see one side when you're passing that you never see when you're not passing, and there are more people offended across the board when you don't pass.

Kip's position outside of the binary of intelligible gender allowed zher to reapproach the metanarrative constructions of male/female, nature/culture, sex/gender as constructions themselves - ones that have very harmful implications, as ze addressed later in the interview in terms of normative pressure and personal safety. Zher understanding of the metanarrative construction as incomplete and incorrect led zher to the desire to see it all 
"blow up." Nancy Tuana argues that such material-semiotic interactions, when subversive to the metanarrative's cosmogony of ontological difference, "explode" the binary metaphysic upon which it is based (65).

In "Fleshing Gender, Sexing the Body," Tuana (1996) actually argues that transgender individuals, while nevertheless sites of the material-semiotic production of identity, do not constitute the same subversive intra-actions as do productions of identities that lie outside of the gender binary entirely, like the travestis of Brazil or, I would imagine, genderqueer Americans. Her argument is based in the transgender reliance on the metanarratively constructed gender binary and its inherent posturing of "true" sex - a notion which, when deconstructed, belies its situationality within an entire matrix of one-directional, oppositional binaries which, purportedly ontologically, hierarchically position identities and disproportionately benefit some over others. Conceptualizations of "true" sex or "true" gender imply pre-existence, discrete agency, and the valuation of "natural" as an untouched-by-humans dictum of righteous biological determinism, and in relying on the notion of "true" sex or "true" gender, transgender individuals reify the binary metaphysic that restricted them in the first place. She argues that even adding a third sex/gender category does not subvert the underlying binary, as it preserves the nature/not nature binary: "To add to the number of sexes reinforces the view that there is some sort of biological truth to sex, that there is behind the confusion truly a true sex. But such a position also eradicates the complex intra-action involved here" (65). 
I argue, however, that Tuana has severely undertheorized and underestimated the transgender identity. Tuana makes the distinction between the travestis and transgender individuals based on an abstract understanding with no grounding in the narrative subjectivity of trans individuals - nor a sociological examination of the phenomenon of transition and its implications to metanarrative notions of ontological linearity and cohesion. As Lorber (2001) writes, "Treating passing transgenders as unproblematic members in their new status masks their past history and on-going strategies of careful gender construction, data that is rich in the practices of how we all do gender" (126). Tuana, however, fails to realize the ways transgenderism subverts the discursive construction of sex-gender congruence even when located within the normative identities of "male" and "female." While some trans individuals do resolutely honor binary sex/gender (and male/female as "true" genders) in their personal philosophies, they nevertheless subvert the linearity and biologically determinist underpinnings of the metanarrative, just as effectively exploding its underlying metaphysic. Judith Butler (1999 [1990]) acknowledges this site of resistance in Gender Trouble in the context of heteronormativity:

The repetition of heterosexual constructs within sexual cultures both gay and straight may well be the inevitable site of the denaturalization and mobilization of gender categories. The replication of heterosexual constructs in non-heterosexual frames brings into relief the utterly constructed status of the so-called heterosexual original. ... The parodic repetition of 'the original' ... reveals the original to be nothing other than a parody of the idea of the natural and the original. Even if heterosexist constructs circulate as the available sites of power/discourse from which to do gender at all, the question remains: What possibilities of recirculation exist? Which possibilities of doing gender repeat and displace through hyperbole, dissonance, internal confusion, and proliferation the very constructs by which they are mobilized? 
If repetition is bound to persist as the mechanism of the cultural reproduction of identities, then the crucial question emerges: What kind of subversive repetition might call into question the regulatory practice of identity itself? (42)

The transgender embodiment of "male" or "female" is parodic in Butler's estimation in that it demonstrates the constructed nature of those categories which are ostensibly naturalized; embodying while at the same time subverting the categories by denying their basis in the ontological and congruent linearity of sex and gender.

Tuana lacks an understanding of the ways transgender individuals subtly destabilize and provide pushback to the normative conceptualizations of "maleness" and "femaleness." Though framed in reference to the metanarrative's rather Leave-It-ToBeaver-esque gender archetypes, this study's trans respondents nevertheless displayed a wide range of diversity in their particular embodiments of masculinity and femininity. As discussed in the findings, most respondents related undergoing a period of "overcompensation" immediately following transition in which they attempted to personify either hypermasculinized or hyperfeminized caricatures, "like Barbie," but also reported their ultimate discoveries that a truly authentic expression of self was not served by rigid conformity, even to the gender role they'd long desired to embody. Rather, they found the authentic self to be comfortably located in the "blend," in the fluidity between things masculine and things feminine. Lindsay described this realization by way of an anecdote in which she described her post-transition "obsession" with passing:

It used to drive me nuts. ... Up until probably, I don't know... a year ago, we'll say, somewhere in that area - I would not leave the house without putting makeup on. Then it finally got to the point like ...'this is a lot of work!' you know, seriously. So, I'm going to the store, I'm putting on sweats, tee shirt, and that's it. Sandals... you know. And then get called ma'am. You know, it's like ...wow. 
You know? Yeah. Sweet. (laughs). It's like one of my biggest accomplishments, seriously, you know?

When Lindsay realized she could pass without engaging in the performativity she felt was prescribed by metanarrative expectations, she felt freed to include in her personification of femininity aspects of herself she did not initially operationalize as such, including her profession (plumber) and preferred wardrobe (tee shirts and jeans, rather than the skirts and dresses she felt were compulsory on an everyday basis before). In this unique negotiation of identity, trans individuals thus subtly alter the range of acceptable behaviors, actions, and embodiments located within traditional definitions of masculinity and femininity - in so doing, implicating the ongoing production of "traditional" itself.

The transgender appropriation of masculinity is a particularly salient site of subversion. As noted in the findings, all FTM respondents expressed a lifelong compulsion to be male-identified and male-embodied, but each also stated they had no desire to conform to the metanarratively normative male gender role, as did the genderqueer respondents. As Sidney said, "I don't want to conform to the stereotype because I don't like the stereotype." Each noted how limiting and repressed they found normative masculinity; "closed-off," "stoic," and "emotionally repressed" were all terms used. As an expression of their desire to be male and yet still destabilize the traditional operationalization of masculinity, the respondents engaged the countercultural embodiment of "fag masculinity": as Devin said,

Um, I don't think [I conform the male gender role] - and that is kind of confusing as well, because -- I think in some respects like, if you want to get real 
stereotypical, I like camping and fishing and I do construction work, but, you know, when I got out, I'm kind of gay in the respect of like flaming or somethinglike, I like to like dress up and wear skirts in drag kind of stuff, and do kind of performance stuff, and I write poetry, and stuff like that. And I feel like it's really important to be this kind of male person that I am, that is a little more expressive, cause I don't want to get locked into that, like, how men are brought up to not express their emotions and not you know, express themselves and be whole human beings; because I think we all have a little bit of everything, you know? Everybody does, so it's just not - I'm just fighting against it a little bit. It kind of puts me at risk, like, maybe not fitting in, or not like passing all the way, or not like, whatever. I just can't-once you get to this point of trying to be yourself, it's not worth it to tuck things away, I don't think. It's too hard.

In pushing the boundaries of intelligible gender by engaging constructs like fag masculinity, these trans individuals opened the previously dichotomized genders to new operationalizations and embodiments, and in so doing subversively "exploded" the hegemonic structure of binary exclusivity.

\section{Transgenderism and the metanarrative}

Our cultural metanarrative identifies "ontological" sexual dimorphism as naturally occurring evidence and justification of the differential abilities and thus differential gender roles of the sexes. The inequalities between the gender roles are largely legitimated by the physical (non-genital) differential said to exist between the sexes. If this sexually dimorphic physical difference could be demonstrated to be in itself a production, rather than a naturally occurring "fact," the metanarrative which prescribes stratified gender roles loses its justification and thus its validity.

In the theoretical sphere, the discussion of transgenderism demonstrates that while sexual dimorphism is in fact a construction and can be reconstructed, it also renders the conceptualization sexual dimorphism as a limiting and exclusive structure of ability 
irrelevant and subverts the underpinnings of the entire cultural metanarrative. If individuals are able to either re-construct or visibly subvert sexual ("natural") dimorphism, obviously, categories of natural sex (and sexual dimorphism) do not function as ontologically restrictive to the sexes' corresponding genders, and in fact demonstrate the construction of what was ostensibly "natural." Sexual dimorphism is in fact irrelevant to individuals' potentialities. The precept that there are inviolable physical differences that separate the male and female cisgenders is shown to be a construct rather than a biological "fact" - a construct which then becomes subject to the actor's ability to reconstruct or deconstruct it.

Bodily sexual dimorphism, however, has the same cyclic nature that is noted of the gender metanarrative itself: as males and females engage in actions segregated due to beliefs about sexually dimorphic physical ability, those actions in themselves affect the body and its abilities. If men are always asked to lift big items and women to sit it out, men develop muscle mass and women do not. If women are always asked to nurture, the will be attuned to others' emotions and men will not. As Butler noted, the presumed difference is in fact manufactured by our anticipation of it. Trans people disrupt the metanarrative of restrictive cisgender materiality in their appropriation of gendered embodiment: as they construct the transgender appearance and change the gendered aspects of their behavior, even those who do not use hormones or surgery found that as they ceased cisgender performativity, their bodies began to lose explicit gender 
intelligibility; and as they adopted transgender actions, their bodies began to conform to the physical expectations the metanarrative holds as "natural" only to cis-sexuals.

From the theoretical standpoint, in trans bodies, the material and the semiotic meet in the expression of identity and the conscious construction of embodiment. In making the ontologically "impossible" shift, transgenderism demonstrates that embodiment is a complexly negotiated and interwoven interaction. Bodily agency presents no universal physical limitations which would prohibit the embodiment of either gender, regardless of the sex (or sexual dimorphism) of the body. Through intentional sculpting and the exponential accumulativity of gendered action, among other factors, the manifestation of sexual dimorphism is produced. This study explored the lived bodily experience of this manifestation in the narratives of ten individuals. 


\section{Part II:}

Conclusion

I deny that anyone knows, or can know, the nature of the two sexes, as long as they have only been seen in their present relation to one another. If men had ever been found in society without women, or women without men, or if there had been a society of men and women in which the women were not under the control of the men, something might have been positively known about the mental and moral differences which may be inherent in the nature of each. What is now called the nature of women is an eminently artificial thing - the result of forced repression in some directions, unnatural stimulation in others.

JOHN STUART MILL, THE SUBJECTION OF WOMEN, 1869

And if you want to be free, be free / Because there's a million things to be.

CAT STEVENS, IF YOU WANT TO SING OUT, SinG OUT, 1971

-Summary

I approached this research with the primary goal of exploring the lived experience of the construction of sexually dimorphic bodies through the narrative experiences of trans individuals. Narratives were gathered through in-depth qualitative interviews, in which the participants shared deeply personal and richly situated stories, touching on the themes of identity, conformity, performativity, difference, subversion, and the authentic self. I hypothesized that trans individuals participated in an active performativity of gender in order to achieve gender conformity in the transgender context, and that this performativity played an active role in the physical production of the sexually dimorphic transgender body.

I utilized Judith Butler's (1993; 1999 [1990]) terminology of performativity and Nancy Tuana's (1996) epistemology of material-semiotic intra-action as lenses with which to approach the trans narratives. My findings suggest that trans performativity is a 
somewhat polemical concept that must be approached with respect for each respondent's subjectivity. Trans embodiments of gender were framed as the expression of an authentic self, rather than evoked performativity; nevertheless, it was found that trans individuals do possess a more extensive performative vocabulary, as it were, and were thus able to articulate the ways negotiations of embodiment were engaged, both in terms of what is done and what is not done. Further, the findings suggest that trans individuals experience sexually dimorphic bodily change in concert with changes in their gender identities as a result of the complex material-semiotic intra-action that negotiates identity and embodiment.

Throughout this research, it was my goal to honor the subjectivity of the respondents' narrative experiences while still negotiating the significance of transgenderism in the larger theoretical sense. Too often, academics use marginal identities, particularly the intersex and trans identified, as theoretical "pawns" without first grounding their operationalization in the reality experienced by those individuals. Nancy Tuana (1996) in particular is guilty of this in her under-theorization of transgender identity in "Fleshing Gender, Sexing the Body." Judith Lorber (2001) also addresses this balancing act:

The lives of transgenders can be examined from the standpoint of transgendered people and communities, but they also provide grist for a critique of the gendered social order. Those who successfully construct their gender against their sex assignment, whether through cross-dressing or surgical alteration of genitalia, may reaffirm the conventional categories of man and woman, but their own behavior has sabotaged the solidity of the categories. In Garber's words, anyone who passes successfully (by crossing the boundaries) possess an 'extra-ordinary 
power ... to disrupt, expose, and challenge, putting into question the very notion of the 'original' and of stable identity.' ...[S]uccessful passers subtly undermine the gendered social order. (126-127)

It can be problematic to discuss transgender as a larger concept without negating the autonomous experience, but hopefully I have proved it possible. Herein, transgender narratives provide the deep richness of subjective identity while also allowing a treatment of transgender as a larger concept insofar as it can push and test the boundaries of the discursive gendered model.

-Can Gendered Behavior Be Reasonably Understood to be a Factor in the Production of Sexually Dimorphic Bodies?

In Pink Brain, Blue Brain, Lise Eliot (2009) describes the way neuroscientists now conceive of the brain: while the brain was previously believed to adhere to an "additive model" of biology (a concept which relies on the valued binary of natural, preexistent ability), it is now evident that the brain actually functions on a model of plasticity. Eliot writes, "the brain actually changes in response to its own experience. ... Simply put, your brain is what you do with it" (6). She goes on to write, "So it's all biology, whether the cause is nature or nurture" (7). Everything we do, see, say, or hear is inscribed into our brain, thus becoming our brain. I argue that we must apply this same understanding of plasticity to the body as well as the brain.

As it is in neuroscience, engaging the concept of plasticity does not imply infinite capacity for transformation in the sense that the brain nor the body cannot take the form of anything; its materiality is still an agentic actor in the production. Plasticity is infinite, 
however, in that it never ends: each day, each moment, each minute action contributes to the ongoing and perpetual production of embodiment. When we do gender inherently in every action, behavior, gesture, movement, and choice, how could we believe it wouldn't have an effect on our embodiments?

Tuana (1996) asserts that phenomena approached with anything other than an epistemology of material-semiotic intra-action essentially leaves us with misunderstanding: when viewed through the rigid structures of binary ontology, we restrict ourselves to only a myopic and perhaps nearsighted conception of the object. I find this true in relation to our culture's attitude about the physical difference between men and women, which is resolutely framed strictly in terms of the "natural" side of the nature/culture, male/female, body/mind, sex/gender binary system: refusing to consider any factors other than the ontological and so-perceived biological determinism of the body in the production of sexual dimorphism is short-sighted and betrays a severely limited sociological imagination. In doing so, we delegitimize our contributions and deny our own agency in the construction of our experiences and identity.

Like in the body, the manifestation of embodiment in the brain is subject to the interpretation of those situated in the cultural metanarrative of ontological difference; and like the body's sexual dimorphism, differences found in the brain are often held up as "evidence" of that selfsame ontology. Fine addresses the conflation that often occurs between differences that may be result not of ontology, but rather the imprinting of a lifetime of gender, and difference that is held up as "natural": people are all too ready to 
equate "actual nature" with "brain." But really, when you think about it, where else but in the brain would we see the effects of socialization or experience? As Mark Liberman puts it, "how else would socially constructed cognitive differences manifest themselves? In flows of pure spiritual energy, with no effect on neuronal activity, cerebral blood flow, and functional brain imaging techniques?" (170)

I argue one should also apply this to the body: how else would a lifetime of gendered action be manifest but in the body?

The findings concur, suggesting that gendered behavior, as a major actor among phenomena in the material-semiotic production of identity, can indeed be reasonably understood to be implicated in the manufacture of embodiment in the case of the respondents.

-Implications for Feminist Theory

When such categories come into question, the reality of gender is also put into crisis: it becomes unclear how to distinguish the real from the unreal. And this is the occasion in which we come to understand that what we take to be 'real,' what we invoke as the naturalized knowledge of gender is, in fact, a changeable and revisable reality.

...no political revolution is possible without a radical shift in one's notion of the possible and the real. (Butler 1999 [1990]: xxii)

A critical engagement of gender transgression and its implications invite new theory and new options to feminism and other agendas that seek to alter or abolish the discursively gendered patriarchal model.

Both Judith Butler (1999 [1990]) and bell hooks (2000 [1984]) identify the mainstream feminist agenda as a movement to achieve male-female equality at face 
value: that is, to provide women with a share of all the benefits men have typically enjoyed in this society, rather than to redefine the gender binary in a way that would not still rely on the maintenance and perpetuation of racism, classism, and other exploitative hierarchies (hooks 46). Unfortunately, the expression of feminism as women finally wanting their share of the privilege men have always taken for granted necessarily pits the two genders against each other: in the fight for finite hierarchical, phallocentric privilege, men stand to lose out if women gain, and are therefore automatically threatened by and opposed to feminist movement. Due to its ingrained ontological bias, mainstream feminism is not phrased or operationalized in a way which posits that both genders - and indeed, all people - have a tremendous amount to gain from feminist movement and revision.

The material-semiotic operationalization of bodies provides both a point of departure from the fallacious metaphysic of binary opposition (within which feminists are forced to attempt to dismantle the master's house with the selfsame master's tools), and in particular the downright subversion of the metanarrative gender cosmogony. The material-semiotic examination of trans bodies holds the potential to demonstrate that the genders nor the sexes are ontological in origin, nor are they nontransgressable. Trans bodies have the potential to demonstrate that sexual dimorphism is not a manifestation of biological determinism, but a product of bodily plasticity formed out of the interrelation of the enactment of gender, the environment, and the body, et al. If the physical basis for the gender metanarrative's mythic gender hegemony is destabilized by such examinations 
of trans bodies, feminists would have the opportunity to use the knowledge gleaned therein in ways which engage further subversion to the extent of explosion.

In turn, explosion provides a site for a feminist revisioning of gender epistemology. Tuana envisions a destabilized reimagining of gender which understands the interplay of body and culture to be both "material-and-semiotic," thus avoiding determinist dichotomies: "we should not treat inscriptive and phenomenological accounts as an either/or choice, but rather as different approaches for creating embodied philosophies" (59, emphasis added). Judith Lorber (2001) in turn recommends destabilizing the gender categories; she writes,

In short, because it includes men, attends as well to other subordinating social statuses that also have to be undermined, but most of all, because it directly challenges the structure and framework of women's oppression and inequality, a degendering movement is what I would like to see as the feminist politics of the new century. (132)

Understanding the body as an agentic actor in the production of embodiment, rather than a site for divisive biological determinism, provides feminist theory and feminist action with a point of departure from the metanarrative model of ontological binarism. In its ability to subvert the binary metaphysic and engage the construction of embodiment so as to reduce, rather than emphasize, difference, feminism has an opportunity to advocate for new model of gender - or degender - that can account for intersectional justice and move beyond its current limitations. 


\section{REFERNCE LIST}

Ablow, Keith. 2011. "J. Crew Plants the Seeds for Gender Identity." FOX News. Retrieved August 3, 2011 (http://www.foxnews.com/health/2011/04/11/j-crewplants-seeds-gender-identity/\#ixzz1U0GWz5Xp).

de Beauvoir, Simone. 1952 (1949). The Second Sex. New York: Everyman Books Alfred A. Knopf.

Bloom, Amy (2002). Normal: Transsexual CEOs, Cross-dressing Cops, and Hermaphrodites with Attitude. Random House, Inc, New York.

Butler, Judith. 1999, 1990. Gender Trouble: Feminism and the Subversion of Identity. New York: Routledge.

---. 1993. Bodies That Matter: On the Discursive Limits of Sex. London: Psychology Press.

Chick, Kay A, Rose Ann Heilman-Houser, and Maxwell W Hunter. 2002. "The Impact of Childcare on Gender Role Development and Gender Stereotypes." Early Childhood Education Journal 29 (3): 149-153.

Davis, Kate. 2001. "Southern Comfort." [videorecording]/a Q-Ball Productions Film. New York City, New York: HBO Theatrical Documentary USA.

Dreger, Alice Domurat. 1998. Hermaphrodites and the Medical Invention of Sex. Cambridge: Harvard UP.

Dworkin, Shari. 2001. "'Holding Back:' Negotiating a Glass Ceiling on Women's Muscular Strength." Sociological Perspectives 44 (3): 333-350.

Eliot, Lise. 2009. Pink Brain, Blue Brain: How Small Differences Create Troublesome Gaps - and What We Can Do About It. Boston, New York: Houghton Mifflin Harcourt.

Feinberg, Leslie. 2001. “Trans Health Crisis: For Us It's Life or Death.” American Journal of Public Health 91: 897-901.

Fine, Cordelia (2010). Delusions of Gender: How Our Minds, Society, and Neurosexism Create Difference. New York, London: W. W. Norton \& Company. 
Fausto-Sterling, Anne. 1985. Myths of Gender: Biological Theories About Women and Men. Second Edition. New York: Basic Books.

---. 2000. Sexing the Body. New York: Basic Books - Perseus Book Group.

Fox Keller, Evelyn. 1987. "The Gender/Science System: or, Is Sex to Gender as Nature is to Science?" Hypatia 2(3): 37-49.

Gorely, Trish, Rachel Holroyd, and David Kirk. 2003. "Muscularity, the Habitus and the Social Construction of Gender: towards a gender-relevant physical education." British Journal of Sociology of Education 24(4): 429-446.

Herdt, Gilbert, ed. 1993. Third Sex, Third Gender: Beyond Sexual Dimorphism in Culture and History. New York: Zone Books.

hooks, bell. 2000, 1984. Feminist Theory: From Margin to Center. 2nd Ed. Cambridge, MA: South End Press.

Ingold, Tim. 2004. "Culture on the Ground: The World Perceived Through Feet." Journal of Material Culture 9 (3): 315-340.

Intersex Society of North America. 2011. Rohnert Park, CA: Intersex Society of North America. Retrieved October 12, 2011 (www.insa.org).

James, Susan Donaldson. 2011. "J. Crew Ad with Boy's Pink Toenails Creates Stir." ABC News. Retrieved August 2, 2011 (http://abcnews.go.com/Health/crew-adboy-painting-toenails-pink-stirs-transgender/story?id=13358903).

Kessler, Suzanne. 1998. Lessons From the Intersexed. New Brunswick: Rutgers UP.

Kitzinger, Celia. 1999. "Intersexuality: Deconstructing the Sex/Gender Binary." Feminism \& Psychology 9 (4): 493-498.

Life \& Style Weekly. 2010. "Why is Angelina Turning Shiloh into a Boy?" Life \& Style Weekly. Retrieved August 2, 2011 (http://www.lifeandstylemag.com/2010/03/ large-1011-cover.html).

Lorber, Judith. 1993. "Believing is Seeing: Biology as Ideology." Gender and Society 7(4): 568-81.

---. 1994. Paradoxes of Gender. New Haven: Yale UP.

--- and Patricia Yancey Martin. 1997. "The Socially Constructed Body: Insights from Feminist Theory." Illuminating Social Life. Peter Kivisto. Thousand Oaks: Pine Forge Press. 
--- and Lisa Jean Moore. 2000. Gender and the Social Construction of Illness. Lanham: AltaMira Press.

---. 2001. "It's the 21st Century - Do You Know What Gender You Are?" An International Feminist Challenge to Theory 5: 119-137.

---. 2005. Breaking the Bowls. New York: W.W. Norton \& Company.

Lorde, Audre. 1984. Sister Outsider: Essays and Speeches. Berkeley: Crossing Press.

Lowe, Donald. 1995. The Body In Late-Capitalist USA. Durham: Duke UP.

M., Shannon. 2011. "Pregnant and Socializing? Not in My Bar." New York, NY:

Care2. Retrieved October 18, 2011 (http://www.care2.com/causes/pregnant-andsocializing-not-in-my-bar1.html).

Meyerowitz, Joanne. 2008. How Sex Changed: A History of Transsexuality in the United States. Cambridge: Harvard UP.

Messner, Michael. 1990. "When Bodies are Weapons: Masculinity and Violence in Sport." Internal Review for the Sociology of Sport. 25: 203-217.

Molleson, Theya. 2007. "A Method for the Stud of Activity Related Skeletal Morphologies." Bioarchaeology of the Near East (1): 5-33

Ramet, Sabrina Petra, Ed. 1996. Gender Reversals and Gender Cultures: Anthropological and Historical Perspectives. New York: Routledge.

Rudacille, Deborah (2005). The Riddle of Gender: Science, Activism, and Transgender Rights. New York: Pantheon Books.

Sahni M, Verma N, Narula D, Varghese RM, Sreenivas V, et al. 2008. "Missing Girls in India: Infanticide, Feticide and Made-to-Order Pregnancies? Insights from Hospital-Based Sex-Ratio-at-Birth over the Last Century." PLoS ONE 3(5): e2224 (http://www.plosone.org/article/info:doi/10.1371/journal.pone.0002224).

Schilt, Kristen and Laurel Westbrook. 2009. "Doing Gender, Doing Heteronormativity: 'Gender Normals,' Transgender People, and the Social Maintenance of Heterosexuality." Gender \& Society 23 (4): 440-464.

ScienceDaily. 2006. "Maternal Diet During Pregnancy Can Impact Offspring for Generations, Study Shows." Rockville, MD: ScienceDaily. Retrieved October 18, 2011 (http://www.sciencedaily.com/releases/2006/11/061113180343.htm). 
---. 2011. "Mother's Diet Influences Baby's Allergies, Research Suggests." Rockville, MD: ScienceDaily. Retrieved October 18, 2011 (http://www.sciencedaily.com /releases/2011/09/110908161444.htm)

Setchell, Kenneth, Nadine Brown, Xueheng Zhao, Stephanie Lindley, James Heubi, Eileen King, and Mark Messina. 2011. "Soy Isoflavone Phase II Metabolism Differs Between Rodents and Humans: Implications for the Effect on Breast Cancer Risk." American Journal of Clinical Nutrition. 94 (5): 1284-1294.

Strauss, Anselm and Juliet Corbin. 1998. Basics of Qualitative Reserach: Techniques and Procedures for Developing Grounded Theory. Second Ed. SAGE Publications: Thousand Oaks, London, New Delhi

Stephens, John and Robyn McCallum. 1998. Retelling Stories, Framing Culture: Traditional Story and Metanarratives in Children's Literature. London: Routledge.

Stryker, Susan. 2008. Transgender History. Berkeley: Seal Press.

Sullivan, Shannon. 2000. "Reconfiguring Gender with John Dewey: Habit, Bodies, and Cultural Change." Hypatia 15 (1): 23-40.

Tuana, Nancy. 1993. The Less Noble Sex. Bloomington: Indiana UP.

---. 1996. "Fleshing Gender, Sexing the Body: Refiguring the Sex/Gender Distinction." Southern Journal of Philosophy, 35 (Supplement): 53-71.

---, William Cowling, Maurice Hamington, Greg Johnson, and Terrance MacMullan, eds. 2002. Revealing Male Bodies. Bloomington: Indiana UP.

Totman, Richard. 2003. The Third Sex: Kathoey - Thailand's Ladyboys. Thailand: Silkworm Books.

Verbrugge, Martha. 1997. "Recreating the Body: Women's Physical Education and the Science of Sex Differences in America, 1900-1940." Bulletin of the History of Medicine 71 (2): 273-304.

Vincent, Norah. 2006. Self-Made Man: One woman's year disguised as a man. New York: Penguin Books.

Wahab, Stephanie. 2003. "Creating Knowledge Collaboratively with Female Sex Workers: Insights from a Qualitative, Feminist, and Participatory Study." Qualitative Inquiry 9: 625-642. 
West, Candace and Don Zimmerman. 1987. "Doing Gender." Gender \& Society 1(2): $125-148$.

van den Wijngaard, Marianne. 1997. Reinventing the Sexes: The Biomedical Construction of Femininity and Masculinity. Bloomington: Indiana UP. 


\section{APPENDIX A: INTERVIEW GUIDE}

(Distributes and discusses Letter of Informed Consent.) In addition to the consent information, there are few other points I wanted to emphasize. Most of these questions are going to be open-ended and are not the kind that have right or wrong answers, or yes-or-no answers - it's more like having a conversation, and I'm interested in whatever you have to say. Take as much time as you like thinking about the questions before or during answering them, and feel free to talk as much as you want. These questions are going to vary from the general to the personal, so feel free to ask me to clarify, rephrase, or to decline any questions. Some of these questions might get a little repetitive, so feel free to point that out and say, well, I think I already covered most of what you're asking, etc. If there's ever a point at which I misspeak or say something that makes you feel uncomfortable or (hopefully not) offended, please feel free to bring that to my attention so that I can resolve and avoid such transgressions in the future. I might also be taking a few notes to remind myself of things I need to come back to; please let me know if it's distracting at all! (Introduces self and asks for permission to audio-record the interview; verbal consent to participate is recorded.)

\section{$\underline{\text { Scene }(\text { Personal) }}$}

\section{How do you identify, in terms of gender?}

Do you identify with a specific gender?

Do you consider yourself transgender/transsexual/androgynous/transgressive?

Do you feel like you 'conform' to or 'fit in with' a stereotypical/ archetypical/

"normal" gender role?

Is it your goal to 'conform' to or 'fit in with' an archetypical/"normal" gender role?

Can you give me examples of the ways in which you feel like you conform/do not conform to the gender archetype? 


\section{Have you ever identified differently than you do now?}

Do you identify with the adjective "masculine" (in any way)?

In what ways (specifically)?

Do you identify with the adjective "feminine" (in any way)?

In what ways (specifically)?

If you had to guess, how do you think others perceive your gender? (Do you think you 'pass')?

What are the reasons you guess that?

What do you think about the idea of "passing"? Is "passing" important?

What actions do you take to ensure that you pass?/What do you think you would have to do to ensure that you would pass?

Scene General.

How do you define the term 'gender?'

Is gender a strict binary? Are there only two genders?

Is gender changeable? Is it plastic or static?

\section{How about 'sex' - how would you define that word/concept?}

Are sex and gender different things/concepts?

(And so, sex and gender are different in that ... lead them into an explanation) 
What do you see as the relationship between sex and gender?

\section{$\underline{\text { Scene (General) }}$}

In general, do you believe that there is a physical difference between men and women (that goes beyond genitalia)?

What are those physical differences, specifically?

How would you say that this difference occurs? (Is it natural, biological?)

In your opinion, what are the implications of this (physical) difference?

Do you think that the mainstream culture believes, or assumes, that there is a physical difference between men and women?

What are the differences that the stereotype assumes? /Are these differences the same as the ones you listed?

Can you think of any examples of these differences?

Have you had any experiences that come to mind in which you or someone you know participated, or declined to participate, in an activity due to the physical assumptions made (by themselves, or others) about their gender (role)?

What stands out to you about that story? 
Can you think of an example in which a person whose sex traditionally

corresponded with their gender was belittled due to inadequate

presentation/embodiment of sexual dimorphism?

$\underline{\text { Scene (Personal) }}$

Have you ever felt that you needed to alter your body (in any way - surgery to tweezing) so that you could conform to the physical stereotype of a specific gender?

Can you describe the process of changing your gender/ not conforming to gender?

What was the first thing you did in order to change your gender?

Do you consider your gender to be performative? How so?

Did you consider any former gender identities to be performative?

What did those performances entail, specifically?

What aspects of your body were affected or changed (when you changed your gender)?

Were these changes more the result of conscious alteration or were they spurious?

What are ways in which you consciously changed your body?

Were there any physical affects that you did not anticipate?

Do you personally experience difference in the ways the genders treat (diet, exercise, body language, body presence, dress, primping, etc), either within your own change or simply by observing others around you?

S. K. Lewis - Gendering the Body / Appendix A: Interview Guide 
Specifically, what are the differences you notice? (Examples: diet, exercise, body language/mannerism, dress, body modification/grooming, style/fashion.)

Is there a difference in the way that you exercise now than you did before your transition/change in identity?

Is there a difference in the way that you eat now than you did before your transition/change in identity?

Are there any other ways that you feel physically different now than you did before your transition/change in identity?

Has your relationship with your body changed at all?

Do you / How do you think about gender in your everyday life/on a day-to-day basis?

Do you / How do you think about sex in your everyday life/on a day-to-day basis?

Is there anything that I'm missing - can you think of any other questions that I should ask?

Do you want to add anything more to anything we've talked about?

Would it be ok to contact you if I find I have any more questions for a short follow-up interview?

(Thanks.) Would you like a copy of the finished product? If so, one will be provided electronically via email or in hard copy through regular mail. 


\title{
GenderQueer? \\ *do you identify as trans, androgynous, or genderqueer? \\ *are you interested in talking about your experiences with gender? \\ *are you over the age of $18 ?$
}

\begin{abstract}
If so, please call or email me! I'm a trans ally and master's student in
Sociology/Women's Studies at Portland State seeking volunteers to interview during the month of April. The interviews are for my thesis, which is a project exploring the ways individuals who identify as transgender, transsexual, or genderqueer define and experience gender in their everyday lives.
\end{abstract}

All information and identifying markers of individuals who choose to be interviewed will be kept strictly confidential and will be destroyed after the completion of the project. (For questions or more information about confidentiality, please feel free to contact me.) Each interview should last between 30 and 90 minutes and can take place in a location of the interviewee's choice.

If you are at all interested in being interviewed, or would simply like more information, please contact me either by phone or email. Thank you!

Sarah Lewis / Portland State University

sklewis@pdx.edu, (503)515-3142

S. K. Lewis - Gendering the Body / Appendix B: Call For Participants 


\section{APPENDIX C: INTERMEDIARY SCRIPT AND COVER LETTER}

\section{Intermediary Script}

"I have a friend at PSU who's doing a project on gender and how people experience it in their lives. She's looking for people to interview and I was wondering if you might be interested in talking to her." (If they are interested, it would not be her responsibility to explain the project in more depth - she would simply refer them to me.) "If you'd like more information about the project, here's a cover sheet with her email, phone number, and a brief description of the general project."

\section{Cover Letter for Intermediary Distribution}

Hello,

I'm a graduate student at Portland State University working on a thesis for the Department of Sociology. I am currently looking for volunteers to interview for a project about gender and how people experience it individually in their lives. I'm specifically trying to locate people who identify as trans, queer, butch, androgynous, drag, or anyone whose beliefs, values, lifestyles, or experiences allow for room to experience gender in nontraditional ways (and whom are over the age of 18).

The project will result in a theoretical paper that discusses gender and the different ways it can be experienced by individuals, specifically focusing on the experiences of altering, changing, switching, or living beyond gender. If you would like a more detailed description of the project, please contact me. 
All information and identifying markers of individuals who choose to be interviewed will be kept strictly confidential and will be destroyed after the completion of the paper; pseudonyms will be used to refer to interview subjects in the body of the paper. For questions or more information about confidentiality, please contact me.

If you are at all interested in being interviewed during the month of April or would simply like more information, please contact me either by phone, email, or mail. (Interviews should last between 30 and 90 minutes.) Thanks so much!

Sincerely,

Sarah Lewis

sklewis@pdx.edu, (503)515-3142

PO Box 9084, Portland OR, 97207 


\section{APPENDIX D: QUESTIONNAIRE}

\section{Here it is: the interview!}

Thank you again so much for taking this on!

In addition to the consent letter you read earlier, there are few other points I wanted to bring up and/or re-emphasize:

Please feel free to skip questions! Please feel free to note if and when the questions seem repetitive and to refer back to previous answers. Likewise, please let me know if any part of this interview makes you feel uncomfortable or offended. The questions range from really broad, like the definition of terms, to really personal. One thing I'm particularly interested in exploring is the relationship people who identify as trans or genderqueer have with their bodies, so you'll notice some questions that definitely pertain to that.

These questions are TOTALLY open ended. Please feel free to write as much or as little as you want for each question. Any format is great - please don't worry about grammar or spelling, etc. As we discussed via email, please feel free to email me with any questions or clarifications; if at any point you would like to set up a time for us to instant message, either just to ask questions or to finish the 'interview,' just let me know!

Feel free to take your time with this, too - no deadline!

\section{The Questions}

1. I don't know if you're familiar with Kate Bornstein - ze is the author of several great books, including My Gender Workbook, in which ze published a great little 
exercise. Ze put up a post in the cyber community and asked people to define themselves in 25 words or less. (Most respondents did not stick to 25 words exactly.) Which 25 words would you choose?

2. How do you identify, in terms of gender?

3. Do you feel like you 'conform' to or 'fit in with' a stereotypical/ archetypical/ "normal" gender role, and why? Is it your goal to 'conform' to or 'fit in with' an archetypical/"normal" gender role?

4. Have you ever identified differently (in terms of gender) than you do now?

5. Do you take hormones?

6. Do you identify with the adjective "masculine"?

7. Do you identify with the adjective "feminine"?

8. If you had to guess, how do you think others perceive your gender? Do you think you 'pass'?

9. What do you think about the idea of "passing"? Is "passing" important?

10. What actions do you take to ensure that you 'pass'? OR What actions do you think you would have to take in order to 'pass'?

11. How do you define the term 'gender?'

12. How do you define the term 'sex?'

13. How do you define the term 'transgender?'

14. How do you define the term 'genderqueer?'

15. How would you define 'stereotypical/mainstream gender'? 
16. Do you believe that there is a physical difference between men and women (that goes beyond genitalia)?

a) What are those physical differences, specifically?

b) If there is a difference, how would you say that this difference occurs? (Is it natural, biological?)

c) In your opinion, what are the implications of this (physical) difference?

17. Have you had any experiences that come to mind in which you or someone you know participated, or declined to participate, in an activity due to the physical assumptions made (by themselves, or others) about their gender (role)?

18. Can you think of an example in which a person whose sex traditionally corresponds to their gender was belittled due to inadequate presentation/embodiment of sexual dimorphism?

19. How have you dealt with ideas of gender-appropriate physical difference in your own life? Have you ever felt that you needed to alter your body (in any way surgery to tweezing) so that you could conform to the physical stereotype of a specific gender?

20. Can you describe the process of changing your gender/ not conforming to gender?

21. Do you consider your gender to be performative? How so? What are physical considerations you have taken in your performativity?

22. What aspects of your body were affected or changed when you changed/departed from your gender? Were these changes more the result of conscious alteration? Were there any physical affects that you did not anticipate? 
23. Do you personally experience difference in the ways the genders treat
a) diet,
b) exercise,
c) body language/poise,
d) body modification/grooming,

either within your own change or simply by observing others around you? If so, what are the differences you notice?

24. Is there a difference in the way that you exercise now than you did before your transition/change in identity?

25. Is there a difference in the way that you eat now than you did before your transition/change in identity?

26. Are there any other ways that you feel physically different now than you did before your transition/change in identity?

27. Is there anything that I'm missing - can you think of any other questions that I should ask?

Thank you so much! The whole project should be completed relatively soon, and I will more than happy to send you a copy. 


\section{APPENDIX E: COVER LETTER OF INFORMED CONSENT}

Cover Letter of Informed Consent.

"Social versus Biological Determinism: Sexual Dimorphism, Gendered Dimorphism, and the Patriarchal Model."

Principal Investigator: Sarah Lewis, Graduate Student, Department of Sociology at Portland State University.

Phone: 503-725-3958

Email: $\underline{\text { sklewis@pdx.edu }}$

You are invited to participate in a research study conducted by Sarah Lewis, an M.S. candidate at Portland State University, Department of Sociology. This research is part of the researcher's master's thesis, a requirement of the degree. This project is supervised by Grant Farr, the student's advisor and a faculty member at Portland State University. He can be reached via email at farrg@ pdx.edu or via phone at 503-725-3908.

The researcher hopes to learn how subjects' individual experiences with gender and gender transgression have affected their everyday lives, including how they think of and view gender roles, how gender affects their everyday decisions and actions, and how their potential experiences regarding change, fluidity, or rejection of gender have similarly affected them.

Your participation is voluntary. You do not have to take part in this study, and it will not affect you nor your relationship with Portland State University if you do not. You may also stop the interview at any point.

If you decide to participate, you will be asked to take part in one interview conducted by the researcher. The researcher will ask your permission to tape record the interview. (If you do not agree to be tape recorded, you can still be interviewed if you wish.) If you consent to being tape recorded, you are also welcome to withdraw that consent and turn off the recorder at any time. 
All information will be kept strictly confidential, including names, phone numbers, email addresses, other identifying markers, etc. In all drafts, notes, and in the finished project, pseudonyms will be assigned to all interviewees and no real names will be used. All information will be destroyed after the completion of the project, including the tapes of the interviews. The interview will consist of open-ended questions about your personal experience and opinion. You may decline to answer any or all questions at any time. No one else will be present during the interview, and the location of the interview will be determined by the participant. If you do not have a suggestion for a location for the interview, the researcher will suggest several locations for your selection. The duration of the interview will range anywhere from 30 to 90 minutes.

While participating in this study, it is possible that you may experience some discomfort or embarrassment from the questions asked due to their controversial nature. The researcher will do everything possible to remain tactful, respectful, and sensitive. In addition, you are invited to decline to answer any question that makes you uncomfortable. You may not receive any direct benefit from taking part in this study, but the study may help to increase knowledge, which may help others in the future.

Any information that is obtained in connection with this study that can be linked to you or identify you will be kept confidential. This information will be kept confidential through the use of pseudonyms, which will be used for the duration of the study and in any subsequent document or publication. This confidentiality is limited only by mandatory reporting requirements, such as instances in which subjects might reveal imminent harm to one's self or to others.

If you have problems or concerns about your participation in this study or your rights as a research subject, please contact the Human Subjects Research Review Committee, Office of Research and Sponsored Projects, 111 Cramer Hall, Portland State University, (503) 725-4288. If you have any questions about the study itself, please contact Sarah Lewis at (503) 725-3958 or sklewis@pdx.edu. 
Your verbal consent indicates that you have read and understand the above information and agree to take part in this study. Please understand that you may withdraw your consent at any time without penalty, and that, by giving consent, you are not waiving any legal claims, rights, or remedies. The researcher will provide you with a copy of this form for your own records. If you would like a copy of the finished research, the researcher will be happy to provide one either through physical mail or email. 